\title{
Long-term study on coarse mode aerosols in the Amazon rain forest with the frequent intrusion of Saharan dust plumes
}

\author{
Daniel Moran-Zuloaga ${ }^{1}$, Florian Ditas ${ }^{1}$, David Walter ${ }^{1}$, Jorge Saturno ${ }^{1, a}$, Joel Brito ${ }^{2, b}$, Samara Carbone ${ }^{2, c}$, \\ Xuguang Chi ${ }^{1, \mathrm{~d}}$, Isabella Hrabě de Angelis ${ }^{1}$, Holger Baars ${ }^{3}$, Ricardo H. M. Godoi ${ }^{4}$, Birgit Heese ${ }^{3}$, Bruna A. Holanda ${ }^{1}$, \\ Jošt V. Lavrič ${ }^{5}$, Scot T. Martin ${ }^{6,7}$, Jing Ming ${ }^{1}$, Mira L. Pöhlker ${ }^{1}$, Nina Ruckteschler ${ }^{1}$, Hang Su ${ }^{1,8}$, Yaqiang Wang ${ }^{9}$, \\ Qiaoqiao Wang ${ }^{1,8}$, Zhibin Wang ${ }^{1}$, Bettina Weber ${ }^{1}$, Stefan Wolff ${ }^{1,10}$, Paulo Artaxo ${ }^{2}$, Ulrich Pöschl ${ }^{1}$, \\ Meinrat O. Andreae ${ }^{1,11}$, and Christopher Pöhlker ${ }^{1}$ \\ ${ }^{1}$ Multiphase Chemistry \& Biogeochemistry Departments, Max Planck Institute for Chemistry, 55020 Mainz, Germany \\ ${ }^{2}$ Institute of Physics, University of São Paulo, São Paulo 05508-900, Brazil \\ ${ }^{3}$ Leibniz Institute for Tropospheric Research, Permoserstraße 15, 04318 Leipzig, Germany \\ ${ }^{4}$ Environmental Engineering Department, Federal University of Parana, Curitiba PR, Brazil \\ ${ }^{5}$ Department of Biogeochemical Systems, Max Planck Institute for Biogeochemistry, 07701 Jena, Germany \\ ${ }^{6}$ John A. Paulson School of Engineering and Applied Sciences, Harvard University, Cambridge, MA 02138, USA \\ ${ }^{7}$ Department of Earth and Planetary Sciences, Harvard University, Cambridge, MA 02138, USA \\ ${ }^{8}$ Institute for Environmental and Climate Research, Jinan University, Guangzhou, 510630, China \\ ${ }^{9}$ State Key Laboratory of Severe Weather \& Key Laboratory of Atmospheric Chemistry of CMA, \\ Chinese Academy of Meteorological Sciences, Beijing, China \\ ${ }^{10}$ Instituto Nacional de Pesquisas da Amazonia, Manaus-AM, CEP 69083-000, Brazil \\ ${ }^{11}$ Scripps Institution of Oceanography, University of California San Diego, La Jolla, CA 92037, USA \\ ${ }^{a}$ now at: Physikalisch-Technische Bundesanstalt, Bundesallee 100, 38116 Braunschweig, Germany \\ ${ }^{b}$ now at: Laboratory for Meteorological Physics, Université Clermont Auvergne, 63000 Clermont-Ferrand, France \\ ${ }^{c}$ now at: Federal University of Uberlândia, Uberlândia-MG, 38408-100, Brazil \\ ${ }^{d}$ now at: Institute for Climate and Global Change Research \& School of Atmospheric Sciences, Nanjing University, \\ Nanjing, 210093, China
}

Correspondence: Daniel Moran-Zuloaga (daniel.moran@mpic.de) and Christopher Pöhlker (c.pohlker@mpic.de)

Received: 6 November 2017 - Discussion started: 13 December 2017

Revised: 20 April 2018 - Accepted: 12 May 2018 - Published: 16 July 2018

\begin{abstract}
In the Amazonian atmosphere, the aerosol coarse mode comprises a complex, diverse, and variable mixture of bioaerosols emitted from the rain forest ecosystem, longrange transported Saharan dust (we use Sahara as shorthand for the dust source regions in Africa north of the Equator), marine aerosols from the Atlantic Ocean, and coarse smoke particles from deforestation fires. For the rain forest, the coarse mode particles are of significance with respect to biogeochemical and hydrological cycling, as well as ecology and biogeography. However, knowledge on the physicochemical and biological properties as well as the ecological role of the Amazonian coarse mode is still sparse. This study presents results from multi-year coarse mode measure-
\end{abstract}

ments at the remote Amazon Tall Tower Observatory (ATTO) site. It combines online aerosol observations, selected remote sensing and modeling results, as well as dedicated coarse mode sampling and analysis. The focal points of this study are a systematic characterization of aerosol coarse mode abundance and properties in the Amazonian atmosphere as well as a detailed analysis of the frequent, pulse-wise intrusion of African long-range transport (LRT) aerosols (comprising Saharan dust and African biomass burning smoke) into the Amazon Basin.

We find that, on a multi-year time scale, the Amazonian coarse mode maintains remarkably constant concentration levels (with $0.4 \mathrm{~cm}^{-3}$ and $4.0 \mu \mathrm{g} \mathrm{m}{ }^{-3}$ in the wet vs. $1.2 \mathrm{~cm}^{-3}$ 
and $6.5 \mu \mathrm{g} \mathrm{m}^{-3}$ in the dry season) with rather weak seasonality (in terms of abundance and size spectrum), which is in stark contrast to the pronounced biomass burning-driven seasonality of the submicron aerosol population and related parameters. For most of the time, bioaerosol particles from the forest biome account for a major fraction of the coarse mode background population. However, from December to April there are episodic intrusions of African LRT aerosols, comprising Saharan dust, sea salt particles from the transatlantic passage, and African biomass burning smoke. Remarkably, during the core period of this LRT season (i.e., FebruaryMarch), the presence of LRT influence, occurring as a sequence of pulse-like plumes, appears to be the norm rather than an exception. The LRT pulses increase the coarse mode concentrations drastically (up to $100 \mu \mathrm{g} \mathrm{m}^{-3}$ ) and alter the coarse mode composition as well as its size spectrum. Efficient transport of the LRT plumes into the Amazon Basin takes place in response to specific mesoscale circulation patterns in combination with the episodic absence of rain-related aerosol scavenging en route. Based on a modeling study, we estimated a dust deposition flux of $5-10 \mathrm{~kg} \mathrm{ha}^{-1} \mathrm{a}^{-1}$ in the region of the ATTO site. Furthermore, a chemical analysis quantified the substantial increase of crustal and sea salt elements under LRT conditions in comparison to the background coarse mode composition. With these results, we estimated the deposition fluxes of various elements that are considered as nutrients for the rain forest ecosystem. These estimates range from few $\mathrm{g} \mathrm{ha}^{-1} \mathrm{a}^{-1}$ up to several hundreds of $\mathrm{g} \mathrm{ha}^{-1} \mathrm{a}^{-1}$ in the ATTO region.

The long-term data presented here provide a statistically solid basis for future studies of the manifold aspects of the dynamic coarse mode aerosol cycling in the Amazon. Thus, it may help to understand its biogeochemical relevance in this ecosystem as well as to evaluate to what extent anthropogenic influences have altered the coarse mode cycling already.

\section{Introduction}

The Amazon rain forest is of particular relevance in Earth system science. It represents a vulnerable ecosystem of global importance, which is increasingly disturbed by the combination of climate change and agricultural as well as infrastructural expansion (Davidson et al., 2012). In fact, the Amazon has been ranked as one of the potential tipping points in the global climate system (Lenton et al., 2008). Furthermore, it represents a unique location to study the human influence on the atmosphere as it represents one of the few remaining continental places where episodes with a nearpristine atmospheric state can be found (Andreae, 2007; Martin et al., 2010a; Pöschl et al., 2010).

Since the late 1980s, numerous field campaigns have been conducted in the Amazon region, which focused on specific aspects of the complex atmospheric cycling for time periods of weeks, months, and in some cases up to years (e.g., Andreae et al., 1988, 2004, 2015; Talbot et al., 1988, 1990; Harriss et al., 1990; Artaxo et al., 1993, 2013b; Martin et al., 2010a, 2016; Brito et al., 2014; Wendisch et al., 2016). In 2010/11, the Amazon tall tower observatory (ATTO) has been established $\sim 150 \mathrm{~km}$ northeast (NE) of the city of Manaus, Brazil, for continuous and detailed observation of meteorology, trace gases, aerosols, and ecology in order to study long-term trends of the Amazonian hydrological and biogeochemical cycling in relation to the increasing extent of manmade perturbations (Andreae et al., 2015).

Generally speaking, the central Amazonian atmosphere swings back and forth between a mostly clean wet season (typically February to May) and a substantially polluted dry season (typically August to November) with corresponding transition periods in between (Martin et al., 2010b; Andreae et al., 2015). This oscillating atmospheric state is determined by the position of the intertropical convergence zone (ITCZ) and the corresponding trade wind circulation as well as the strong seasonality in biomass burning in Africa and South America (Martin et al., 2010a, b; Fuchs and Cermak, 2015; Abdelkader et al., 2017). Figure 1 serves as a general illustration of the large-scale atmospheric circulation, as well as the predominant aerosol and trace gas emissions patterns in the Atlantic region that govern the overall atmospheric seasonality in the Amazon Basin. In particular, the contrasting atmospheric states of the wet vs. dry season are emphasized.

In Fig. 1a and b, the cloud top temperature maps visualize areas with deep convective clouds (i.e., cold cloud tops), which correspond - particularly over the ocean - to the position of the ITCZ. During the wet season, the ITCZ is located (slightly) south of the ATTO site, which entails a northeasterly (NE) trade wind advection as visualized by backward trajectory (BT) ensembles. Here, the trades typically bring air masses from the Atlantic Ocean, which pass over extended and almost untouched forest areas while traveling into the Amazon Basin. During the dry season, the ITCZ is located north of the ATTO site and the trade winds arrive from southeasterly (SE) directions. The SE trades travel over urban and extended agricultural areas in South America and, thus, are prone to bring substantial amounts of anthropogenic pollution into the central Amazon. A detailed description of the corresponding land cover types in the ATTO site's footprint can be found elsewhere (Pöhlker et al., 2018). Note that the ITCZ-related changes between Northern and Southern Hemispheric influences are most pronounced for the central Amazon region, which experiences the ITCZ overpasses, whereas in the northern and southern Amazon regions, the hemispheric air mass changes are less pronounced.

Figure $1 \mathrm{c}$ and $\mathrm{d}$ show a superposition of precipitation and the BT ensembles, visualizing that the most intense precipitation rates are observed co-located with the deep convection in the ITCZ belt. The combination of precipitation maps and $\mathrm{BT}$ ensembles further shows qualitatively the probability 
Wet season (01 Feb-31 May)
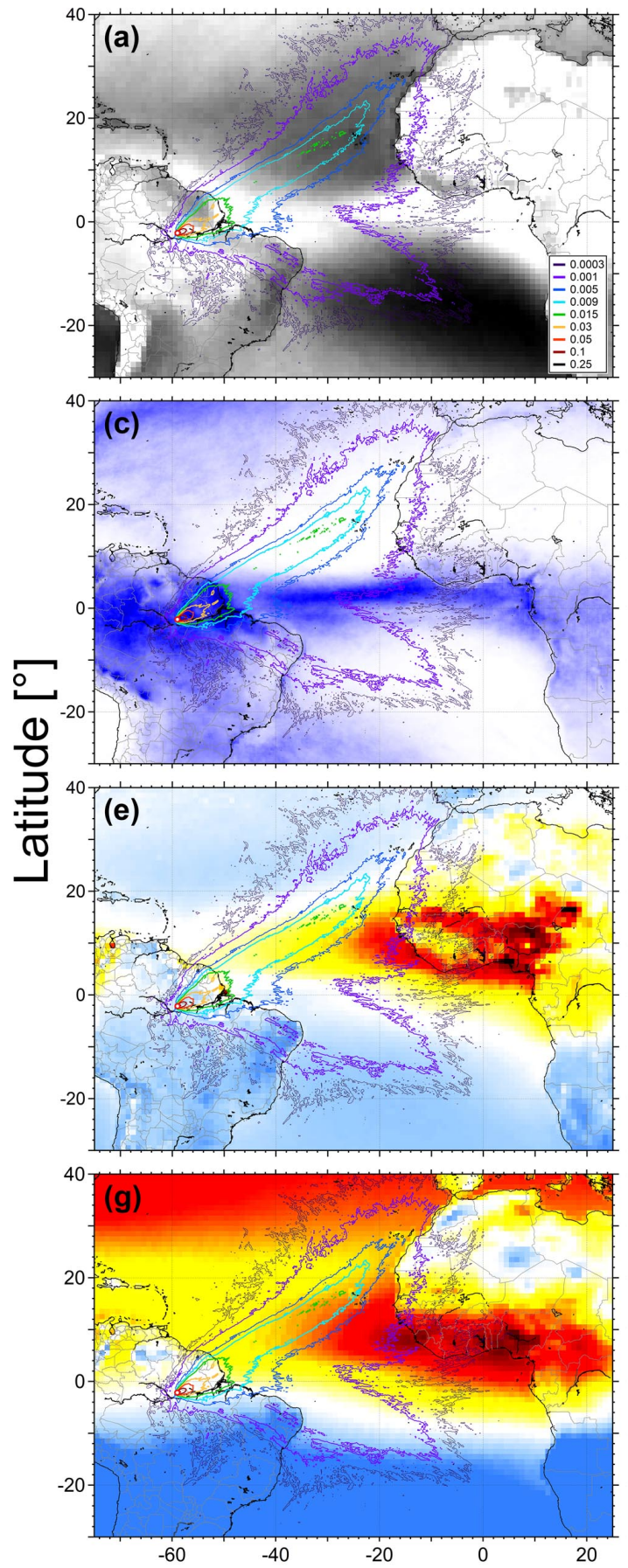

Dry season (01 Aug-30 Nov)
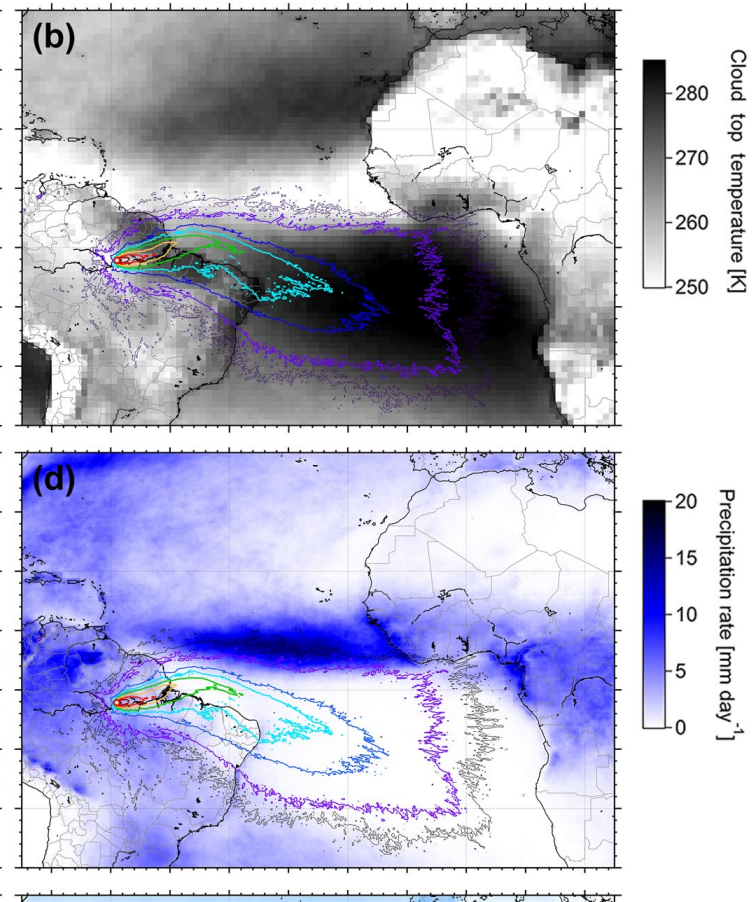
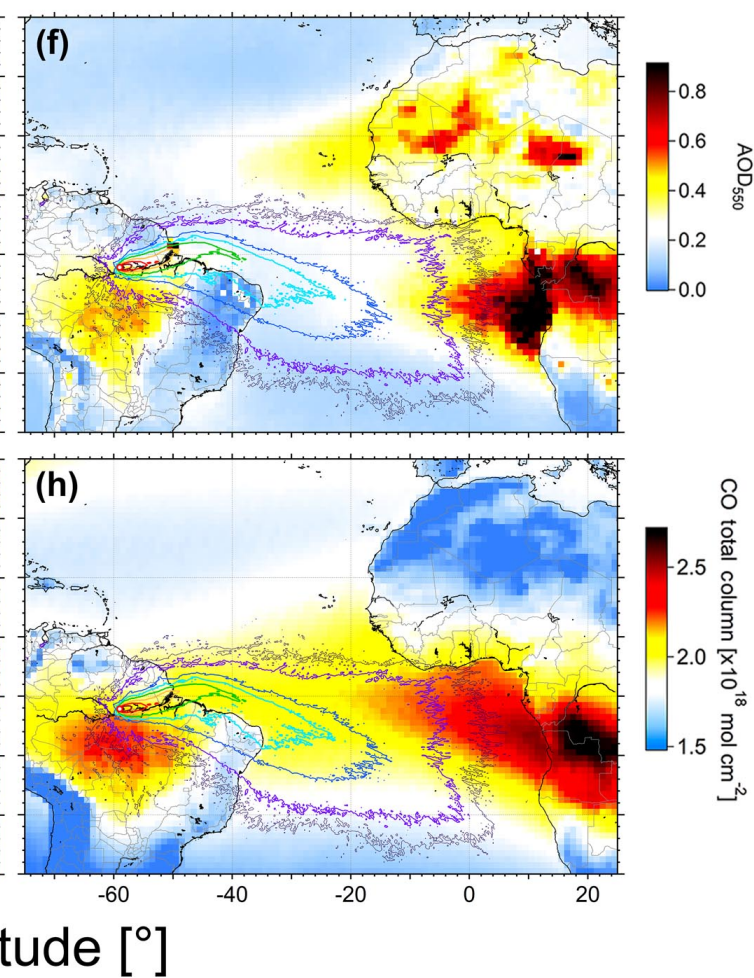

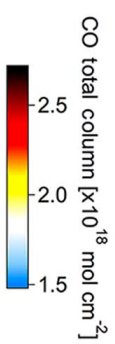

Figure 1. Composite maps combining backward trajectory ensembles with satellite data products contrasting wet and dry conditions in Amazonia. Multi-year time periods from 2008 to 2016 were averaged to retrieve representative results. All wet season data shown here represent averages of the months February-May and the dry season data represent averages of the months August-November. Backward trajectory ensembles are shown as contour plots with contour lines representing fraction of occurrence of overpassing trajectories in a certain region as described in Pöhlker et al. (2018) (see legend in a). (a, b) MODIS-derived cloud top temperature data showing location of ITCZ belt with deep convective clouds and corresponding cold cloud tops. (c, d) TRMM-derived precipitation rate showing regions where strong rain-related aerosol scavenging is expected. The belt with strongest precipitation rates is collocated with the ITCZ. (e, f) MODIS-derived aerosol optical depth (AOD) illustrating the dominant aerosol sources in Africa and South America relevant for the ATTO site measurements. $(\mathbf{g}, \mathbf{h})$ AIRS-derived CO maps illustrating hot spots of biomass burning with strong CO emissions. 
of rain-related scavenging of long-range transported aerosols in the advected air masses along their transport track. For the wet season, the NE trajectories meet the ITCZ rain belt at about $3^{\circ} \mathrm{N}$. This means that for the transatlantic passage north of $3^{\circ} \mathrm{N}$ (i.e., in the subtropical latitudes) no major wet deposition of the transported aerosol load is expected. Once the BTs intersect the rain belt south of $3^{\circ} \mathrm{N}$, aerosol scavenging becomes a substantial aerosol loss mechanism, which acts as a barrier for southwards transport (Abdelkader et al., 2017) and "efficiently scrubs out aerosols" from the advected air masses (Andreae et al., 2012). The dry season scenario is different: here the ITCZ rain belt is located mostly north of $2^{\circ} \mathrm{N}$. This implies that the SE trajectories mostly bypass the most intense rain fields. Accordingly, the probability of aerosol scavenging during the dry season is much lower and there is a higher likelihood that (pyrogenic and other) LRT aerosols from Africa are transported (far) into the central Amazon Basin.

Figure 1e and $\mathrm{f}$ combine aerosol optical depth (AOD) maps with the BT data to visualize the major African and South American aerosol sources that influence the atmospheric state in the central Amazon. The main fraction of the anthropogenic aerosol that is observed at the ATTO site is related to biomass burning emissions from deforestation, savanna, grassland, and agricultural waste fires in Africa and South America. These, mostly man-made, burning activities on both continents follow a pronounced seasonality: in northern Africa, a winter fire maximum (i.e., December-March) is observed due to intense savanna and grassland fires in and south of the Sahel belt $\left(5-15^{\circ} \mathrm{N}\right)$, while in southern Africa a pronounced dry-season maximum (i.e., June-October) occurs in the Miombo woodlands $\left(5-20^{\circ} \mathrm{S}\right)$ (Barbosa et al., 1999; Edwards et al., 2006). Consequently, both sources result in extended pollution plumes mixed with dust that travel westwards over the Atlantic Ocean, as visible in Fig. 1e and f. In South America, strong biomass burning activity due to agriculture and deforestation fires, occurs from August to November, mostly along the southern margin of the Amazon forest (the so-called "arc of deforestation") and in the extended agricultural and Cerrado savanna areas further south (Edwards et al., 2006; Pöhlker et al., 2018).

In addition to the biomass burning smoke, various urban and industrial emissions in Africa (e.g., from the cities and oil rigs in the Gulf of Guinea) and South America (e.g., from the densely populated southeastern Brazilian coastline) may also contribute to the anthropogenic aerosol burden (see Pöhlker et al., 2018). Figure $1 \mathrm{~g}$ and h, show the satellite-retrieved total carbon monoxide (CO) column, which highlights the locations of major biomass burning activities, such as strong fire activity in the Sahel region during the Amazonian wet season as well as fires in the tropical latitudes in both, Africa and South America, during the Amazonian dry season.

Beside these man-made emissions, transcontinental advection of Saharan (we use Sahara as shorthand for the dust source regions in Africa north of the Equator) dust across the Atlantic Ocean represents a major source of LRT aerosol that is relevant for the central Amazon (Prospero et al., 1981, 2014; Swap et al., 1992; Formenti et al., 2001; Schepanski et al., 2009; Abouchami et al., 2013; Di Biagio et al., 2017). The boreal summer dust plumes (August and later) are clearly visible in Fig. If as they pass over the Atlantic Ocean in a latitude belt between 12 and $20^{\circ} \mathrm{N}$. The winter dust plumes (February-May) in Fig. 1e pass over the ocean in a latitude belt between 6 and $14^{\circ} \mathrm{N}$. During the wet season conditions, the backward trajectory bundle transects the dust-related AOD plume over the ocean, whereas no significant overlap is observed for the dry season months. This underlines that the Saharan desert represents a relevant aerosol source for the Amazon Basin almost exclusively during the wet season. It has to be noted that the wet season dust plumes are typically mixed with smoke from African savanna fires (Koren et al., 2006; Liu et al., 2008; Ben-Ami et al., 2010). Accordingly, the pronounced AOD plume in Fig. 1e likely represents a mixed signal from dust and smoke as discussed in more detail later in this work.

In the Amazonian atmosphere, a characteristic tri-modal aerosol size distribution prevails, which - in terms of number concentrations - consists of a rather pronounced and persistent Aitken mode, a mostly dominant accumulation mode, and a comparatively weak coarse mode (Andreae et al., 2015). The multimodal shape of the size distribution is the result of the interplay of different aerosol sources as well as complex aerosol transformation processes (for further information see Sect. S2.1 in the Supplement) (Zhou et al., 2002; Martin et al., 2010b). The coarse mode ${ }^{1}$ - which is the focus of the present study - originates from different aerosol sources, such as direct emissions of primary biological aerosol particles (PBAP), marine aerosols, long-range transport (LRT) of Saharan dust plumes, and a coarse mode fraction of biomass burning aerosols (Martin et al., 2010b; Huffman et al., 2012). Coarse mode aerosols play several important roles in the rain forest ecosystem. They can act as ice nuclei (i.e., bioaerosol particles that are ice-active at high temperatures) and giant cloud condensation nuclei in aerosol-cloud interaction (Prenni et al., 2009; Pöschl et al., 2010). The advected Saharan dust particles, which mostly occur in the coarse mode, are regarded as important fertilizers for the comparably poor Amazonian soils (e.g., by bringing iron and phosphorous) (Swap et al., 1992; Rizzolo et al., 2017). Furthermore, the highly abundant and diverse PBAP population ensures the spread of various organisms in the ecosystem (Womack et al., 2015; Fröhlich-Nowoisky et al., 2016). Further details on these major sources of Amazonian coarse mode particles and their relevance can be found in Sect. S2.2.

\footnotetext{
${ }^{1}$ Note that different definitions of the coarse mode have been used in the literature (e.g., $\geq 1 \mu \mathrm{m}, \geq 2 \mu \mathrm{m}$, and $\geq 2.5 \mu \mathrm{m}$ ). Here we used the most common definition, which specifies all particles $\geq 1 \mu \mathrm{m}$ as coarse mode aerosol.
} 
The majority of aerosol studies from the Amazon Basin has focused on the life cycle and processing of the submicron size range of the aerosol population and its relevance for the Earth's climate system (Martin et al., 2010b; Artaxo et al., 2013a; Andreae et al., 2015, 2018). Its seasonal variability, superimposed on a background of biogenic, mostly secondary organic aerosol (Pöschl et al., 2010), is largely governed by the extent of biomass burning activities in Africa and South America as well as the transport patterns of the emitted aerosols. Accordingly, the anthropogenic impact on the fine mode aerosol, including its links to biogeochemical and hydrological cycling, is particularly pronounced. Conversely, the atmospheric life cycle of the aerosol coarse mode is not primarily driven by a pollution-related seasonality, but rather defined by the emission and transport of natural aerosols (i.e., desert dust, sea spray, and primary bioaerosols), which are released and dispersed on different spatiotemporal scales. Whether and to what extent human activities, such as deforestation fires and land use change, have already altered the coarse mode cycling in the Amazon compared to the preindustrial state, is largely unknown. Furthermore, to what extent coarse mode particles (e.g., as IN or giant $\mathrm{CCN}$ ) have a direct influence on clouds, precipitation, and thus the hydrological cycle in the Amazon also bears unanswered questions. So far, only a few studies have provided first insights into the coarse mode properties and variability in the central Amazon (Huffman et al., 2012; Artaxo et al., 2013b; Womack et al., 2015; Whitehead et al., 2016).

This study aims to reduce this knowledge gap by presenting a systematic overview of the coarse mode variability from a three-year measurement period at a remote Amazonian site. However, a comprehensive analysis of the complex coarse mode cycling in the Amazon is clearly beyond the scope of this manuscript. Accordingly, we focused on the following two goals: (i) first, we aim to present a general overview of the characteristic seasonal variability in the coarse mode concentration and size distribution to highlight annually recurring patterns. This general characterization is supposed to serve as baseline for follow-up studies with in-depth analyses of aspects that are only briefly addressed here. (ii) Second, we selected the frequent transport of African dust into the Amazon Basin, which can be observed very clearly in the coarse mode variability. We highlight the atmospheric conditions that explain the episodic transport of African dust into the central Amazon in relation to the characteristic signals that are observed in the coarse mode aerosol population as well as related parameters. Although the primary focus of this work is the aerosol coarse mode, selected aspects of the accumulation mode variability have also been included in the analysis and discussion, where they help to clarify the overall picture of the relevant atmospheric conditions and processes.

\section{Materials and methods}

\subsection{Aerosol observations at the Amazon Tall Tower Observatory (ATTO) site}

The aerosol data discussed in this study have been collected at the ATTO site $\left(2^{\circ} 08.602^{\prime} \mathrm{S}, 59^{\circ} 00.033^{\prime} \mathrm{W}, 130 \mathrm{~m}\right.$ above sea level), which is located $\sim 150 \mathrm{~km}$ NE of Manaus, Brazil. The ATTO site has been established as a long-term research station for aerosol, trace gas, meteorological, and ecological studies in the central Amazon forest. A comprehensive set of information on the ATTO site can be found in an overview paper by Andreae et al. (2015). In 2014 and 2015, the ATTO site was part of the international large-scale field campaign GoAmazon2014/5 that was conducted in and around the city of Manaus from 1 January 2014 until 31 December 2015 (Martin et al., 2016, 2017). During GoAmazon2014/5, the ATTO site served as the clean background site (T0a). Two intensive observation periods (IOPs) took place: IOP1 from 1 February to 31 March 2014, and IOP2 from 15 August to 15 October 2014. Furthermore, the measurement period of this study overlapped with the GermanBrazilian ACRIDICON-CHUVA measurement campaign in September 2014 (Machado et al., 2014; Wendisch et al., 2016), where detailed ground-based and aircraft measurements were performed over a large area of the Amazon Basin.

In this study, we mostly focus on measurement data obtained at the ATTO site. However, some selected results (i.e., analysis of filter samples, see Sect. 2.4) from the "neighbor" $\mathrm{ZF} 2$ site, which is located $60 \mathrm{~km}$ north of Manaus and about $100 \mathrm{~km}$ southwest of the ATTO site, were taken into account (Martin et al., 2010a; Artaxo et al., 2013a). A comparison of results from the ATTO and ZF2 sites is justified by the fact that on average similar atmospheric conditions and air mass advection patterns prevail at both locations, as shown in Pöhlker et al. (2018). Also the aerosol (optical) properties, analyzed in Saturno et al. (2017a), are comparable. However, some degree of uncertainty is associated with this comparison and has to be taken into account carefully.

\subsection{Long-term measurements with optical particle sizing and data analysis}

This study is based on measurements with an optical particle sizer (OPS, model 3330, TSI Inc. Shoreview, MN, USA), which has been operated continuously at the ATTO site since 30 January 2014. It covers 38 months of OPS data from 30 January 2014 until 30 April 2017. The instrument performs single particle counting and sizing (in the range of 0.3 to $10 \mu \mathrm{m}$, divided into 16 size bins) based on aerosol light scattering. All aerosol particle sizes throughout this study represent particle diameters. The OPS size range covers the aerosol coarse mode as well as the "tail" of the accumulation mode, which peaks at $\sim 0.15 \mu$ m (Huffman et al., 2012; 
Andreae et al., 2015). The measured aerosol number size distributions $\left(\mathrm{d} N / \mathrm{d} \log D_{\mathrm{o}}\right)$ were converted into surface size $\left(\mathrm{d} S / \mathrm{d} \log D_{\mathrm{o}}\right)$ and volume size distributions $\left(\mathrm{d} V / \mathrm{d} \log D_{\mathrm{o}}\right)$, assuming spherical particles with a shape factor of 1 and a density of $1 \mathrm{~g} \mathrm{~cm}^{-3}$. The sampling intervals and thus the time resolution of the measurements were set to $5 \mathrm{~min}$. The OPS is being operated inside a measurement container at the base of a triangular mast, getting ambient air from a $25 \mathrm{~mm}$ stainless steel inlet line with a total suspended matter (TSP) inlet head at $60 \mathrm{~m}$ a.g.l. and $\sim 30 \mathrm{~m}$ above canopy height (for further details see Andreae et al., 2015; Pöhlker et al., 2016). The sample air is dried by silica diffusion dryers to a relative humidity (RH) of about $40 \%$. From 30 January 2014 until 2 February 2015 the drying was based on frequent manual exchanges of the silica gel cartridges. Since 2 February 2015, drying has been based on an automated drying system as described in Tuch et al. (2009). The OPS data were recorded by the software package "aerosol instrument manager" (AIM, version 9.0, TSI Inc.). Further analysis and processing were done with the software packages IGOR Pro (version 6.3.7.2, Wavemetrics, Inc.; Portland, OR, USA) and R (version 3.2.0, R Development Core Team, 2010). Periods with biased data (i.e., due to changes of silica gel in the dryers, leaks, local contamination) have been flagged and were not included in the present analyses. The aerosol data reported here were converted to standard temperature $\left(0{ }^{\circ} \mathrm{C}\right)$ and pressure $(1013 \mathrm{hPa})(\mathrm{STP})$. The time throughout this study is shown as coordinated universal time (UTC). Local time (LT or UTC -4 ) has only been used for the analysis of diurnal cycles and is marked accordingly.

Optical aerosol sizing techniques have been widely used in aerosol research. However, the following aspects have to be kept in mind: (i) optical aerosol sizing - based on the correlation of particle size and the intensity of light scattering pulses - is one of three widely used approaches to retrieve equivalent diameters of coarse mode particles. The other experimental strategies rely on geometric or aerodynamic particle sizing (Gwaze et al., 2007; Huffman et al., 2012). (ii) The resulting equivalent optical $\left(D_{\mathrm{o}}\right)$, geometric $\left(D_{\mathrm{p}}\right)$, and aerodynamic $\left(D_{\mathrm{a}}\right)$ diameters and corresponding aerosol size distributions typically deviate substantially due to systematic experimental biases. (iii) In a direct comparison of $D_{\mathrm{o}}, D_{\mathrm{p}}$, and $D_{\text {a }}$ retrievals, Reid et al. (2003a) stated that optical sizing has the largest biases of all three techniques. Specifically, it tends to oversize particles (up to factor 2) and results in a broadening of the coarse mode. These aspects have to be critically considered throughout the subsequent discussion of the OPSderived results in this study.

\subsection{Inlet aspiration and transmission efficiency with particle loss corrections}

Online aerosol analysis and sampling in the field typically rely on dedicated inlet systems that transport the ambient air to the instruments and/or samplers. However, sampling through an inlet is always non-ideal and, thus, creates sampling artifacts as well as biases the measurement results (von der Weiden et al., 2009). Representative aerosol analysis requires high aspiration rates (i.e., isoaxial and isokinetic conditions) and high tube transmission efficiencies (i.e., minimized losses) (von der Weiden et al., 2009; Byeon et al., 2015). For the tube transmission, the most relevant particle loss mechanisms (i.e., diffusion, sedimentation, and inertial deposition) are strongly size dependent, and coarse mode aerosol particles, which are the focus of the present study, are particularly prone to the deposition- and inertia-related artifacts. Since the overall sampling efficiency is critical for the representativeness and interpretation of the coarse mode results reported here, we conducted a detailed analysis of relevant particle losses in the inlet system and applied a corresponding particle loss correction to the OPS data. Details can be found in Sect. S1.1.

\subsection{Aerosol filter sampling for gravimetric and x-ray fluorescence analyses}

Aerosol filters for gravimetric, $\mathrm{x}$-ray fluorescence, and further analysis are collected at the ATTO site on a continuous basis. Prior to February 2016, the samples were collected with a two-stage impactor. After February 2016, the samples were collected with an automated Partisol ${ }^{\mathrm{TM}}$ filter sampler (model 2025i, Thermo Fisher Scientific, Waltham, MA, USA). The samplers were placed on a platform on the walk-up tower at a height $\sim 50 \mathrm{~m}$ above ground level (Andreae et al., 2015). The sampling was conducted sizesegregated on a "fine" mode filter (with $D<2.5 \mu \mathrm{m}$ ) and a "coarse" mode filter (with $2.5<D<10 \mu \mathrm{m}$ ) ${ }^{2}$. The samples were mostly collected on a 5-7 day basis with a low volume sampler $\left(16.7 \mathrm{~L} \mathrm{~min}^{-1}\right)$ with $47 \mathrm{~mm}$ diameter and $0.4 \mu \mathrm{m}$ pore size polycarbonate filters. A similar continuous filter sampling has been conducted at the ZF2 site as well.

The gravimetric analysis was conducted according to a protocol of the US Environmental Protection Agency. Mass concentrations were obtained gravimetrically using an electronic microbalance with a readability of $1 \mu \mathrm{g}$ (Mettler Toledo, model MX5) in a controlled-atmosphere room under defined conditions (i.e., RH $35 \%$ and $20^{\circ} \mathrm{C}$ ). Filters were equilibrated for $24 \mathrm{~h}$ prior weighing. Electrostatic charges were controlled with radioactive ${ }^{210}$ Po sources. The experimental error in the elemental mass concentrations is specified as $\pm 5 \%$ (see details in Artaxo et al., 2002, 2013b).

Energy dispersive $\mathrm{x}$-ray fluorescence (EDXRF) analysis was used to quantify elements with atomic numbers $\geq 11$ (Na and heavier) on the filters (Arana et al., 2014). The elements sodium $(\mathrm{Na})$, magnesium $(\mathrm{Mg})$, aluminum $(\mathrm{Al})$, silicon $(\mathrm{Si})$, phosphorus $(\mathrm{P})$, sulfur $(\mathrm{S})$, chlorine $(\mathrm{Cl})$, potas-

\footnotetext{
${ }^{2}$ Note that the definition of fine and coarse mode size ranges in the context of the gravimetric filter analysis (mode separation at $D=2.5 \mu \mathrm{m}$ ) is different from the definition that we used throughout this study (mode separation at $D=1.0 \mu \mathrm{m}$ ).
} 
Table 1. List of African LRT episodes observed at the ATTO site from February 2014 until April 2017. The mean and maximum $M_{1-10}$ values characterize the relative intensity of the dust pulses. For LRT episodes that contain larger data gaps, the $M_{1-10}$ values were put in parentheses. Note that the mean and maximum $M_{1-10}$ values shown here are based on a density of $1 \mathrm{~g} \mathrm{~cm}^{-3}$, see further information in Sect. 2.3. Since typical densities of dust and sea salt components in the LRT plumes are higher (see Table S1), the shown $M_{1-10}$ values represent lower limit values (compare Table 2).

\begin{tabular}{lll|rr}
\hline LRT & \multicolumn{2}{c|}{ Date [UTC] } & $M_{1-10}\left[\mu \mathrm{g} \mathrm{m}^{-3}\right]$ \\
\cline { 2 - 5 } Episodes & Start & End & Mean & Max \\
\hline 2014_1 & 2 Feb 2014 & 5 Feb 2014 & 7.60 & 22.32 \\
2014_2 & 9 Feb 2014 & 21 Feb 2014 & $(12.46)$ & $(77.04)$ \\
2014_3 & 2 Mar 2014 & 12 Mar 2014 & $(14.90)$ & $(41.67)$ \\
2014_4 & 20 Mar 2014 & 24 Mar 2014 & 10.11 & 26.44 \\
2014_5 & 28 Mar 2014 & 1 Apr 2014 & 7.07 & 15.30 \\
2014_6 & 3 Apr 2014 & 5 Apr 2014 & 7.37 & 16.59 \\
2014_7 & 8 Apr 2014 & 14 Apr 2014 & $(10.84)$ & $(24.40)$ \\
2015_1 & 2 Feb 2015 & 18 Feb 2015 & $(8.47)$ & $(23.89)$ \\
2015_2 & 27 Feb 2015 & 9 Mar 2015 & $(9.99)$ & $(38.81)$ \\
2015_3 & 11 Mar 2015 & 14 Mar 2015 & 8.74 & 25.55 \\
2015_4 & 18 Mar 2015 & 25 Mar 2015 & 9.04 & 39.75 \\
2015_5 & 2 Apr 2015 & 10 Apr 2015 & $(19.17)$ & $(59.65)$ \\
2016_1 & 6 Dec 2015 & 12 Dec 2015 & 17.80 & 71.34 \\
2016_2 & 22 Dec 2015 & 25 Dec 2015 & 9.48 & 16.92 \\
$2016 \_3 ~$ & 28 Dec 2015 & 2 Jan 2016 & 11.64 & 30.75 \\
2016_4 & 4 Jan 2016 & 11 Jan 2016 & 11.97 & 40.85 \\
2016_5 & 20 Jan 2016 & 31 Jan 2016 & $(8.14)$ & $(20.83)$ \\
2016_6 & 5 Feb 2016 & 22 Feb 2016 & $(12.88)$ & $(62.44)$ \\
2016_7 & 2 Mar 2016 & 4 Mar 2016 & 12.59 & 37.49 \\
2017_1 & 29 Dec 2016 & 11 Jan 2017 & 10.76 & 25.75 \\
2017_2 & 8 Feb 2017 & 15 Feb 2017 & 18.03 & 46.71 \\
2017_3 & 25 Feb 2017 & 26 Feb 2017 & $(6.94)$ & $(14.34)$ \\
2017_4 & 11 Mar 2017 & 18 Mar 2017 & 6.23 & 28.35 \\
2017_5 & 1 Apr 2017 & 6 Apr 2017 & 25.91 & 106.17 \\
2017_6 & 14 Apr 2017 & 15 Apr 2017 & 7.20 & 31.51 \\
2017_7 & 20 Apr 2017 & 23 Apr 2017 & 8.41 & 27.60 \\
\hline
\end{tabular}

sium $(\mathrm{K})$, calcium $(\mathrm{Ca})$, titanium $(\mathrm{Ti})$, manganese $(\mathrm{Mn})$, and iron $(\mathrm{Fe})$ have been analyzed in detail in the context of this study. The detection limits for the individual elements are shown in Table S3 in the Supplement, based on the work by Arana et al. (2014). The coloring of the elements in the corresponding figures was done according to the Corey-Pauling-Koltun (CPK) color schema (http://jmol. sourceforge.net/jscolors/, last access: 12 October 2017). For the chemical analysis of LRT aerosols as well as aerosols in the absence of strong LRT influence (called non-LRT conditions here), the EDXRF results from five LRT filter and four non-LRT filter samples were taken into account. The selection of filter samples for this analysis is based on the online data analysis: LRT samples span LRT episodes according to Table 1 and non-LRT samples are free of detectable LRT influence. Samples spanning both LRT and non-LRT conditions were omitted in this analysis accordingly. The LRT filters were collected on (i) 6 February 16:18 (UTC) to 9 February $16: 522015$, (ii) 27 February $15: 10$ to 2 March 17:16 2015, (iii) 11 March 17:23 to 13 March 15:54 2015, (iv) 20 March 16:41 to 23 March 16:34 2015, and (v) 2 April 16:41 to 8 April 16:48 2015. The non-LRT filters were collected on (i) 23 February 17:16 to 27 February 14:57 2015, (ii) 27 March 15:51 to 2 April 16:28 2015, (iii) 15 April 17:21 to 20 April $16: 102015$, and (iv) 20 April 16:22 to 24 April 15:43 2015. We report the obtained elemental results for the $D<2.5 \mu \mathrm{m}$ and $2.5<D<10 \mu \mathrm{m}$ size fractions as well as total concentrations and mass fractions, corresponding to the sum of both size fractions. The shown elemental mass concentrations for the LRT case represent average values based on the five LRT filters and the non-LRT results represent averages of the four non-LRT filters. Elemental mass fractions were calculated relative to the gravimetrically determined total mass loading of the filters. For the estimation of elemental deposition fluxes, the difference in mass concentration $M_{\mathrm{LRT}}(X)-M_{\text {non-LRT }}(X)$ for a certain element $X$ as well as the difference in total mass concentration $M_{\mathrm{LRT}}$, total $-M_{\text {non-LRT, total }}$ were taken into account.

\subsection{Comparison of OPS-retrieved aerosol masses and gravimetric analysis}

The calculated aerosol mass concentrations, which are based on the OPS measurements and the PLC (see Sect. 2.3), were validated by means of a comparison with a gravimetric filter analysis, based on ATTO aerosol filters, as outlined in Sect. 2.4. For the comparison, the following two periods with gravimetric results were available: (i) a period from 6 September to 29 November 2014, comprising 10 filters and (ii) a period from 30 September to 8 November 2015, comprising 14 filters. No corresponding gravimetric results were available for the wet season and LRT episodes. The results of the comparison are summarized in Fig. S2 in the Supplement, which shows the coarse mode aerosol mass time series (Fig. S2a and b) as well as a scatter plot with the combined results (Fig. S2c). Figure S2 confirms that the aerosol masses from the direct gravimetric approach and the indirect OPS-based retrieval agree comparatively well. We regard the gravimetric analysis as reference measurement, which confirms that the PLC of the OPS data and the chosen density (i.e., $\rho_{1.0}$ ) are appropriate to yield reliable OPS-based aerosol mass concentrations at the ATTO site in the absence of major dust influence. This implies that during substantial influence of dust and/or sea salt, which are characterized by higher aerosol particle densities $\left(\sim 2 \mathrm{~g} \mathrm{~cm}^{-3}\right.$, see Table $\left.\mathrm{S} 1\right)$, no one-to-one agreement between OPS-based mass retrieval and gravimetry can be expected. In fact, the OPS-derived aerosol mass would underestimate the actual mass. The influence of different densities on the aerosol mass concentration is addressed later in this study in more detail (refer to Table 2). 


\subsection{Supplementary aerosol measurements and instrument comparison}

A broad set of aerosol and trace gas instrumentation is being operated at the ATTO site on a continuous basis (Andreae et al., 2015). In addition to the OPS data analysis, which is the focus of the present study, we used supplementary data from the following online instruments: a condensation particle counter (CPC, model 5412, Grimm Aerosol Technik, Ainring, Germany), a scanning mobility particle sizer (SMPS, model 3082, TSI Inc., Shoreview, MN, USA), an ultra-high sensitivity aerosol spectrometer (UHSAS, DMT, Longmont, CO, USA), a wide-band integrated bioaerosol sensor (WIBS, model 4A, DMT), a three-wavelength integrating nephelometer (Ecotech Aurora 3000, $\lambda=450,525$, and $635 \mathrm{~nm}$ ), a multi-angle aerosol absorption photometer (MAAP, model 5012, Thermo Electron Group, $\lambda=670 \mathrm{~nm}$ ), carbon dioxide $\left(\mathrm{CO}_{2}\right)$, methane $\left(\mathrm{CH}_{4}\right)$, and carbon monoxide (CO) monitors based on cavity ring-down spectroscopy (G1301, G1302 analyzers, Picarro Inc, USA) and a ceilometer (CHM15kx, Jenoptik, Germany). The equivalent black carbon $\left(\mathrm{BC}_{\mathrm{e}}\right)$ mass concentrations, $M_{\mathrm{BCe}}$, were obtained from the MAAP aerosol absorptivity measurements based on ATTO-specific mass absorption coefficients (MAC) as discussed in Saturno et al. (2017a). The ceilometer has been operated at the ATTO site since December 2014. It has been installed with an inclination angle of $15^{\circ}$ to minimize direct sunlight. Frequent comparisons of the sizing instruments have been conducted at the ATTO site to ensure comparability of the individual data sets. Figure S3 presents the results of such a comparison for the instruments OPS (0.3$10 \mu \mathrm{m})$, SMPS $(0.01-0.43 \mu \mathrm{m})$, UHSAS $(0.06-1 \mu \mathrm{m})$, and WIBS $(1.5-10 \mu \mathrm{m})$. The good agreement of the size distributions shows that the results of all instruments are consistent. The ceilometer data was processed according to Heese et al. (2010), specifically dedicated to detect aerosol layers in the free troposphere up to $\sim 4 \mathrm{~km}$ height during daytime hours.

\subsection{Backward trajectory analysis}

Our investigation of the atmospheric transport in this study is based on a systematic backward trajectory (BT) analysis, which has been adopted from a recent study where details can be found (Pöhlker et al., 2018). Briefly, Fig. S4 shows 15 clusters of 3-day BT ensembles, which describe the spatiotemporal variability of air mass movement towards the ATTO site over the NE Amazon Basin. The choice of 15 clusters is explained in Pöhlker et al. (2018). The choice of 3-day BTs is based on the following rationales: (i) The mesoscale circulation that transports the African LRT aerosol plumes from the Atlantic coast into the Amazon Basin are of primary interest for this study. In this regard, the 3-day BTs sufficiently cover the relevant NE fetch across the basin. (ii) Moreover, the region of interest $\mathrm{ROI}_{\text {off }}$ (see details in
Sect. 2.8) is relevant for rain-related aerosol scavenging (i.e., of LRT aerosol, see Fig. 1c and d), which is of particular relevance for the analyzed phenomena. Figure S4 illustrates that the air masses at the ATTO site arrive almost exclusively in a rather narrow easterly wind sector (between 45 and $120^{\circ}$ ). Within this sector, four BT subgroups can be identified: (i) a northeasterly (NE) track including the clusters NE1, NE2, and NE3; (ii) an east-northeasterly (ENE) track including the clusters ENE1, ENE2, ENE3, and ENE4; (iii) an easterly (E) track including the clusters E1, E2, E3, and E4; and (iv) a group of "inland" trajectories in east-southeasterly (ESE) directions including clusters ESE1, ESE2, and ESE3 as well as one cluster towards the southwest (SW1). Furthermore, the cumulative precipitation along the $\mathrm{BT}$ tracks, $P_{\mathrm{BT}}$, has been calculated based on the HYSPLIT model output. Note that the HYSPLIT precipitation output is provided "at the grid cell where the trajectory is located and does not depend on the cloud value at the height of the trajectory" (comment by G. Rolph at https://hysplitbbs.arl.noaa.gov/viewtopic.php?t= 577, last access: 15 March 2018).

\subsection{Satellite data analysis}

The satellite data products used in this study were obtained from the Giovanni web-based application by the Goddard Earth Sciences Data and Innovation web interface (http:// giovanni.gsfc.nasa.gov/, last access: 4 July 2017) (Acker and Leptoukh, 2007). The following satellite products were used: (i) aerosol optical depth (AOD) at a wavelength of $550 \mathrm{~nm}$ from the moderate resolution imaging spectroradiometers (MODIS) on the satellites Terra and Aqua (combined dark target deep blue AOD products MOD08_D3_V6 and MYD08_D3_V6), (ii) cloud top temperature data from the atmospheric infrared sounder (AIRS) instruments on board of Terra and Aqua (AIRX3STD_v006 product), (iii) precipitation data from the tropical rainfall measuring mission (TRMM) mission (TRMM_3B42_Daily_v7 product), and (iv) CO total column data from the AIRS instruments on board of Terra and Aqua (AIRS3STD_v006 product). These data sets were used as time-average maps as well as time series for specified regions of interest (ROI). The time series of MODIS and TRMM satellite data products were obtained as area averages within two ROIs: (i) a ROI in front of the NE coast of the basin ("offshore"), called $\mathrm{ROI}_{\text {off }}$ ( 49 to $37^{\circ} \mathrm{W}$; 0 to $12^{\circ} \mathrm{N}$ ) and (ii) a ROI covering the ATTO region, called $\mathrm{ROI}_{\mathrm{ATTO}}\left(59.5\right.$ to $54^{\circ} \mathrm{W} ; 3.5^{\circ} \mathrm{S}$ to $2.4^{\circ} \mathrm{N}$ ); both ROIs are displayed in Fig. S4. The data files were exported as netcdf (Network Common Data Form, version 3.x) or ascii files. Further data processing was conducted in IGOR Pro. Cloud Lidar Aerosol Infrared Pathfinder Satellite (CALIPSO) data products - i.e., lidar profiles from the cloud-aerosol lidar with orthogonal polarization (CALIOP) - were obtained from the website: https://www-calipso.larc.nasa.gov/ (last access: 15 June 2017). Daily wind data and precipitation were obtained from National Center for Environmental Pre- 
diction NCEP (http://www.esrl.noaa.gov/psd/data, last access: 20 September 2016) and using the software MeteoInfo (see details in Wang, 2014).

\subsection{GEOS-Chem modeling}

The modeling results used here are based on GEOSChem version 9-02 (http://www.geos-chem.org/, last access: 17 May 2017). GEOS-Chem is a chemical transport model with a global 3-D model of atmospheric composition driven by assimilated meteorological data GEOS-5 FP from the NASA Global Modeling and Assimilation Office (GMAO). Aerosol types simulated in GEOS-Chem include carbonaceous aerosols (fine mode), sulfate-nitrateammonium aerosols (fine mode), fine and coarse mode sea salt, and mineral dust in four size classes. For details, we refer the reader to a previous study by Wang et al. (2016), which showed that GEOS-Chem successfully captured the observed variation in aerosol properties in the Amazon Basin during January-April 2014.

\subsection{Amazonian seasonality, nomenclature, and definition of LRT episodes}

This study utilizes the definition of the Amazonian seasons according to M. Pöhlker et al. (2016) as follows: (i) the "wet season" spans February to May and shows the cleanest atmospheric state, (ii) the "transition period from wet to dry season" spans June and July, (iii) the "dry season" months August to November show the highest pollution levels, and (iv) the "transition period from dry to wet season" spans December and January. For the present analysis, all results referring to "transition period" include both, the transition period from wet to dry season and the transition period from dry to wet season. Results referring to the "LRT episodes" of a certain year or for the entire measurement period represent averaged results from the individual LRT episodes as listed in Table 1. Note that LRT episodes in this study refer exclusively to LRT during the Amazonian wet season, when African dust and smoke has been transported to the Amazon. During the dry season, LRT aerosols (mostly smoke without dust) from southern Africa arrive in the Amazon Basin via similar transport mechanisms. These dry season LRT events, which typically do not transport substantial dust loads and, thus, are less relevant for the coarse mode, have not been addressed in the context of this study. Details regarding dry season LRT aerosols can be found in Saturno et al. (2017a, b). Results referring to the "wet season without LRT" represent average data from the wet season time frame with the corresponding LRT episodes in Table 1 being excluded.

As LRT episodes, we defined periods with continuous dust influence at the ATTO site, when the following three criteria were fulfilled: (i) increased AOD values were detected by the spaceborne MODIS instruments (see examples in Figs. 11 and S11) for clear detection of African dust out- breaks, transatlantic passage, and arrival at the South American coast, (ii) the maximum of daily averaged coarse mode mass concentrations, $M_{1-10}$ exceeded $9 \mu \mathrm{g} \mathrm{m}^{-3}$ (average wet season concentration +2 standard deviations), as a sensitive marker for the abundance of supermicron particles, and (iii) the $M_{1-10}$ time series showed a peak-like increase that lasted longer than one day. Episodes with chemical information on aerosol composition (i.e., based on weekly filter samples, see Sect. 2.4) confirm that the aforementioned criteria are sufficient to identify major and medium dust events. The observed LRT episodes typically span periods from 2 to 20 days. However, it has to be noted that the definition of the (precise) beginning and end of each LRT episodes may be considered arbitrary to some extent because of the comparatively high variability of the $M_{1-10}$ background.

\section{Results and Discussion}

\subsection{Time series of the aerosol coarse mode and related parameters}

The overview Fig. 2 shows coarse mode aerosol data from almost two and a half years (February 2014 until June 2016) ${ }^{3}$. It combines this data with selected meteorological and aerosol time series and, thus, puts the coarse mode trends in the context of the overall atmospheric seasonality at the ATTO site. Figure 2a displays the daily frequency of occur-

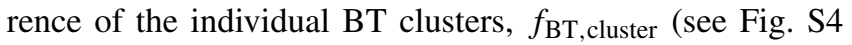
for BT cluster overview). This shows the clear prevalence of northeasterly (NE) and east-northeasterly (ENE) trajectories during the wet season (i.e., February-April), followed by a rather sudden shift to easterly (E) and east-southeasterly (ESE) trajectories towards the end of the wet season (i.e., May). During the subsequent transition period (i.e., JuneJuly) and most of the dry season (i.e., August-October), E and ESE trajectories prevail. Eventually, at the end of the dry season (i.e., November) and in the subsequent transition period (i.e., December-January), the dominant wind direction gradually swings back from SE to NE directions.

In general, the seasonality in the atmospheric composition in the central Amazon is largely driven by the seasonal cycle of vegetation fire activity in combination with the changing air mass transport patterns. This biomass burning seasonality is detectable in most aerosol parameters (Andreae et al., 2015; Pöhlker et al., 2016). As examples in Fig. 2b and c, the accumulation mode abundance, $M_{\mathrm{BCe}}$, and the aerosol scattering coefficient, $\sigma_{\mathrm{sp}}$, time series showed pronounced maxima, with highest concentrations during the core months of the dry season (i.e., August-October). In this overall picture, the coarse mode seasonality shows different trends. This

\footnotetext{
${ }^{3}$ Figure 2 covers the LRT episodes 2014, 2015, and 2016. Note that we also analyzed the LRT episodes in 2017 for this work, however, decided to limit the time frame of Fig. 2 to only three LRT episodes for the sake of clarity (for details see Sect. 2.2).
} 


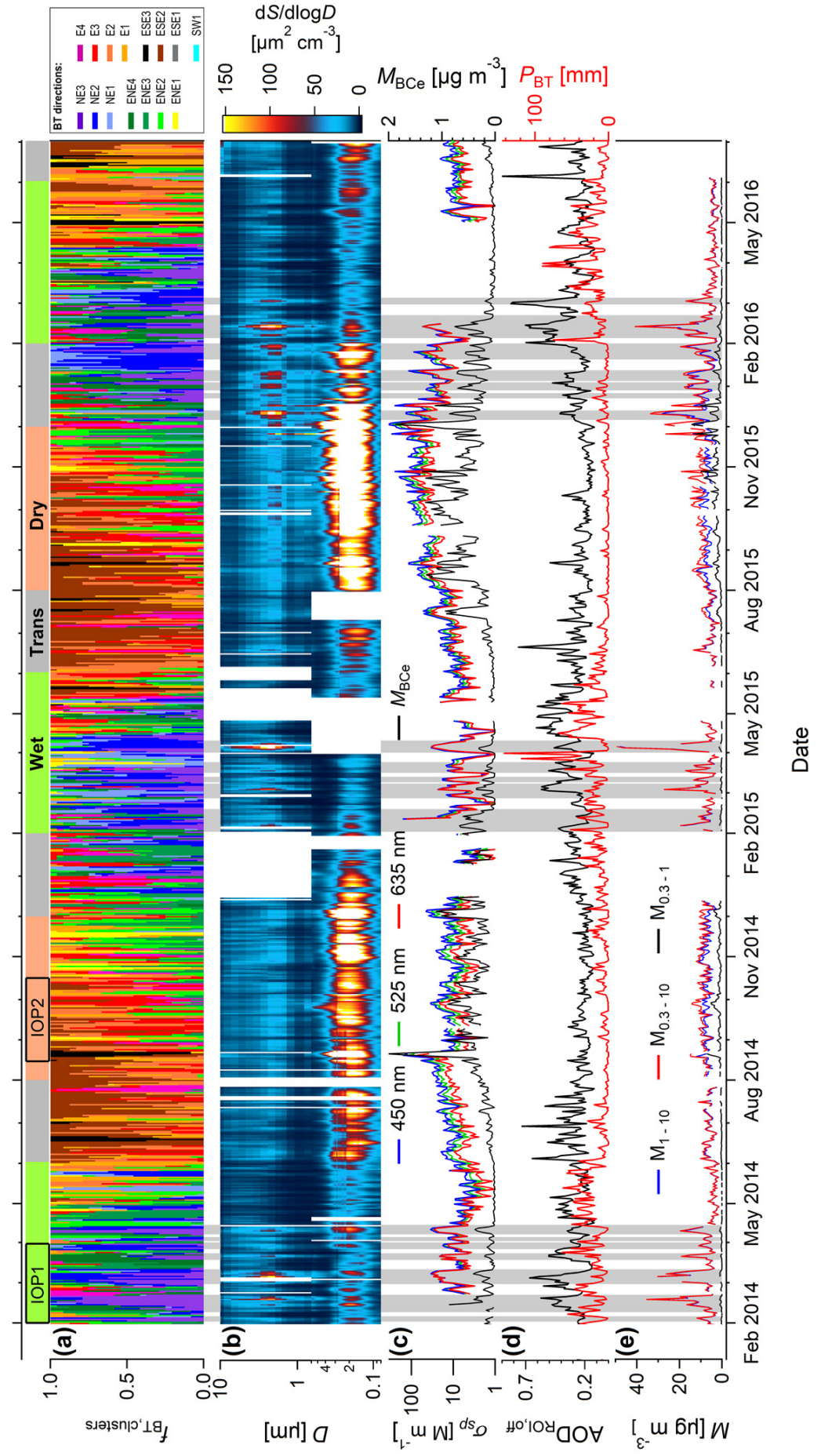

Figure 2. Overview of the long-term meteorological and aerosol time series emphasizing coarse mode data, in the context of atmospheric seasonality at the ATTO site, with time series representing daily averages. (a) Frequency of occurrence, $f_{\mathrm{BT}}$, clusters, of 15 back trajectory clusters as displayed in Fig. S4 (with identical color coding). (b) Image plot of aerosol surface size distribution for the size range from $80 \mathrm{~nm}$ to $10 \mu \mathrm{m}$. (c, left axis) Time series of the aerosol scattering coefficients, $\sigma_{\mathrm{sp}}$, at three different wavelengths. (c, right axis) Time series of equivalent black carbon $\left(\mathrm{BC}_{\mathrm{e}}\right)$ with mass absorption cross-sections (MAC) at $637 \mathrm{~nm}$ that represent conditions in the ATTO region (wet season: $11.4 \mathrm{~m}^{2} \mathrm{~g}^{-1}$; dry season: $12.3 \mathrm{~m}^{2} \mathrm{~g}^{-1}$ ). (d, left axis) Satellite-retrieved aerosol optical depth at $550 \mathrm{~nm}$, area-averaged over offshore region of interest $\left(\mathrm{ROI}_{\mathrm{off}}\right.$, see Fig. S4). The AOD $\mathrm{ROI}$, off time series represents the average of the MODIS data sets from the satellites Aqua and Terra (d, right axis) HYSPLIT-retrieved accumulated precipitation $P_{\mathrm{BT}}$ along the trajectory tracks. (e) Aerosol mass concentrations in the size ranges $0.3-10 \mu \mathrm{m}\left(M_{0.3-10}\right), 1-10 \mu \mathrm{m}\left(M_{1-10}\right)$, and $0.3-1 \mu \mathrm{m}\left(M_{0.3-1}\right)$. Colored shading in the top of the figure visualizes the Amazonian seasons (see Sect. 2.10) as well as the intensive operation periods (IOPs) 1 and 2 of the GoAmazon2014/5 project. Gray vertical bands mark episodes when Saharan LRT aerosol was measured at the ATTO site (see Table 1). 
can be seen in the plot of the surface size distribution ${ }^{4}$ (i.e., from 1 to $10 \mu \mathrm{m}$, Fig. $2 \mathrm{~b}$ ) as well as in Fig. 2e as time series of total aerosol mass concentration covering the size ranges $0.3-10 \mu \mathrm{m}\left(M_{0.3-10}\right), 1-10 \mu \mathrm{m}\left(M_{1-10}\right)$, and $0.3-1 \mu \mathrm{m}$ $\left(M_{0.3-1}\right)$. Particularly, $M_{1-10}$ represents a sensitive indicator for the overall abundance of coarse particles (i.e., $>1 \mu \mathrm{m}$ ). The coarse mode aerosol mass concentration, $M_{1-10}$, was generally low and ranged below $10 \mu \mathrm{g} \mathrm{m}^{-3}$ for most of the measurement period. The trend was only interrupted by annually reoccurring and well defined peaks, which mostly occurred in the period December to April as detectable in Fig. $2 b$ and e.

The observed peaks in $M_{1-10}$, which Fig. 2 highlights with gray vertical shading, represent the frequent intrusion of African LRT dust and combustion aerosol plumes (called here LRT episodes). The identification of major LRT episodes in the ATTO data was rather straightforward as they are associated with pronounced increases in the aerosol parameters, $M_{1-10}$ and $M_{\mathrm{BCe}}$. However, the detection of minor and/or "diluted" LRT episodes turned out to be difficult in certain cases, due to the variable coarse mode background, which is mostly driven by PBAP cycling. The criteria that were used for the definition of LRT episodes are outlined in Sect. 2.10. Table 1 summarizes all detected ${ }^{5}$ major and medium LRT episodes from February 2014 to April 2017. Note that the $M_{1-10}$ peaks clearly coincide with corresponding signals in $M_{\mathrm{BCe}}$ and $\sigma_{\mathrm{sp}}$, underlining that the LRT aerosols typically represent mixtures of Saharan dust (mostly in the coarse mode), biomass burning smoke (mostly in the accumulation mode), and sea spray (in the coarse and accumulation modes) (Quinn et al., 1996; O'Dowd et al., 2008; Wang et al., 2016; Aller et al., 2017; Huang and Jaeglé, 2017). Accordingly, the image plot of the aerosol size distribution shows (pronounced) LRT pulses in both the superand submicron size ranges. Note in this context that also the scattering Ångström exponent, $\stackrel{\leftrightarrow}{s c a}_{\text {sca }}$, is a sensitive indicator for the presence of coarse mode particles. Qualitatively, this effect can be seen in Fig. 2c by means of a decreasing difference of the three $\sigma_{\mathrm{sp}}$ time series during LRT episodes. Quantitatively, this effect is shown by Saturno et al. (2017a) in

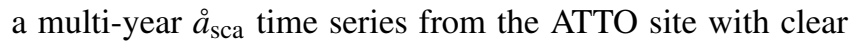
$\stackrel{\circ}{a}_{\text {sca }}$ decreases during the presence of African dust aerosols. Mostly, the LRT episodes occurred in a rather defined time window from December to April, which was described previously as the "Amazonian dust season" (Andreae, 1983; Swap et al., 1992; Formenti et al., 2001; Rizzolo et al., 2017).

\footnotetext{
${ }^{4} \mathrm{We}$ chose the surface size distribution as an adequate representation of the aerosol population, since the corresponding image plot shows the aerosol concentrations in the sub- and supermicron ranges at comparable intensities.

${ }^{5}$ Due to several data gaps, particularly between December 2014 and May 2015, the coverage of the LRT episodes in 2015 is incomplete. As LRT episodes likely occurred during the data gaps, these events were not covered by the present analysis and, thus, are not listed in Table 1.
}

The pulse-wise arrival of African LRT aerosol plumes at the ATTO site, as shown in Fig. 2, appears to be controlled by the following three factors: (1) arrival and availability of LRT aerosol plumes at the South American coast, (2) atmospheric circulation in the NE Amazon Basin and its efficiency to transport dust from the coast towards the ATTO site, and (3) the extent of wet deposition of the aerosol load en route. Note that (2) and (3) are related to some extent since aerosol deposition by precipitation plays a central role in both of them. However, we decided to outline both aspects separately for the sake of clarity.

Relating to (1), Saharan dust outbreaks are frequent and circulation patterns and aerosol deposition over the Atlantic Ocean define if, and to what extent, the LRT plumes arrive at the NE margins of the basin (Gläser et al., 2015). To analyze this arrival of dust plumes on a temporal scale with areaaveraged satellite data, we defined an (offshore) region of interest $\left(\mathrm{ROI}_{\text {off }}\right) \mathrm{NE}$ of the Amazon River delta, over the Atlantic Ocean, as displayed in Fig. S4. This ROI off $_{\text {intersects }}$ with the main tracks of the wet season trajectory clusters (i.e., NE and ENE) and further covers the arriving LRT plumes. The resulting satellite-derived and $\mathrm{ROI}_{\text {off-averaged } \mathrm{AOD}}$ time series $\left(\mathrm{AOD}_{\mathrm{ROI}}\right.$, off $)$ is displayed in Fig. 2d. Note that the transport time of the air masses over the last $\sim 1500 \mathrm{~km}$ from the $\mathrm{ROI}_{\text {off }}$ to the ATTO site takes on average 3 days (Pöhlker et al., 2018). In order to (qualitatively) compare the $M_{1-10}$ signals at the ATTO site with the AOD $\mathrm{ROI}_{\text {, off variabil- }}$ ity of arriving dust plumes at the coast, we "synchronized" both time series via lagging the $\mathrm{AOD}_{\mathrm{ROI}}$, off data by 3 days. In other words, the direct comparison of the shifted $\mathrm{AOD}_{\mathrm{ROI}}$, off time series shows the amount of dust that potentially arrived at the ATTO site (Fig. 2d) vs. the $M_{1-10}$ time series that indicates the amount of dust that actually arrived (Fig. 2e). This comparison (Fig. 2d vs. e) indicates that only a rather small fraction of the dust load at the coast actually reached the ATTO site (i.e., the majority of $\mathrm{AOD}_{\mathrm{ROI}}$, off peaks did not result in $M_{1-10}$ signals). The following examples in Fig. 2 illustrate these trends: the pronounced dust pulses at the ATTO site around 18 February, 7 March, and 10 April 2014 were clearly related to corresponding $\mathrm{AOD}_{\mathrm{ROI}, \text { off }}$ increases. However, note that the intensities of $M_{1-10}$ and $\mathrm{AOD}_{\mathrm{ROI}}$, off in this relationship did not necessarily correlate. For instance, the $M_{1-10}$ pulse on 6 April 2015, which represents one of the strongest signals observed during the entire measurement period, was associated with a comparatively weak signal in $\mathrm{AOD}_{\mathrm{ROI}}$, off. Furthermore, all April-May periods in Fig. 2 showed pronounced and continuous $\mathrm{AOD}_{\mathrm{ROI}}$, off signals, however only sparse dust transport towards the ATTO region as shown by the few occurring $M_{1-10}$ peaks. To further underline these aspects, the Fig. S5 focuses specifically on a direct $M_{1-10}$ vs. AOD $\mathrm{ROI}_{\text {, off }}$ comparison. In summary, the AOD $\mathrm{ROI}_{\text {, off }}$ vs. $M_{1-10}$ time series underline that the LRT plume transport from the coast over the NE region of the basin towards the ATTO site can be regarded as a "bottleneck", as most of the LRT aerosol load appears to be scav- 
enged on its way here, which is subject of detailed discussion in the following paragraphs.

Relating to (2), a second key factor appears to be the efficiency of dust transport coming from the coast to the ATTO site. In this context, efficiency means a direct and fast transport of air masses from regions with enhanced arriving dust loads in front of the coast towards the ATTO site. This relationship can be illustrated by means of the frequency of occurrence of the BT clusters $f_{\mathrm{BT}}$ (Fig. 2a). Specifically, the occurrence of $M_{1-10}$ peaks appears to be predominantly associated with high $f_{\mathrm{BT}}$ of those $\mathrm{BT}$ clusters that reach furthest to the NE: namely NE2 and NE3. The majority of dust pulses in Fig. 2 followed this trend. To mention a few characteristic examples: all $M_{1-10}$ pulses from February to April 2014 precisely coincide with the purple-bluish peaks of high NE2 and NE3 $f_{\mathrm{BT}}$ in Fig. 2a. The efficiency aspect of the transport can be further explained by the spatiotemporal trends in Fig. 3, which display the longitude-averaged Hovmöller plots for satellite-derived AOD levels and precipitation rate $P_{\text {TRMM }}$. The geographic dimensions of the Hovmöller plots are based on the $\mathrm{ROI}_{\text {off }}$ : the longitudinal range ( 49 to $37^{\circ} \mathrm{W}$ ), which is averaged in the Hovmöller representation, is identi-

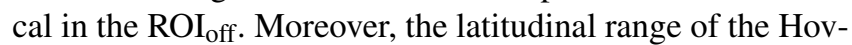
möller plot $\left(10^{\circ} \mathrm{S}\right.$ to $\left.30^{\circ} \mathrm{N}\right)$ includes the $\operatorname{ROI}_{\text {off }}\left(0\right.$ to $\left.12^{\circ} \mathrm{N}\right)$, however, it reaches further north and south. Figure 3a illustrates the annual latitudinal shifts in the LRT plume position (Huang et al., 2010). Thus, at the beginning of the year during February and March, the southernmost position was observed with an AOD maximum at $\sim 6^{\circ} \mathrm{N}$. The northernmost position is observed in July and August with an AOD maximum at $\sim 17^{\circ} \mathrm{N}$. In parallel, a pronounced spatiotemporal shift can be found in $P_{\text {TRMM }}$ : particularly in March the southernmost position of the $P_{\text {TRMM }}$ maximum is observed at $\sim 0^{\circ} \mathrm{N}$, whereas the northernmost position occurs in September at $\sim 7^{\circ} \mathrm{N}$, which corresponds with the ITCZ shifts as previously shown in Fig. 1c and d.

In the light of Fig. 3, the high dust transport efficiency of the BT clusters NE2 and NE3 can be explained as follows: (i) both clusters reached comparatively far to the north and, thus, had the highest overlap with the densest LRT plume regions (i.e., both clusters transect the AOD maximum at $\sim 7^{\circ} \mathrm{N}$; compare Figs. 1e and 3a). Thus, they tended to transport (on average) the highest LRT aerosol loads into the basin. (ii) Both clusters are comparatively "long", which reflects high air mass velocities and, thus, minimizes the probability of aerosol scavenging. (iii) Moreover, both clusters bypassed the densest rain fields in the north and, thus, tended to avoid intense scavenging (compare Figs. 1c and 3b). Overall, this study clearly shows that the clusters NE2 and NE3 are particularly efficient dust transporters, as they have maximum overlap with the high-AOD region and, at the same time, a rather small overlap with high- $P_{\text {TRMM }}$ regions. In contrast, the ENE clusters have less overlap with the dense AOD fields and higher probability to receive larger amounts of precipitation. Accordingly, periods with high frequency of
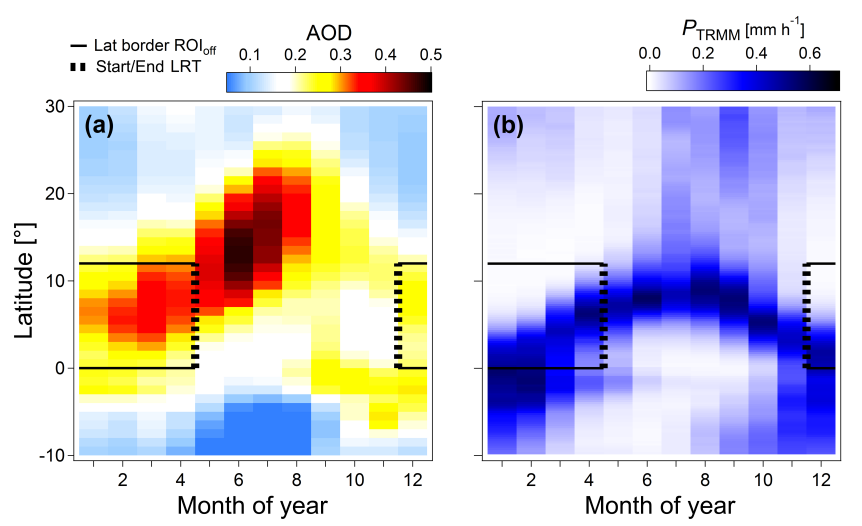

Figure 3. Longitude-averaged Hovmöller plots for (a) MODISderived aerosol optical depth (AOD) and (b) TRMM-derived precipitation rate, $P_{\text {TRMM }}$. The average AOD data represent a time period from July 2002 to June 2016. The average precipitation rate data represent a time period from December 1997 to March 2016. Long time periods have been chosen (maximum of available satellite data) to extract representative seasonal trends. The averaged longitude range of the plots from 49 to $37^{\circ} \mathrm{W}$ corresponds with the longitude dimension of the $\mathrm{ROI}_{\mathrm{off}}$ in Fig. S4. The latitudinal range of the Hovmöller plots spans from $10^{\circ} \mathrm{S}$ to $30^{\circ} \mathrm{N}$. The solid black lines mark the latitudinal margins of the $\operatorname{ROI}_{\text {off }}\left(0\right.$ to $\left.12^{\circ} \mathrm{N}\right)$ and the black dashed lines mark the start (December) and end (April) of the period when most African LRT aerosol transport towards the ATTO site has been observed.

occurrence of the ENE clusters were typically not associated with increased $M_{1-10}$ levels. The influence of the air mass transport track and rain fields is discussed in further detail by means of a case study in Sect. 3.5.

Relating to (3): wet deposition is the dominant aerosol loss mechanism in tropical latitudes because of their intense precipitation (Huang et al., 2009; Martin et al., 2010a; Abdelkader et al., 2017). According to Fig. 1c, comparatively small scavenging rates are expected for most of the dust's transatlantic passage (i.e., north of $3^{\circ} \mathrm{N}$ ), whereas precipitation rates (on average) increase instantaneously when the air masses meet the ITCZ rain belt. A direct comparison of the cumulative precipitation, $P_{\mathrm{BT}}$, for 3-day vs. 9-day BTs shows that most of the rain (on average $\sim 75 \%$, see Fig. S6) occurred during the last 3 days of the air mass journey, underlining that the region of the ITCZ belt is most important for aerosol wet deposition. Along these lines, the daily averages of $P_{\mathrm{BT}}$ along the 3-day BT tracks represent a measure for the extent of scavenging rates that the air masses experience in the NE basin. The intense precipitation in the NE basin defines if and to what extent the LRT plumes reached the ATTO region. The $P_{\mathrm{BT}}$ time series shown in Fig. $2 \mathrm{~d}$ and its comparison with $M_{1-10}$ in Fig. 2e clearly underlines this relationship: virtually all $M_{1-10}$ pulses correspond with relative minima in the $P_{\mathrm{BT}}$ time series and vice versa. This shows, expectedly, that the dust burden arriving at ATTO was inversely related to the cumulative amount of rain that the corresponding air 
masses experienced. In other words, only dust plumes that survived the intense rain-related scavenging had a chance to arrive in the ATTO region. Good examples for this relationship (among many others) are the dust pulses around 18 February 2014 and 6 April 2015. Note that the HYSPLIT precipitation output, which is calculated per grid cell, does not depend on altitude and cloud cover (see Sect. 2.7). Thus, this analysis does not exclude that dust is transported at high altitudes over the precipitating clouds and mixed downwards in the ATTO region. However, the clear inverse relationship between the $P_{\mathrm{BT}}$ and $M_{1-10}$ variability underlines empirically that $P_{\mathrm{BT}}$ can be used as a simple but reliable proxy for the extent of rain-related scavenging.

Based on the time series in Fig. 2, we calculated mean seasonal cycles of selected aerosol, trace gas, and meteorological parameters, which were combined into Fig. 4. Meteorologically, Fig. 4a shows the seasonal BT patterns. The annual oscillation between wet vs. dry season BTs stands out clearly. More specifically, the BT patterns illustrate the timing of changes in the dominant wind direction, such as its swing from $\mathrm{NH}$ to $\mathrm{SH}$ and back upon latitudinal passage of the ITCZ. Further details related to Fig. 4a can be found elsewhere (Pöhlker et al., 2018). Figure 4b shows the seasonality of two different precipitation parameters: $P_{\mathrm{BT}}$ and the TRMM-derived precipitation rate, $P_{\text {TRMM }}$, in the ROI $_{\text {ATTO }}$ (see Fig. S4). The $P_{\mathrm{BT}}$ data represents a measure for the aerosol scavenging in the transported air masses and, thus, provides important information about (LRT) aerosol removal en route. In contrast, the $P_{\text {TRMM }}$ data represents a regional characterization of the precipitation in an area around ATTO. The seasonality in $P_{\text {TRMM }}$ shows a rather broad maximum spanning most of the wet season (i.e., February-May), whereas the seasonal trends in $P_{\mathrm{BT}}$ show a comparatively narrow and well pronounced maximum in April and May. Figure $4 \mathrm{c}$ shows the seasonality of the pollution tracers $M_{\mathrm{BCe}}$ and carbon monoxide mole fraction, $c_{\mathrm{CO}}$, reflecting the pronounced biomass burning seasonality in South America as well as Africa as a major source of LRT pollution. The cleanest episodes in terms of pollution aerosols (see $M_{\mathrm{BCe}}$ ) occurred between April and May, which could be explained by the maximum in aerosol scavenging (see highest $P_{\mathrm{BT}}$ values in April and May) (see Pöhlker et al., 2017). In parallel, a minimum in biomass burning occurrence is typically found during this period (i.e., the Amazonian burning season has not started yet and the frequency of savanna fires in West Africa declines after February) (Andreae et al., 2015). The seasonality of the MODIS-derived parameter, $\mathrm{AOD}_{\mathrm{ROI}}$, off, in Fig. 4d, representing arriving LRT plumes in the NE coast of the basin, shows a comparatively broad peak with a maximum around March.

Figure $4 \mathrm{e}$ shows the seasonality of the coarse mode aerosol abundance (represented by $M_{1-10}$ ) at ATTO, which is displayed in two variations: (i) as a data set that includes the entire time series and, thus, reflects the $M_{1-10}$ seasonality with all coarse mode-relevant aerosol sources (" $M_{1-10}$ with LRT")

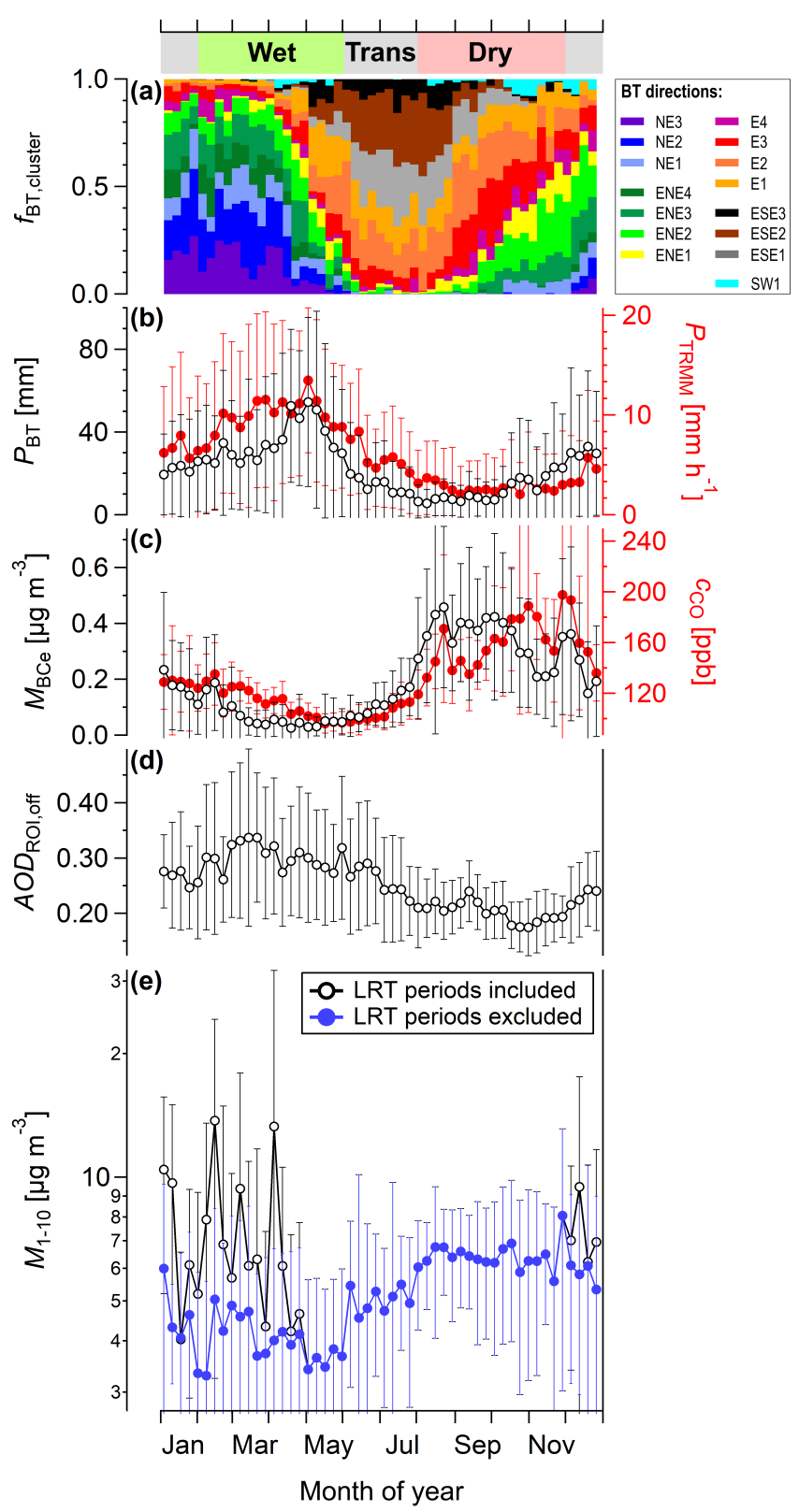

Figure 4. Seasonal cycle of selected meteorological, trace gas, and aerosol parameters in the central Amazon. (a) Weekly frequency of occurrence of backward trajectory clusters according to Pöhlker et al. (2018). (b) Precipitation products $P_{\mathrm{BT}}$, representing cumulative precipitation along BT tracks, and $P_{\mathrm{TRMM}}$, representing TRMMderived precipitation within $\mathrm{ROI}_{\mathrm{ATTO}}$ (see Fig. S4). (c) Pollution tracers $\mathrm{BC}_{\mathrm{e}}$ mass concentration, $M_{\mathrm{BCe}}$, and carbon monoxide mole fraction, $c_{\mathrm{CO}}$. The $\mathrm{BC}_{\mathrm{e}}$ data includes ATTO and $\mathrm{ZF} 2$ site measurements, spanning from 2008 to 2017. CO data includes ATTO site measurements from 2012 to 2017. (d) MODIS-derived AOD data within $\mathrm{ROI}_{\text {off }}$ as defined in Fig. S4, spanning from 2000 to 2016. (e) OPS-based coarse mode aerosol mass in two configurations: with and without LRT peaks, according to Table 1. Data are shown as weekly averages with error bars representing one standard deviation. 

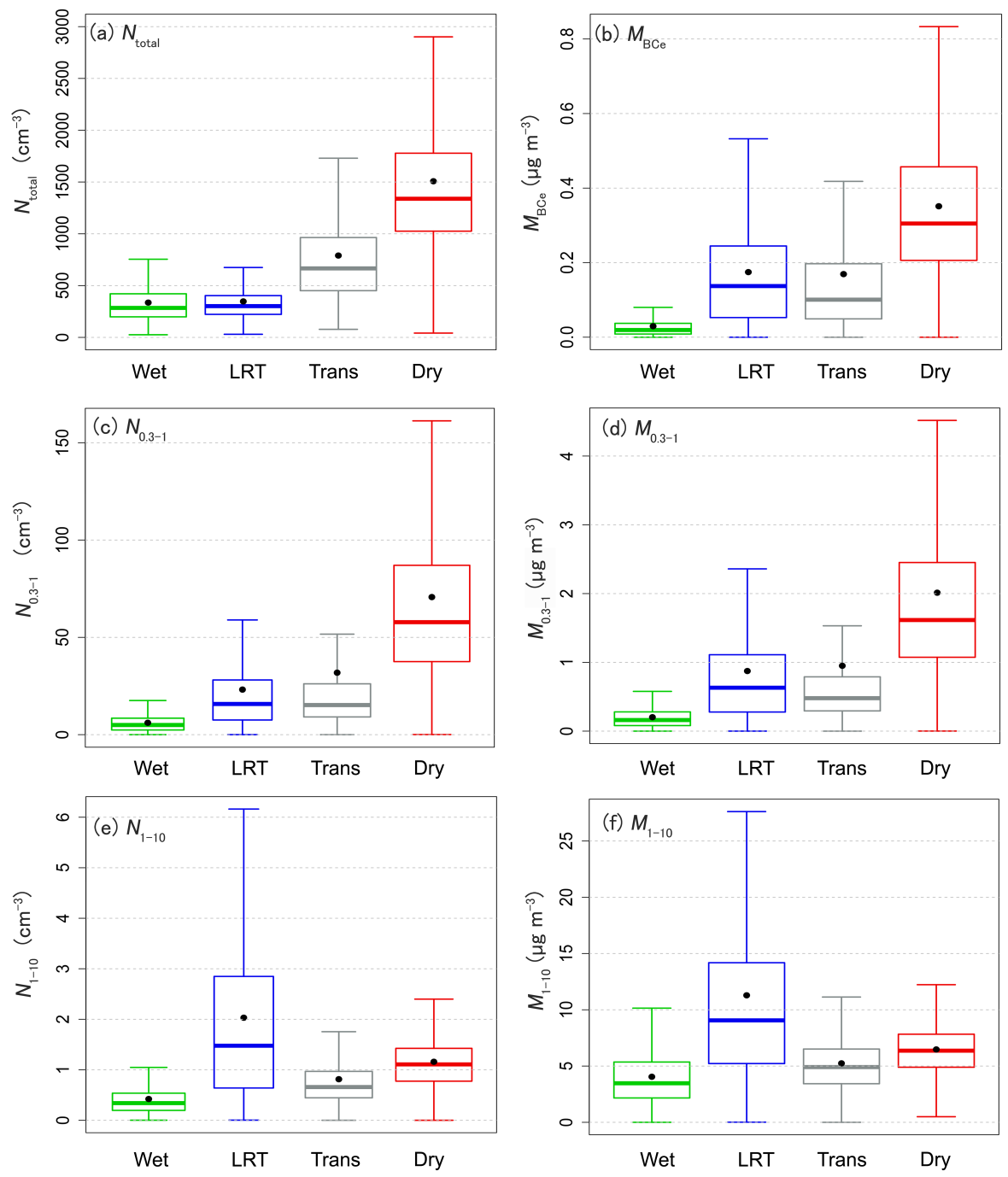

Figure 5. Statistical distributions (box-and-whisker plots) of (a) total aerosol number concentration ( $>4 \mathrm{~nm}, \mathrm{CPC}$ derived), (b) $\mathrm{BC}_{\mathrm{e}}$ mass concentration, $M_{\mathrm{BCe}},(\mathbf{c})$ aerosol number concentration in the size range $0.3-1 \mu \mathrm{m}$, (d) aerosol mass concentration in the size range $0.3-1 \mu \mathrm{m}$, (e) aerosol number concentration in the size range 1-10 $\mu \mathrm{m}$, and (f) aerosol mass concentration in the size range 1-10 $\mu \mathrm{m}$. Wet season, LRT episodes, transition periods, and dry season were defined according to Sect. 2.10. Data included here span from February 2014 to April 2017. The boxes show the median (thick horizontal line), mean (black dot), 25 percentile (Q1, lower border of the box), and 75 percentile (Q3, upper border). The range between Q1 and Q3 is called interquartile range: IQR $=$ Q3-Q1. The lower whisker shows the lowest measured value still within 1.5 IQR of the lower quartile, and the highest measured value still within 1.5 IQR of the upper quartile, see Tukey (1977).

and (ii) as a data set excluding all LRT periods as defined in Table 1 and, thus, reflecting the $M_{1-10}$ seasonality without (most of) the African LRT influence (" $M_{1-10}$ without LRT"). The " $M_{1-10}$ with LRT" data expectedly shows its highest levels in the dust season (December-April) with weekly average concentrations frequently exceeding $10 \mu \mathrm{g} \mathrm{m}^{-3}$. In contrast, the " $M_{1-10}$ without LRT" data shows a rather modest seasonal cycle with average concentrations around 6$7 \mu \mathrm{g} \mathrm{m}^{-3}$ during the dry season (i.e., broad maximum spanning August-October) and around $4 \mu \mathrm{g} \mathrm{m}^{-3}$ during the wet season (i.e., with a minimum in April). In the absence of African LRT influence, the coarse mode mostly comprises bioaerosols from local/regional sources (see also Pöschl et al., 2010; Huffman et al., 2012). Accordingly, Fig. 4e indicates that the Amazonian atmosphere contains a rather constant coarse mode background, in which bioaerosols likely account for a dominant fraction. As possible explanation for this (modest) seasonality of the " $M_{1-10}$ without LRT" background, we suggest that this could be determined by (i) differences in aerosols scavenging frequency (see seasonality of $P_{\mathrm{BT}}$ ), (ii) a certain fraction of coarse mode particles originating from biomass burning plumes, and/or (iii) different bioaerosol emissions patterns and strength in the wet vs. dry season. 


\subsection{Seasonally averaged aerosol concentrations and size distributions}

Figure 5 and Table 2 provide a statistical summary of selected aerosol concentrations, resolved by season. Figure $5 \mathrm{a}$ and $\mathrm{b}$ show the seasonal levels of $N_{\text {total }}$ and $M_{\mathrm{BCe}}$, reflecting the characteristic biomass burning driven seasonal patterns: the wet season shows clean background concentrations (i.e., median with interquartile range, IQR (25th-75th percentiles): $N_{\text {total }}=283(197-420) \mathrm{cm}^{-3}$ and $\left.M_{\mathrm{BCe}}=0.02(0.02-0.04) \mu \mathrm{g} \mathrm{m}^{-3}\right)$, whereas highest concentration levels occur in the dry season (i.e., $N_{\text {total }}=1337$ (1021-1776) $\mathrm{cm}^{-3}$ and $\left.M_{\mathrm{BCe}}=0.30(0.21-0.46) \mu \mathrm{g} \mathrm{m}^{-3}\right)$. The transitions periods represent an intermediate state in between these extremes (i.e., $N_{\text {total }}=663(448-963) \mathrm{cm}^{-3}$ and $\left.M_{\mathrm{BCe}}=0.10(0.05-0.20) \mu \mathrm{g} \mathrm{m}^{-3}\right)$. During the LRT season, we observed a clear $M_{\mathrm{BCe}}$ enhancement in comparison to the wet season background (i.e., $M_{\mathrm{BCe}}=0.14$ (0.05$0.24) \mu \mathrm{g} \mathrm{m}^{-3}$ vs. $\left.M_{\mathrm{BCe}}=0.02(0.02-0.04) \mu \mathrm{g} \mathrm{m}^{-3}\right)$, due to the smoke fraction in the advected African LRT plumes. Remarkably, the $N_{\text {total }}$ levels for wet vs. LRT episodes show no statistically significant difference. This suggests that $M_{\mathrm{BCe}}$ is a sensitive indicator to discriminate near-pristine episodes and periods that are influenced by long-range transported African pollution, whereas the use of $N_{\text {total }}$ as a pollution tracer may be misleading (see also Pöhlker et al., 2017).

The statistics of the multi-year OPS data is presented as number and mass concentrations for two size ranges: the range from 0.3 to $1 \mu \mathrm{m}$ in Fig. $5 \mathrm{c}$ and d covers the largeparticle tail of the accumulation mode and, thus, to a certain extent follows the biomass burning seasonality, similar to $N_{\text {total }}$ and $M_{\mathrm{BCe}}$. Note that the parameters, which are sensitive to biomass burning pollution (i.e., $N_{\text {total }}, M_{\mathrm{BCe}}$, $\left.N_{0.3-1}, M_{0.3-1}\right)$ generally show a wide range of statistical scattering (see large IQR), which can be explained by the fact that dry season aerosol time series are characterized by a sequence of high-concentration peaks due to the plume-wise advection of biomass burning emissions (see Pöhlker et al., 2017; Saturno et al., 2017a). In contrast, the range from 1 to $10 \mu \mathrm{m}$ in Fig. 5e and f represents the coarse mode seasonality, which differs from the biomass burning patterns. The $N_{1-10}$ and $M_{1-10}$ levels show a modest increase from the wet season $\left(N_{1-10}=0.3(0.2-\right.$ $\left.0.5) \mathrm{cm}^{-3}, M_{1-10}=3.5(2.2-5.4) \mu \mathrm{g} \mathrm{m}^{-3}\right)$ over the transition periods $\left(N_{1-10}=0.7(0.4-1.0) \mathrm{cm}^{-3}, M_{1-10}=4.9\right.$ (3.46.5) $\left.\mu \mathrm{g} \mathrm{m}^{-3}\right)$ to the dry season $\left(N_{1-10}=1.1(0.8-1.4) \mathrm{cm}^{-3}\right.$, $\left.M_{1-10}=6.4(4.9-7.8) \mu \mathrm{g} \mathrm{m}^{-3}\right)$. The highest concentrations for $N_{1-10}$ and $M_{1-10}$ levels clearly occurred during African LRT influence $\left(N_{1-10}=1.5(0.6-2.8) \mathrm{cm}^{-3}, M_{1-10}=9.1\right.$ $\left.(5.2-14.2) \mu \mathrm{g} \mathrm{m}^{-3}\right)$.

To discuss our observed $N_{1-10}$ and $M_{1-10}$ concentrations in the context of previous measurements, we summarized the results from related studies in Table 3. A certain number of previous studies from the central and southern Amazonian region reported coarse mode concentrations, which agree well with the $N_{1-10}$ and $M_{1-10}$ levels in this work (Artaxo et al., 2002, 2013b; Graham et al., 2003; Guyon et al., 2003; Huffman et al., 2012; Whitehead et al., 2016). For comparison, we added a few studies from other locations and ecosystems (i.e., boreal and semi-arid forest sites) to Table 3, which suggest that the coarse mode (background) concentrations in different forested ecosystems are remarkably similar and range around $0.5 \mathrm{~cm}^{-3}$ (Schumacher et al., 2013).

Figure 6 illustrates the seasonal differences in the aerosol size distributions obtained from the multi-year OPS measurements. Similar to the number and mass concentrations in Fig. 5e and f, we observed the strongest coarse mode during African LRT episodes, followed by the dry season, the transition periods, and lastly the wet season. In addition to these concentration trends, the coarse mode also reveals seasonal characteristic shapes (see surface and volume size distributions in Fig. $6 \mathrm{~b}$ and c). Under wet season conditions, the coarse mode maximum is shifted towards large diameters $(\sim 2.8 \mu \mathrm{m}$ in the surface and $\sim 4.2 \mu \mathrm{m}$ in the volume size distributions) and the entire mode can be characterized as a broad monomodal distribution. In contrast, during the dry season, the coarse mode shape is clearly different. It has a multimodal appearance and the strongest, rather narrow peak is located at $\sim 1.7 \mu \mathrm{m}$ (surface size distribution) and $\sim 2.0 \mu \mathrm{m}$ (volume size distribution), respectively. Towards larger diameters, a pronounced shoulder indicates the presence of one or two further modes. During the transition periods, the coarse mode resembles a mixture of the wet and dry season size distributions. The coarse mode shape during Saharan dust influence appears monomodal with its maximum at $\sim 2.0 \mu \mathrm{m}$ (surface size distribution) and $\sim 2.4 \mu \mathrm{m}$ (volume size distribution), respectively. Our best approximation for the volume size distribution of the actually advected LRT aerosols without the persistent biogenic background in the coarse mode is shown in Fig. $6 \mathrm{~d}$ and has been obtained by subtracting the LRT and wet-season volume size distributions (see Fig. 6c). This "LRT-wet" volume size distribution resembles a dust mass size distribution based on data from the CLAIRE-98 experiment in Balbina, Brazil (for details see Formenti et al., 2001). Here, the quantified concentrations of the dust marker cations aluminum $(\mathrm{Al})$, silicon $(\mathrm{Si})$, calcium $(\mathrm{Ca})$, magnesium $(\mathrm{Mg})$, and iron $(\mathrm{Fe})$ as reported in Formenti et al. (2001) were converted into their corresponding oxides (i.e., $\mathrm{Al}_{2} \mathrm{O}_{3}, \mathrm{SiO}_{2}, \mathrm{CaO}, \mathrm{MgO}, \mathrm{Fe}_{2} \mathrm{O}_{3}$ ) to obtain an overall mass size distribution of the advected dust aerosol, as shown in Fig. 6d. The comparison underlines that the volume size distribution of the advected LRT aerosols shows a characteristic peak between 2 and $3 \mu \mathrm{m}$.

For comparison, we added coarse mode size distributions from two previous Amazonian studies to Fig. 6. It has to be kept in mind that optical particle sizing may deviate from geometric and/or aerodynamic sizing approaches (see also Sect. 2.2). Huffman et al. (2012) conducted a multi-week measurement in the central Amazon during the wet season using an ultra-violet aerodynamic particle sizer (UV-APS) to 


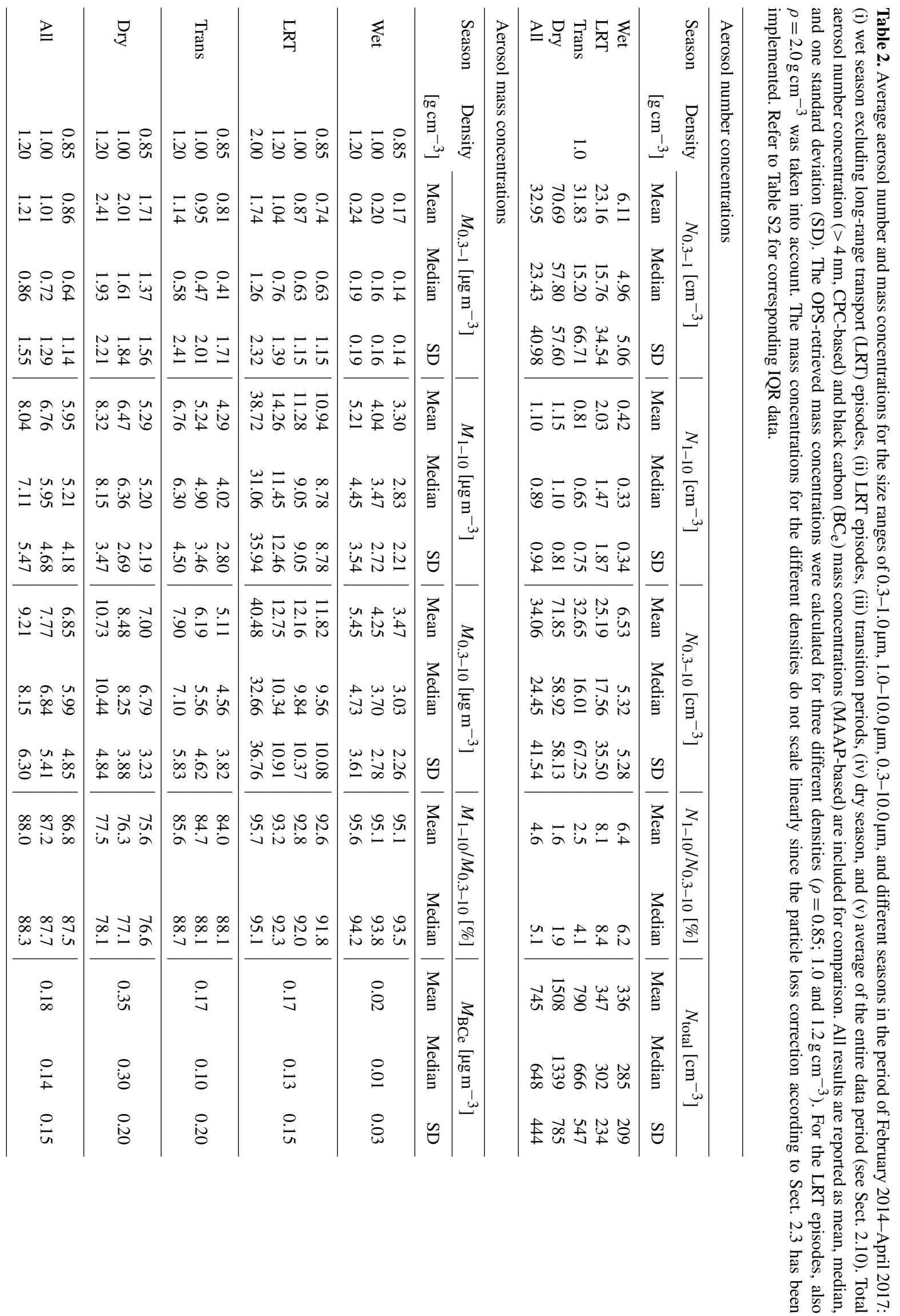




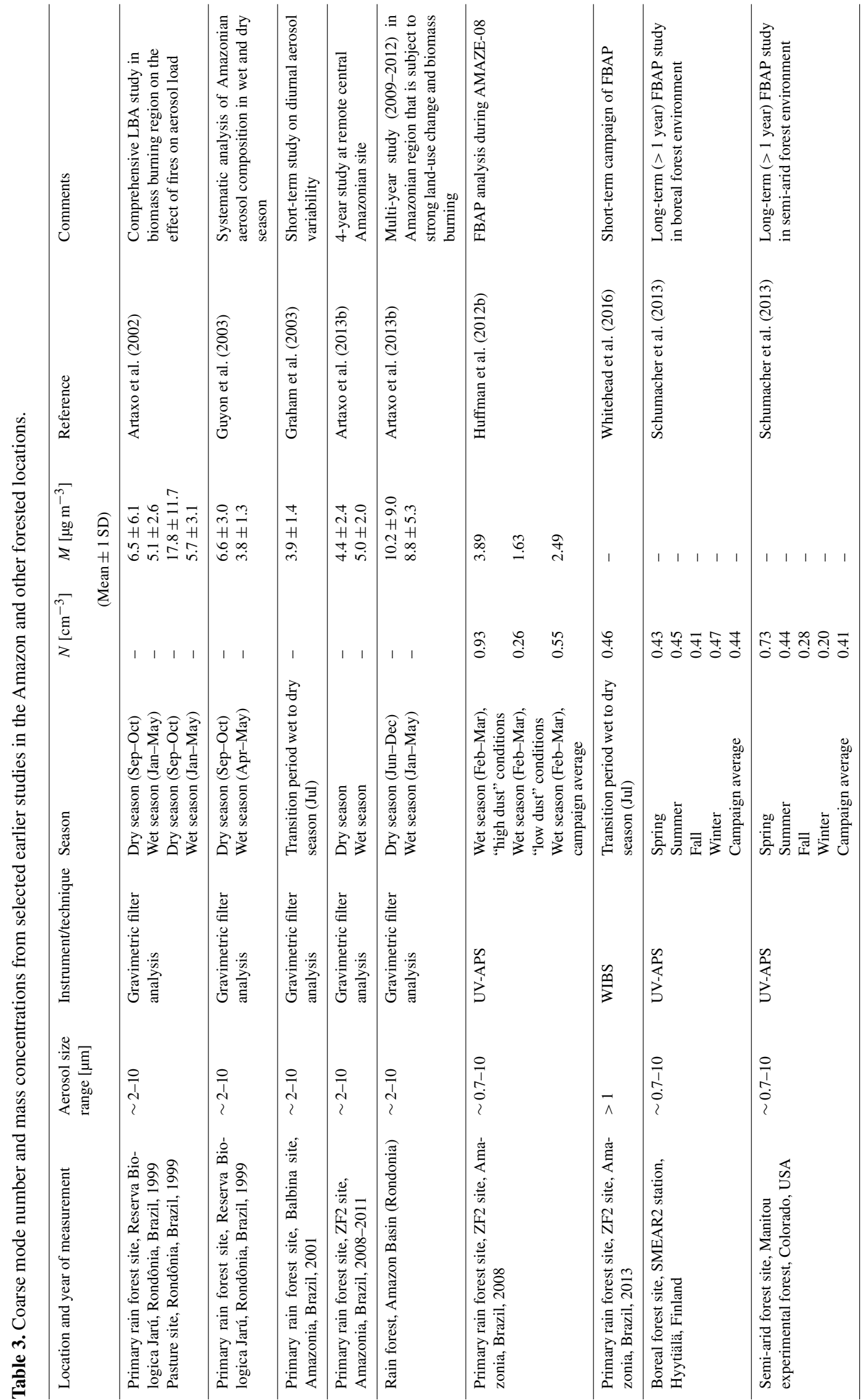



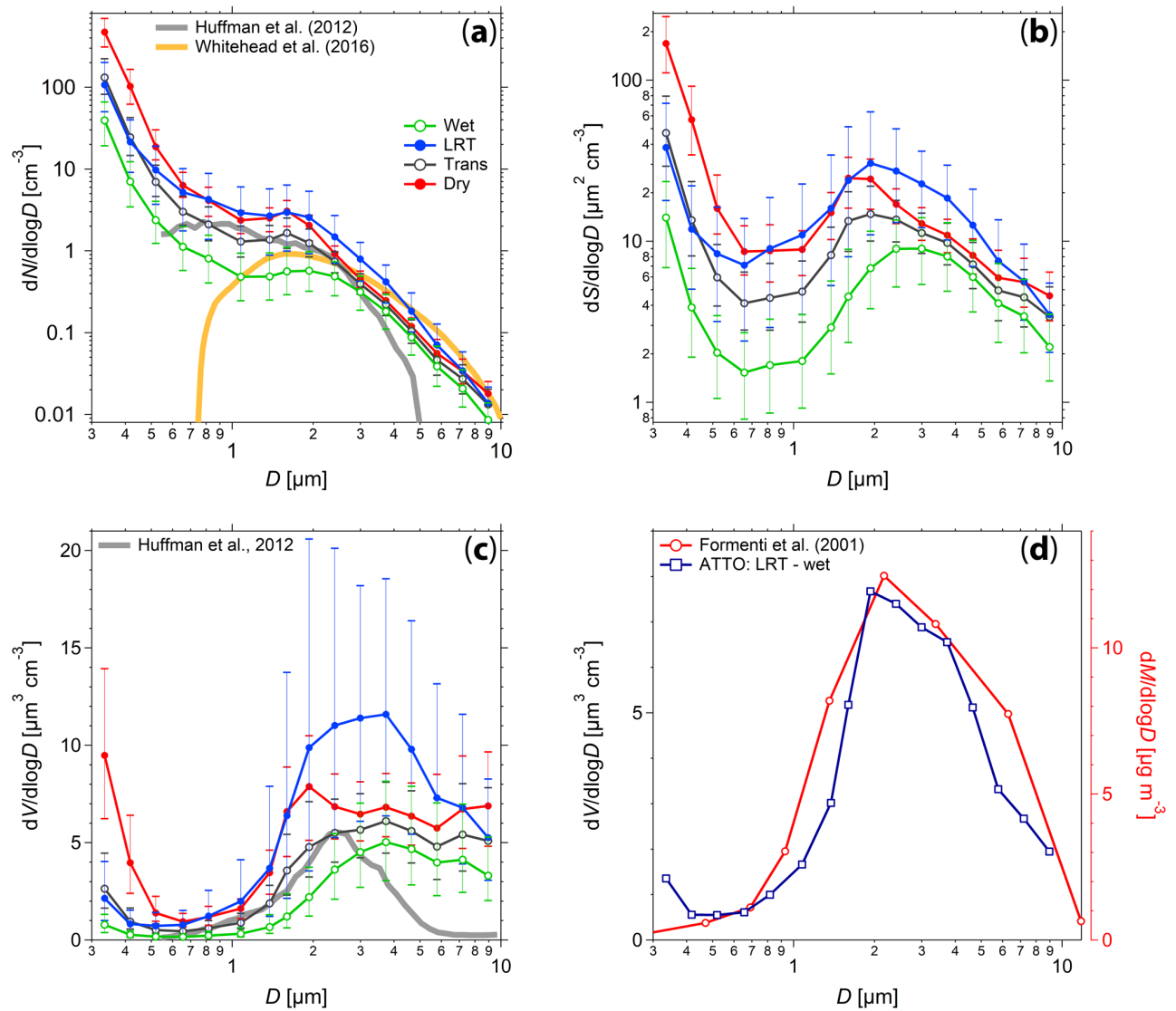

Figure 6. Seasonal variation of coarse mode aerosol size distributions, based on OPS data from February 2014 until April 2017: (a) number size distributions, $\mathrm{d} N / \mathrm{d} \log D$, (b) surface size distributions, $\mathrm{d} S / \mathrm{d} \log D$, and (c) volume size distributions, $\mathrm{d} V / \mathrm{d} \log D$. The $\mathrm{d} S / \mathrm{d} \log D$ and $\mathrm{d} V / \mathrm{d} \log D$ distributions were calculated based on $\mathrm{d} N / \mathrm{d} \log D$ assuming spherical particles (see Sect. 2.2). Markers represent median values with error bars as 25th and 75th percentiles. (d) Volume size distribution representing actually advected LRT aerosols at ATTO (median LRT $\mathrm{d} V / \mathrm{d} \log D-$ median wet $\mathrm{d} V / \mathrm{d} \log D$ distributions from c) and mass size distributions $\mathrm{d} M / \mathrm{d} \log D$ for dust conditions during CLAIRE-98 experiment in Balbina, Brazil, as specified in Formenti et al. (2001). For the CLAIRE-98 distributions, the results from three filter samples taken between 24 and 27 March 1998 were averaged. The size range of the OPS covers both the coarse mode (1-10 $\mu \mathrm{m})$ and the large diameter tail of the accumulation mode $(0.3-1 \mu \mathrm{m})$. In terms of the coarse mode, quantitative information on its location, intensity, and shape were obtained. The accumulation mode information is semi-quantitative, since only a part of the mode is covered, which suffices to estimate the overall accumulation mode strength. For definition of the seasons refer to Sect. 2.10. Particle size distributions from the Amazonian studies by Huffman et al. (2012) and Whitehead et al. (2016) were included for comparison.

probe wet season conditions with African dust influence. The resulting campaign average number and volume size distributions agree well with our observations for particle sizes $<3 \mu \mathrm{m}$ (Fig. 6a and c). ${ }^{6}$ For diameters $>3 \mu \mathrm{m}$, the OPSbased results shows much higher particles abundances than the UV-APS-based distributions. This deviation can probably be explained by a combination of different reasons. An important aspect could be that optical particle sizing tends

\footnotetext{
${ }^{6}$ During the UV-APS measurement period (i.e., the AMAZE-08 campaign), several African LRT episodes occurred (Martin et al., 2010). Accordingly, the campaign average size distributions, which were reported by Huffman et al. (2012) and are shown in Fig. 6a and c, represent a LRT/wet season mixture. This is consistent with the fact that the resulting UV-APS size distributions are located in between the OPS-derived wet and LRT season states.
}

to oversize aerosol particles relative to aerodynamic particle sizing (i.e., UV-APS) (Reid et al., 2003b). Moreover, optical sizing is often associated with a broadening of the distributions. Both of these tendencies are consistent with our observations in Fig. 6a and have also been reported previously for the Amazonian coarse mode (Martin et al., 2010a). However, a systematic and long-term comparison of optical and aerodynamic particle size properties of Amazonian aerosols is subject of ongoing work. The second study for comparison was conducted by Whitehead et al. (2016) using a WIBS (optical sizing) to probe several weeks of the transition period from wet to dry season (Fig. 6a). The WIBS data agree well with our observations for the particle size range $>2 \mu \mathrm{m}$. Below $2 \mu \mathrm{m}$, the detection efficiency of the WIBS drops, which 

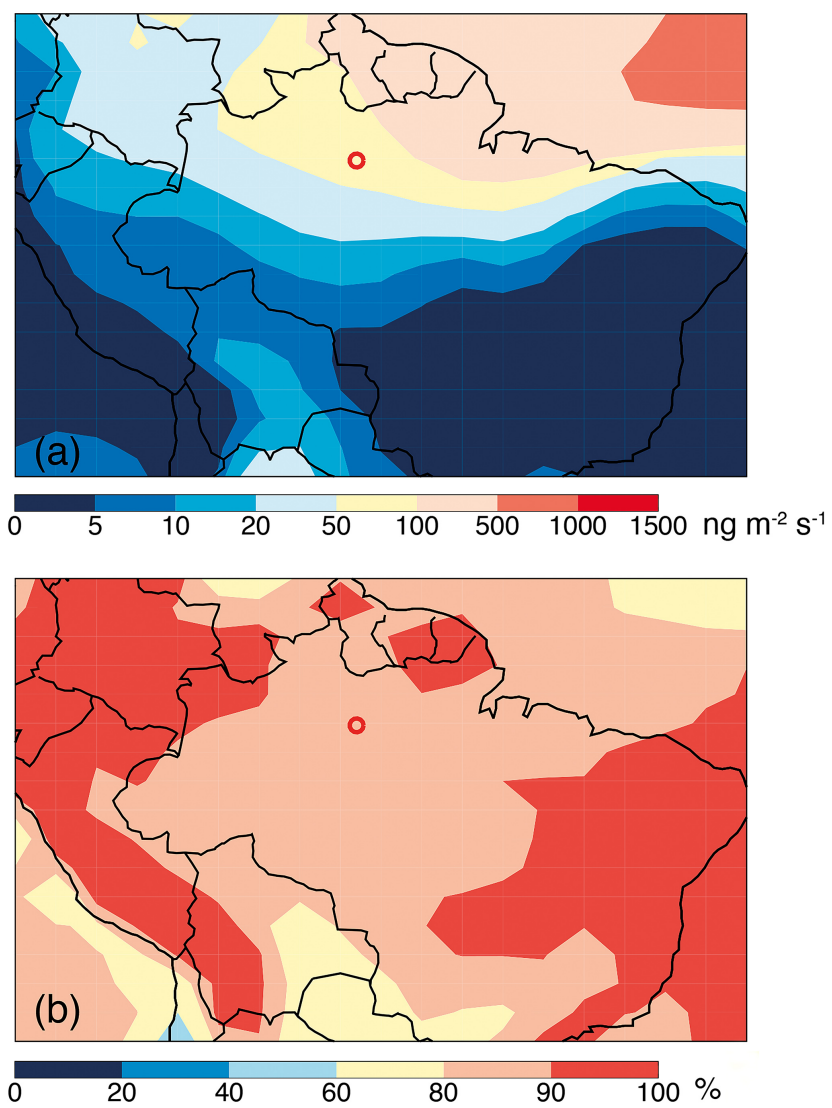

Figure 7. GEOS-Chem model results representing: (a) dust aerosol deposition flux and (b) contribution of wet dust deposition (rain out and wash out) relative to total deposition flux. Both data products were calculated from January to April 2014. The location of the ATTO site is represented by a red marker.

probably explains the deviation between WIBS and OPS in this range.

\subsection{Comparison of experimental data and GEOS-Chem model results}

For the wet season and LRT episodes of the years 2014 and 2015, a comparison of the experimental data (i.e., $M_{0.3-10}$ ) and GEOS-Chem model results along the lines of the study by Wang et al. (2016) was conducted. Measured and modeled results show a rather accurate agreement, particularly for the timing and mass concentrations of the LRT episodes. The corresponding time series and a bivariate regression fit are shown in Figs. S7 and S8. The good agreement indicates that the relevant factors, controlling the dust transport into the basin, are accurately covered by the model. Based on this convincing model result validation, we extracted further data products from the model runs, which highlight relevant atmospheric and ecological aspects of the dust deposition in the Amazon Basin.
The effective dust deposition, which introduces essential micro- and macronutrients onto the low-fertility Amazonian soils, is a relevant aspect from an ecological perspective (e.g., Swap et al., 1992; Okin et al., 2004; Bristow et al., 2010; Rizzolo et al., 2017). Figure 7a displays a map of the modeled dust deposition flux into the basin. For the Amazon region and during the time period January to April 2014, the model predicts average deposition fluxes from 5 to $500 \mathrm{ng} \mathrm{m}^{-2} \mathrm{~s}^{-1}$, which is in good agreement with previous studies, e.g., by Yu et al. (2015), who indicated a 7-year-average deposition flux in the range from 25 to $160 \mathrm{ng} \mathrm{m}^{-2} \mathrm{~s}^{-1}$ for the entire Amazon area. Note that the dust deposition occurs heterogeneously across the basin. The highest deposition fluxes (about 100$500 \mathrm{ng} \mathrm{m}^{-2} \mathrm{~s}^{-1}$ ) can be found in the NE of the basin (i.e., the Guiana shield and the region around the Amazon River delta), whereas deposition fluxes decrease towards the southwest.

According to the model, the belt within the deposition gradient that includes the ATTO region (shown in yellow), received an average effective dust deposition of about 50$100 \mathrm{ng} \mathrm{m}^{-2} \mathrm{~s}^{-1}$ during the 2014 dust season (i.e., JanuaryApril 2014). Since January to April represent the LRT core months and include most of the LRT episodes, we assume that most of the dust deposition occurs within this time window. Accordingly, the deposited mass from January to April is regarded as a good representation of the total annual deposition. Thus, based on the average deposition flux, we obtained a total annual deposited dust mass of about $0.5-1 \mathrm{~g} \mathrm{~m}^{-2}$ or $5-10 \mathrm{~kg} \mathrm{ha}^{-1}$ for 2014 , respectively. This is in good agreement with the total deposited mass of 8 $50 \mathrm{~kg} \mathrm{ha}^{-1} \mathrm{a}^{-1}$ reported by Yu et al. (2015) as well as the study by Swap et al. (1992), in which the authors estimate that the total mass of introduced dust "may amount to as much as $190 \mathrm{~kg} \mathrm{ha}^{-1} \mathrm{a}^{-1}$ " in the northeastern basin. We propose that the results obtained here for the year 2014 can be regarded as representative for a typical dust deposition scenario in the Amazon region, since 2014 was generally an "average" year without pronounced precipitation and circulation anomalies (Pöhlker et al., 2016, 2018). Moreover, the four LRT seasons (2014-2017) analyzed in this study show generally similar trends and patterns. Given that the atmospheric input of essential dust-related nutrients plays a crucial role in rain forest ecology, differences in forest structure and diversity (e.g., total biomass) may reflect the spatial difference in dust deposition as shown in Fig. 7a. This link between atmospheric nutrient input and forest ecology has already been subject of previous studies, however, it requires further research to answer various open questions.

As an additional aspect, Fig. 7b emphasizes that the deposition of dust into the basin is predominantly driven by wet processes (i.e., rain out and wash out), which is consistent with previous aspects in this study (e.g., the rain-related pulse-wise modulation of dust plume transport in the basin). Swap et al. (1992) similarly emphasized that in the Amazonian wet season atmosphere, "precipitation scavenging is 


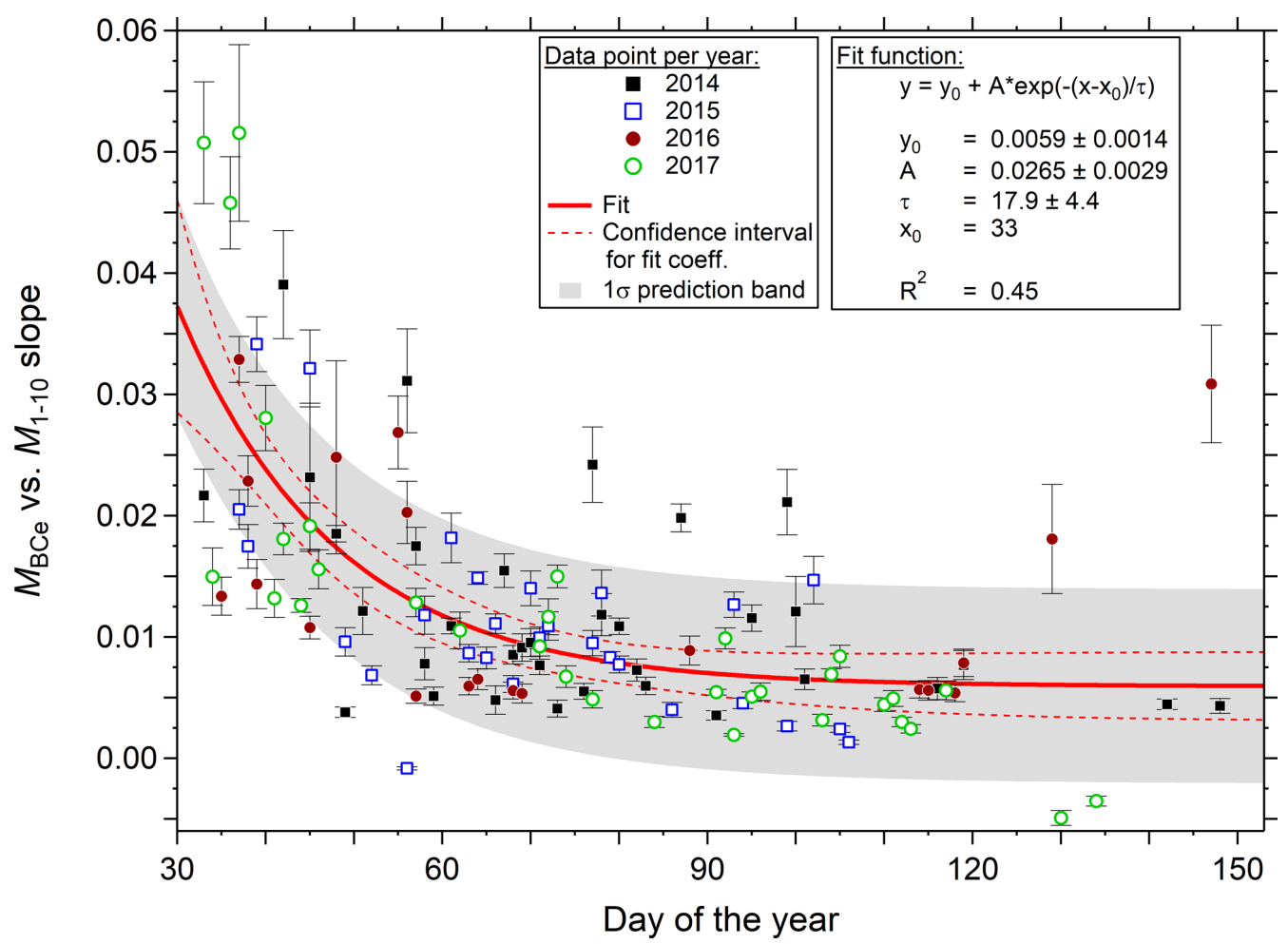

Figure 8. Temporal trend of the slopes from correlations between $M_{\mathrm{BCe}}$ and $M_{1-10}$ from systematic bivariate regression fit analysis during the wet season period. Bivariate regression fits (with offset) have been performed every day during the wet season months of February to May for the years 2014 to 2017 . The results have been filtered and only those slope data points from regression fits with a clear correlation (i.e., with a correlation factor $R^{2}>0.5$ ) are shown here. The error bars represent the standard error of the slope. To emphasize the overall trend, an exponential fit has been added with its $1 \sigma$ prediction band.

the principal removal mechanism of Saharan dust". This result further underlines that potential changes in precipitation patterns in the Amazon region will also impact the dust deposition into the ecosystem.

\subsection{Quantification of black carbon fraction in the African LRT plumes}

A characteristic feature of the analyzed LRT plumes arriving in the Amazon Basin is their "smokiness", due to the fact that substantial amounts of pyrogenic aerosols from fires in West Africa are mixed into the Saharan dust aerosols as illustrated in Fig. 1. This is a result of the fact that the biomassburning season in West Africa coincides with the period of frequent LRT to the Amazon Basin. The presence of pyrogenic aerosols resulted in high $\mathrm{BC}$ concentrations during the LRT episodes in comparison to the wet season background as shown in Fig. 5. Here, we analyze the relative BC fractions and their variability in more detail. For most LRT plumes, a positive correlation between $M_{1-10}$ and $M_{\mathrm{BCe}}$ was found, underlining the joint arrival of $\mathrm{BC}$ and dust aerosols in the mixed plumes. Selected examples of $M_{1-10}$ vs. $M_{\mathrm{BCe}}$ scatter plots can be found in Fig. S9 with linear bivariate regression fits (with offset), in which the slopes represent the BC fraction relative to the dust aerosol mass. Based on the data shown in Fig. S9, slopes of $0.009 \pm 0.001$ and $0.016 \pm 0.015$ (mean slope $\pm 1 \mathrm{SD}$ ) were found.

Generally, our analysis showed that the relationship between $M_{1-10}$ and $M_{\mathrm{BCe}}$ is characterized by a comparatively high variability due to the spatiotemporal heterogeneity of the LRT plumes depending on their source regions and transport paths from Africa to South America. Along these lines and in order to analyze the temporal trends of the smoke fraction in the arriving plumes, we conducted a systematic linear regression analysis based on the entire dataset analyzed here (i.e., the time frame February to May for the years 2014 to 2017). The corresponding results, which are shown in Fig. 8, clearly indicate that the LRT events in the early wet season (i.e., February) comprise substantially higher smoke fractions (reaching up to 0.05) than the LRT events in the later wet season (i.e., April), when the mean slope converges against $\sim 0.005$. This observation is consistent with concurrently decreasing fire intensities in Africa as described by Barbosa et al. (1999) and supports lidar-based findings from the wet season of 2008 (Baars et al., 2011). 


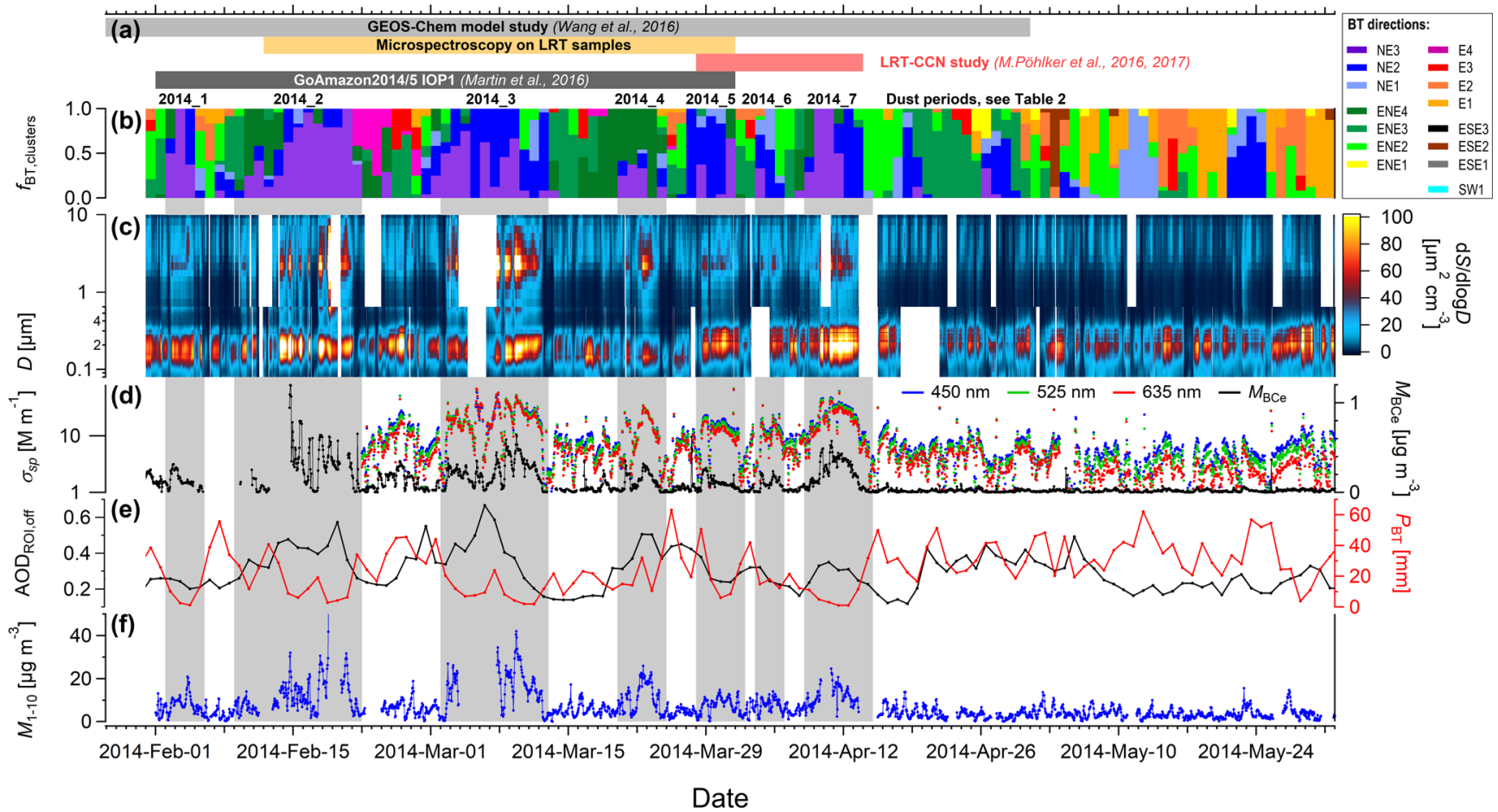

Figure 9. Meteorological and aerosol time series during the wet season 2014 case study. (a) Colored markers represent time periods of relevant intensive observation activities during 2014 case study. (b) Frequency of occurrence, $f_{\mathrm{BT}}$, clusters, of 15 back trajectory clusters as displayed in Fig. S4 (with identical color coding). (c) Image plot of aerosol surface size distribution for the size range from $80 \mathrm{~nm}$ to $10 \mu \mathrm{m}$. (d, left axis) Time series of the aerosol scattering coefficients, $\sigma_{\mathrm{sp}}$, at three different wavelengths. (d, right axis) Equivalent black carbon mass concentration, $M_{\mathrm{BCe}}$, calculated assuming a mass absorption cross Section MAC of $11.4 \mathrm{~m}^{2} \mathrm{~g}^{-1}$ during the wet season. (e, left axis) Satellite-retrieved aerosol optical depth at $550 \mathrm{~nm}$, area-averaged over offshore region of interest $\left(\mathrm{ROI}_{\mathrm{Off}}, \mathrm{see} \mathrm{Fig.} \mathrm{S4).} \mathrm{The} \mathrm{AOD}_{\mathrm{ROI}, \text { off }}\right.$ time series represents the average of the MODIS data sets from the satellites Aqua and Terra. (e, right axis) HYSPLIT-retrieved accumulated precipitation, $P_{\mathrm{BT}}$, along the trajectory tracks. (f) Aerosol mass concentrations in the coarse mode $1-10 \mu \mathrm{m}\left(M_{1-10}\right)$. Time series represent hourly averages, except $f_{\mathrm{BT}}$, clusters, $\mathrm{AOD}$ ROI, off, and $P_{\mathrm{BT}}$. Gray vertical bands mark episodes when Saharan LRT aerosol was measured at the ATTO site (see Table 1). The $f_{\mathrm{BT}}$, clusters, $\mathrm{AOD}$ ROI, off, and $P_{\mathrm{BT}}$ time series are shown as daily averages. The image plot of the aerosol size surface distribution as well as the $\sigma_{\mathrm{sp}}, M_{\mathrm{BCe}}$, and OPS mass concentrations time series are shown as daily averages.

\subsection{Case studies with detailed analysis of specific LRT events}

So far, we have presented the overall and long-term patterns in coarse mode variability and the pulse-wise Saharan dust advection. In the following sections, we zoom into selected time periods and show specific case studies to highlight relevant short-term aspects and observations beyond what has been discussed so far. In particular, we will focus on the LRT episodes of the years 2014 and 2015.

The wet season 2014, which includes seven LRT episodes (2014_1 to 2014_7, see Table 1), is of particular interest since it overlaps with several intensive observation activities (Fig. 9a): (i) the first IOP of the GoAmazon2014/5 campaign, which targeted clean wet season conditions, took place from 1 February to 31 March 2014 (Martin et al., 2017). The GoAmazon2014/5 IOPs are subject of intensive analysis of various facets of atmospheric composition (see https:// www.atmos-chem-phys.net/special_issue392.html, Allan et al., 2015). According to our analysis, the IOP1 contained five LRT episodes (i.e., 2014_1 to 2014_5, see Table 1), which interrupted the Amazonian background conditions with 37 of the 59 IOP1 days being classified as LRT impacted. Accordingly, LRT condition are not an exceptional but rather the predominant atmospheric state during this time period. (ii) Wang et al. (2016) conducted an in-depth GEOS-Chem modeling study on light-absorbing aerosols with African LRT plumes being an important source of pyrogenic and dust aerosols. (iii) The CCN studies by Pöhlker et al. $(2016,2017)$ cover three LRT episodes in 2014 and analyze the CCNrelevant properties of the advected aerosol population (i.e., the LRT episode 2015_7 is discussed in detail there). (iv) Intensive aerosol sampling targeting LRT conditions in February and March 2014 was conducted and the corresponding results using microspectroscopic techniques are currently prepared for a follow-up manuscript on the morphology, mixing state, and composition of the LRT aerosol population. 

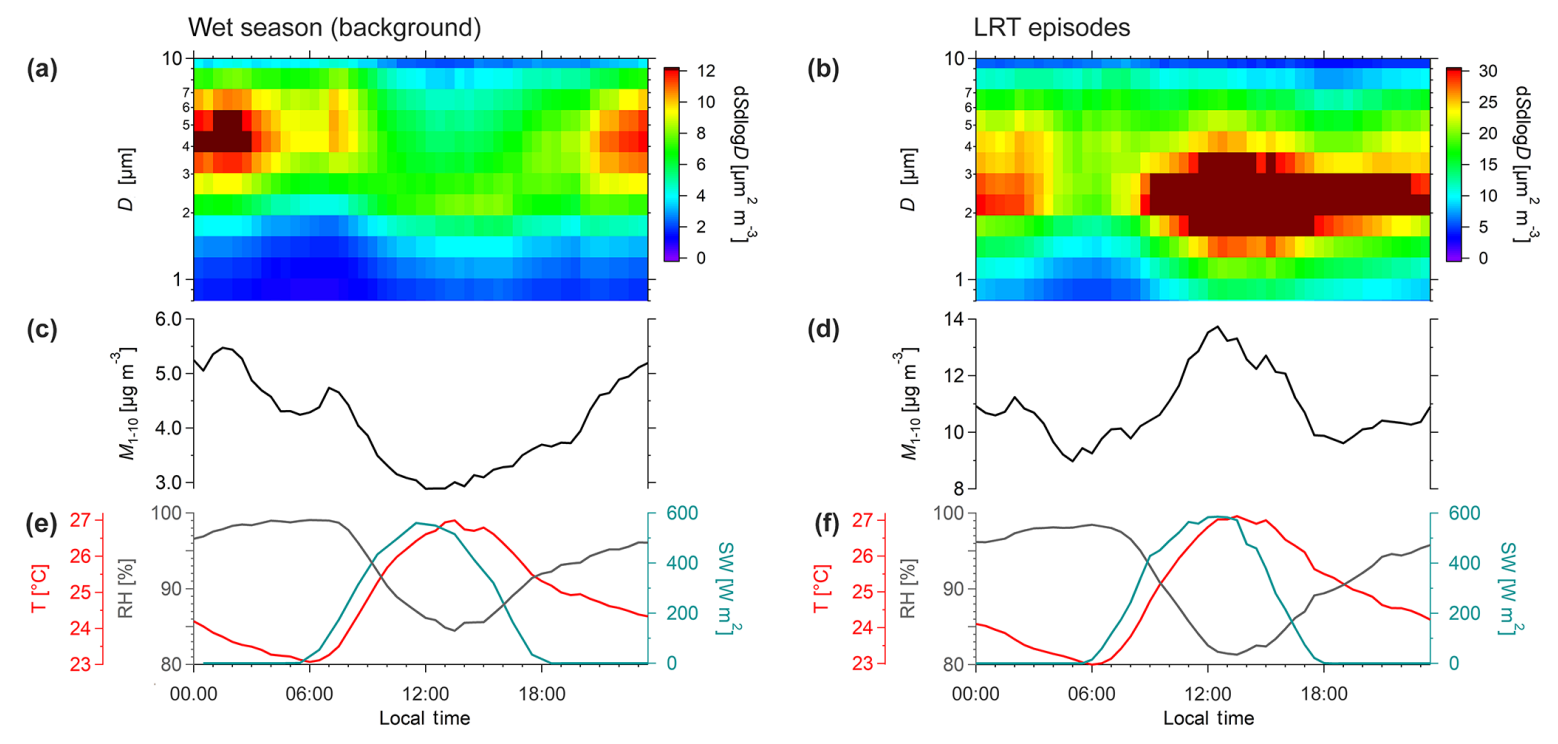

Figure 10. Diurnal cycles in selected aerosol and meteorological parameters during the wet season without major dust influence vs. LRT episodes within the time frame shown in Fig. 9. (a, b) Image plots of aerosol size surface distribution for the size range from 0.8 to $10 \mu \mathrm{m}$. (c, d) Coarse mode aerosol mass concentration $M_{1-10}$ (e, f) Micrometeorological parameters, temperature, RH, and incoming short-wave solar radiation.

For comparison with the conditions in 2014 as shown in Fig. 9, an analogous overview for the LRT episodes in 2015, including five LRT episodes (2015_1 to 2015_5, see Table 1) can be found in Fig. S10. Generally, Figs. 9 and S10 - which display the online aerosol data at hourly resolution in contrast to daily resolution in Fig. 2 - clearly show the characteristic conditions of efficient dust transport towards ATTO as discussed in detail in Sect. 3.1: All observed LRT episodes, represented by $M_{1-10}$, are associated with elevated $\mathrm{AOD}_{\mathrm{ROI}}$ off levels, relative minima in $P_{\mathrm{BT}}$, and a predominance of the back trajectory clusters NE2 and NE3.

In addition to the multi-day LRT peaks in coarse mode abundance, a pronounced diurnal pattern can be recognized in the coarse-mode-relevant time series (i.e., Fig. 9c and f) as well as in $M_{\mathrm{BCe}}$ and $\sigma_{\mathrm{sp}}$. In order to characterize these observations in more detail, we extracted diurnal cycles for two contrasting states: wet season conditions without LRT influence (Fig. 10a) and for LRT episodes only (Fig. 10b). In the absence of LRT influence, our results are consistent with previous observations by Huffman et al. (2012) and Whitehead et al. (2016), showing a maximum in coarse mode abundance during the night (i.e., around 01:00-02:00 LT) and a minimum in coarse mode abundance during afternoon hours (i.e., around 12:00-13:00 LT). It has been suggested by Huffman et al. that these trends are driven by a combination of variable dispersal of biological aerosols, which is "strongly tied to environmental variables, such as solar radiation, temperature, and moisture", as well as the oscillating height of the atmospheric boundary layer that concentrates local emissions during night and dilutes them convectively during the day. Along these lines, Fig. 10a clearly illustrates coherent diurnal patterns of temperature, relative humidity, radiation, and $M_{1-10}$. Remarkably, Fig. 10a and the results by Huffman et al. showed consistently a secondary maximum at 08:00 LT, which could indicate increased sporulation rates due to the onset of solar radiation and continuously high relative humidity levels. The specific responses of PBAP emission mechanisms to micrometeorological conditions are subject of an ongoing analysis. In contrast to this scenario, the diurnal pattern during LRT episodes shows a different trend as shown in Fig. 10b. Here, the highest coarse mode abundance occurred around $\sim$ 12:00 LT, coinciding with the maximum in incoming radiation. This observation suggests that the intrusion of LRT aerosols into the near-surface boundary layer occurred via convective downward mixing from higher altitudes, where the transport of the plumes mostly takes place. After sunset, the $M_{1-10}$ levels decrease instantaneously, suggesting an efficient deposition of the LRT aerosol load to surfaces in the canopy space.

As a further step, we zoomed into two particular LRT episodes for a detailed analysis using satellite-based remote sensing data: (i) the event 2014_7 from 8 to 14 April 2014 and (ii) the event 2015_5 from 2 and 10 April 2015. For the event 2014_7, Figs. 11 and 12 provide a remote sensing characterization of the corresponding dust plume. The sequence of AOD maps in Fig. 11a-d shows the temporal evolution of the African dust outbreak as it passed over the Atlantic Ocean (4 to 5 April), arrived at the northeastern coast of South America (6 to 7 April), and traveled (deeply) into the Amazon Basin( 8 to 11 April). Note that the AOD data indicates a plume arrival on 8 April, which agrees very well with our in situ observation of the actual plume arrival at 


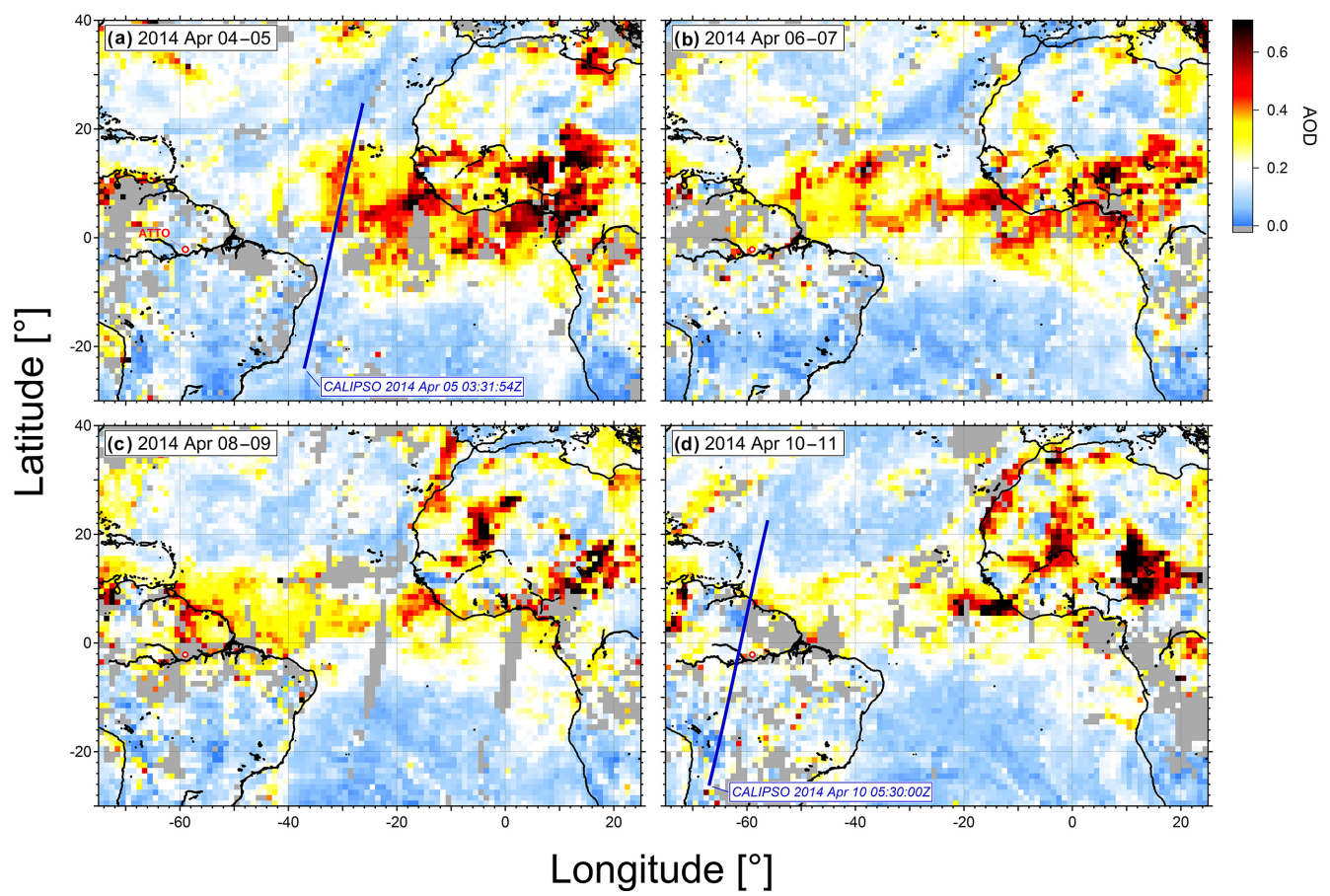

Figure 11. MODIS-derived AOD data showing Saharan dust outbreak, transatlantic passage, and intrusion into the Amazon Basin in the beginning of April 2014. Selected orbits of the CALIPSO spacecraft on 5 and 10 April are shown in (a, d). Corresponding CALIOP lidar profiles transecting the dust plume are displayed in Fig. 12. The gray areas represent pixels with no satellite data for the corresponding time periods.

ATTO as shown in Fig. 9. Figure 11c shows that the plume impacted a large area including southern Venezuela, Guyana, Suriname, French Guiana, and northern Brazil. Accordingly, the detailed presentation of the ATTO measurements for this particular event can be regarded as characteristic for atmospheric conditions under LRT influence in a comparatively large area of the northern Amazon Basin. For comparison, the corresponding AOD maps for the 2015_5 event can be found in Fig. S11.

In addition to the MODIS characterization, Fig. 12 presents lidar data from two CALIPSO overpasses that characterized the dust plume in a rather young state during its transatlantic passage (on 5 April 2014) and at a later stage as it reached the ATTO region (on 10 February 2014). The CALIPSO data for the overpass on 5 April probed the dust plume in the middle of the Atlantic Ocean and emphasizes its large horizontal extent from $20^{\circ} \mathrm{N}$ towards the equator (Fig. 12a, c, e). It further illustrates that the aerosol layer is lofted above the marine boundary layer with a vertical extent up to altitudes around $4-5 \mathrm{~km}$ and a certain degree of stratification. Note in this context that the transatlantic dust transport has been found to characteristically occur in lamella-like stratifications (Ansmann et al., 2009). Although the CALIOP aerosol subtype categorization (Fig. 12e, f) is showing a thin marine layer close to the surface, shallow moist convection likely facilitated the dust layer also to reach down into the marine boundary layer. Further, the aerosol subtype categorization confirms that the Saharan dust outbreaks during this time of the year are typically mixed with substantial amounts of pyrogenic aerosol, in agreement with Figs. 8 and 9 and the related discussion. The CALIPSO overpass on 10 April shows a lidar profile relatively close to the ATTO site (Fig. 12b, d, f). In the region of the ITCZ belt with its deep convective clouds, the signal is completely attenuated (i.e., $0-5^{\circ} \mathrm{S}$ ). However, the cloud-free areas show the presence of a compact and relatively well mixed dust layer up to altitudes of $2-3 \mathrm{~km}$, in agreement with Ansmann et al. (2009). For comparison, an analogous CALIPSO characterization for the LRT episode 2015_5 can be found in Fig. S12, which shows consistent overall trends. Further note that ceilometer measurements at the ATTO site in 2015 confirm that the LRT plumes arrive in the ATTO region as compact and mixed layers below $3 \mathrm{~km}$ (see Fig. S13).

The first prerequisite for effective dust transport to ATTO is the arrival and availability of a dust plume at the South American coast (see Sect. 3.1). For the 2014_7 episode, the remote sensing products shown above indicate the plume arrival at the coast on 6 April. The subsequent effectiveness and the role of wet deposition during its transport over land towards ATTO is illustrated in Fig. 13, presenting a sequence of the average precipitation patterns and wind fields at the $925 \mathrm{hPa}$ level in the respective regions of interest. On 


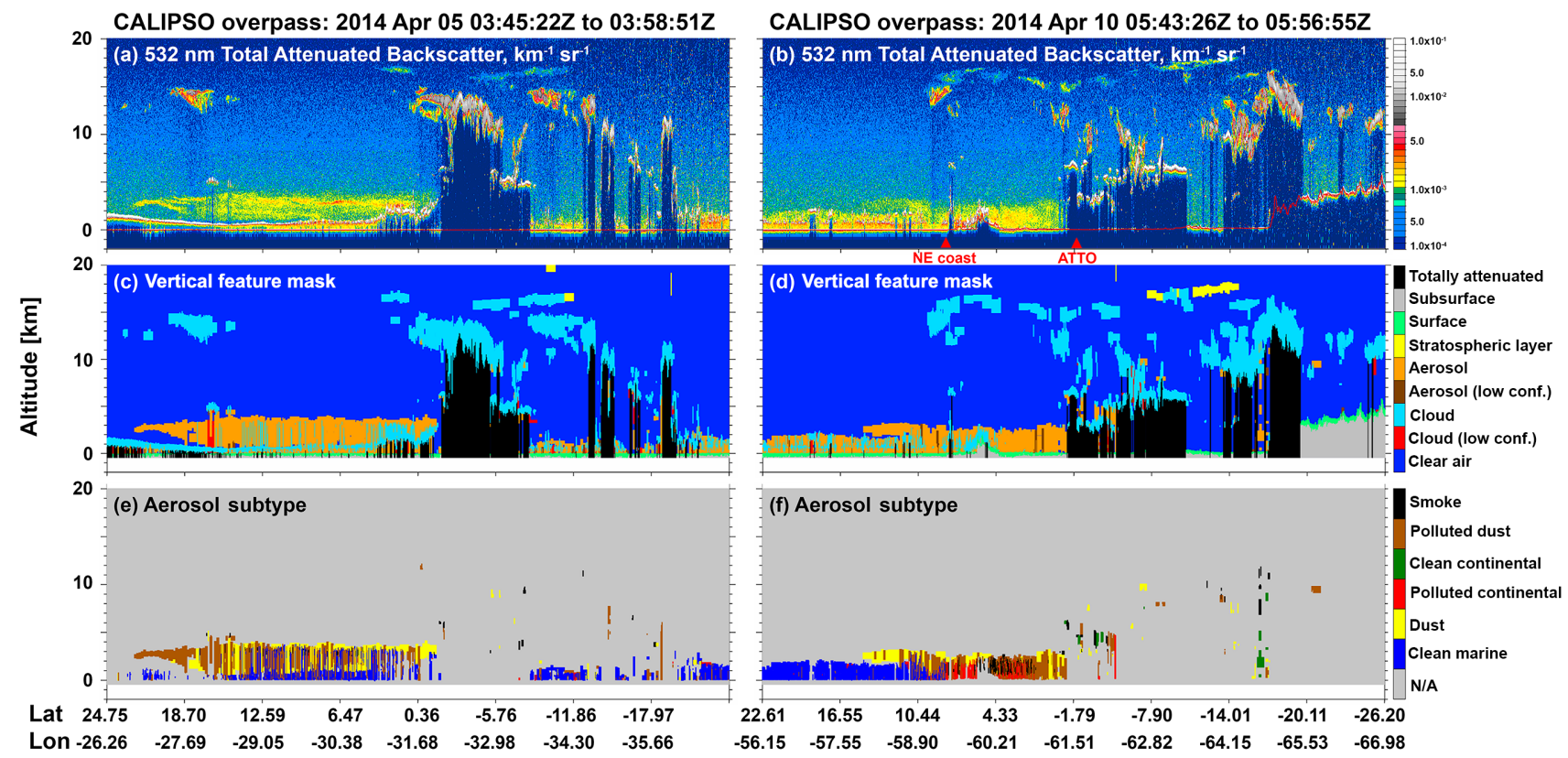

Figure 12. CALIOP lidar profiles of the African dust plume from 5 and 10 April 2014. The corresponding satellite orbits are shown as overlay with the MODIS AOD maps in Fig. 11. Red markers in panel (d) show position of the ATTO site and the northeast South American coast.

2/3 April, we find an almost closed rain band clearly illustrating the position of the ITCZ, which effectively prevents dust transport further south. In the course of the following days, the rain band became disturbed and moved slightly south, leading to a decrease in precipitation over French Guiana, Suriname and the northeastern Amazon Basin. Finally, on 9 and 10 April, precipitation stopped in the NE fetch of ATTO and the NE trade wind circulation established, opening the door for effective advection of dust towards the ATTO site. This interplay of the availability of dust, the timing of transport, and minimal wet deposition underlines the episodic but mesoscale character of dust intrusions into the northeastern basin (Swap et al., 1992). For comparison, an analogous and consistent characterization of the 2015_5 episode can be found in Fig. S14.

\subsection{Chemical characterization of LRT aerosols}

In this section, we present an analysis of the chemical composition of the LRT aerosols that are advected to the ATTO site. This analysis is based on EDXRF data, which are available from the ZF2 site $^{7}$ for the LRT season 2015 (see details in Sect. 2.4). Nine multi-day filter samples have been selected that best represent the conditions with and without LRT influence (see Fig. S10). The results are summarized in Fig. 14 for LRT episodes vs. conditions in the absence of strong LRT plumes (called non-LRT), both for $D<2.5 \mu \mathrm{m}$

\footnotetext{
${ }^{7}$ The atmospheric conditions at the ZF2 and ATTO sites can be considered as comparable as outlined in Sect. 2.1.
}

and $2.5<D<10 \mu \mathrm{m}$. Figure 14 quantifies the elemental contributions to the total collected mass on the filters as well as the mass concentrations of the individual elements. It clearly emerges that the relative fractions and mass concentrations of the dust-related crustal elements $\mathrm{Si}, \mathrm{Al}, \mathrm{Fe}, \mathrm{Ti}$, and $\mathrm{Ca}$ as well as the sea salt-related elements $\mathrm{Na}, \mathrm{Cl}$, and $\mathrm{Mg}$ are - expectedly - higher for LRT than non-LRT conditions. For instance, a total Si mass concentration of $\sim 500 \mathrm{ng} \mathrm{m}^{-3}$ (sum of $D<2.5$ and $2.5<D<10 \mu \mathrm{m}$ size fractions) was observed under LRT influence, whereas $\sim 35 \mathrm{ng} \mathrm{m}^{-3}$ were found under non-LRT conditions. Similarly, total Na mass concentrations went up to $\sim 130 \mathrm{ng} \mathrm{m}^{-3}$ under LRT influence, in contrast to non-detectable amounts for the non-LRT case. Moreover, $\mathrm{S}$ and K concentrations are enhanced under LRT influence. Note in this context that the EDXRF-retrieved sulfate concentrations of $\sim 440 \mathrm{ng} \mathrm{m}^{-3}$ (for $D<2.5 \mu \mathrm{m}$; obtained from conversion of $\mathrm{S}$ into $\mathrm{SO}_{4}^{2-}$ mass) under LRT influence agrees well with the aerosol mass spectrometry-based LRT sulfate concentrations of $\sim 250 \mathrm{ng} \mathrm{m}^{-3}$ (for $D<1 \mu \mathrm{m}$ ) as reported in Pöhlker et al. (2017). Interestingly, only minor amounts of $\mathrm{Cl}$ were found in the $D<2.5 \mu \mathrm{m}$ fraction, which could indicate a strong processing of small $\mathrm{NaCl}$ particles during atmospheric transport and an almost full replacement of the $\mathrm{Cl}^{-}$anion by $\mathrm{NO}_{3}^{-}$and/or $\mathrm{SO}_{4}^{2-}$ anions, which is in agreement with the comparatively high sulfate concentrations in the same size fraction (Laskin et al., 2012). As a further general trend, the fraction of the aforementioned inorganic elements tends to be higher in the particle size fraction $D<2.5 \mu \mathrm{m}$ compared to $2.5<D<10 \mu \mathrm{m}$. The lighter 


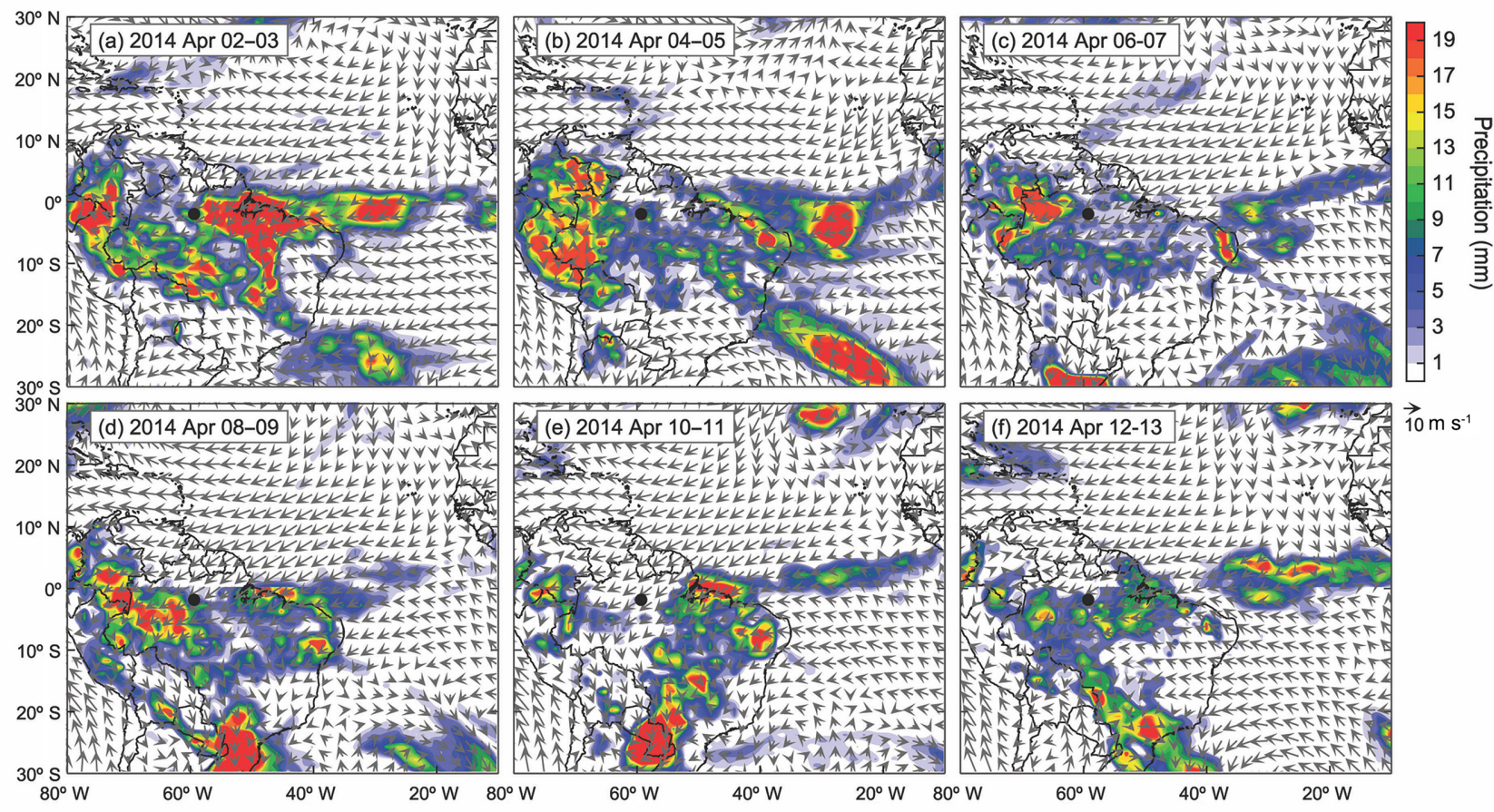

Figure 13. Wind data and precipitation daily averages from NCEP reanalysis data at a spatial resolution of $2.5^{\circ}$ from 2 to 13 April 2014 corresponding to 2014_7 period shown in Fig. 11.

elements with atomic numbers $<11$, which account for the remaining part of the total mass, can predominantly be attributed to $\mathrm{C}, \mathrm{N}$, and $\mathrm{O}$. For all four cases, the CNO contribution accounts for large fractions, ranging from about $71 \%$ (LRT case for $D<2.5 \mu \mathrm{m}$, Fig. 14a) to $97 \%$ (non-LRT case for $2.5<D<10 \mu \mathrm{m}$, Fig. 14d). Under non-LRT conditions, the elements $\mathrm{K}, \mathrm{P}$, and $\mathrm{S}$, which are typically associated with biogenic particles, prevail besides the dominant CNO fraction. ${ }^{8}$ Generally, the results in Fig. 14 agree very well with previous studies on the Amazonian aerosol composition, where detailed discussions can be found (Lawson and Winchester, 1979; Talbot et al., 1990; Graham et al., 2003; Guyon et al., 2003). Note in the context of the high CNO fraction that coarse mode particles in the Amazon are typically coated by SOA (Pöschl et al., 2010).

The elemental data in Fig. 14 can be regarded as an estimate of the typical composition of African LRT aerosols, including Saharan dust, marine aerosols, and smoke, arriving at the ATTO site. This is valuable information as it can be linked to the retrieved dust deposition fluxes in Sect. 3.3. Accordingly, the combination of both results allows to obtain deposition fluxes of individual elements for different regions of the basin (see Fig. 7). This is particularly relevant for those

\footnotetext{
${ }^{8}$ Note that certain traces of dust-related elements (i.e., $\mathrm{Si}, \mathrm{Al}, \mathrm{Fe}$ ) were also found in the non-LRT samples, which can be explained by the fact that the non-LRT samples also received minor amounts of dust from the onset and/or decay of LRT pulses before and afterwards (see Fig. S10).
}

ecologically important elements that are regarded as essential micro- and macronutrients for the rain forest ecosystem, such as $\mathrm{Fe}, \mathrm{P}, \mathrm{S}, \mathrm{Ca}, \mathrm{Mg}, \mathrm{Na}, \mathrm{Cl}$, and others (Swap et al., 1992; Okin et al., 2004; Rizzolo et al., 2017). For the ATTO region, our estimated elemental deposition fluxes are summarized in Table 4. This analysis suggests that the heavier elements with the largest input fluxes are the crustal elements $\mathrm{Si}$ and $\mathrm{Al}$ $\left(\sim 410-810\right.$ and $\left.\sim 200-410 \mathrm{~g} \mathrm{ha}^{-1} \mathrm{a}^{-1}\right)$, followed by sulfur ( 140-270 $\left.\mathrm{g} \mathrm{ha}^{-1} \mathrm{a}^{-1}\right)$, and the sea salt elements, $\mathrm{Cl}$ and $\mathrm{Na}$ $\left(\sim 130-260\right.$ and $\left.\sim 110-230 \mathrm{~g} \mathrm{ha}^{-1} \mathrm{a}^{-1}\right)$. For the ecologically important element $\mathrm{Fe}$, an input of $\sim 120-240 \mathrm{~g} \mathrm{ha}^{-1} \mathrm{a}^{-1}$ into the rain forest ecosystem was estimated. For $\mathrm{P}$, our analysis results in comparatively small input fluxes of about $(\sim 10$ $\left.20 \mathrm{gha}^{-1} \mathrm{a}^{-1}\right)$, since the $\mathrm{P}$ abundance is only slightly enhanced for the LRT $\left(21 \mathrm{ng} \mathrm{m}^{-3}\right)$ in comparison to the nonLRT case $\left(11 \mathrm{ng} \mathrm{m}^{-3}\right)$. Swap et al. (1992) also provide deposition fluxes for some selected elements (i.e., $\mathrm{Na}, \mathrm{K}, \mathrm{Cl}$, P) and ions (i.e., $\mathrm{NH}_{4}^{+}, \mathrm{NO}_{3}^{-}, \mathrm{SO}_{4}^{2-}, \mathrm{PO}_{4}^{3-}$ ). Their deposition fluxes are overall comparable to ours, however, appear to be systematically higher (see Table 4), which is consistent with their significantly higher estimate for the total deposited dust mass (Sect. 3.3). It has to be kept in mind that only part of the total deposited material is soluble and, thus, bioavailable. Accordingly, further dedicated studies on the bioavailable fractions of key nutrient, along the lines of the recent study by Rizzolo et al. (2017), will be needed to explore the link between Saharan dust-related nutrient input and rain forest ecology in more detail. 


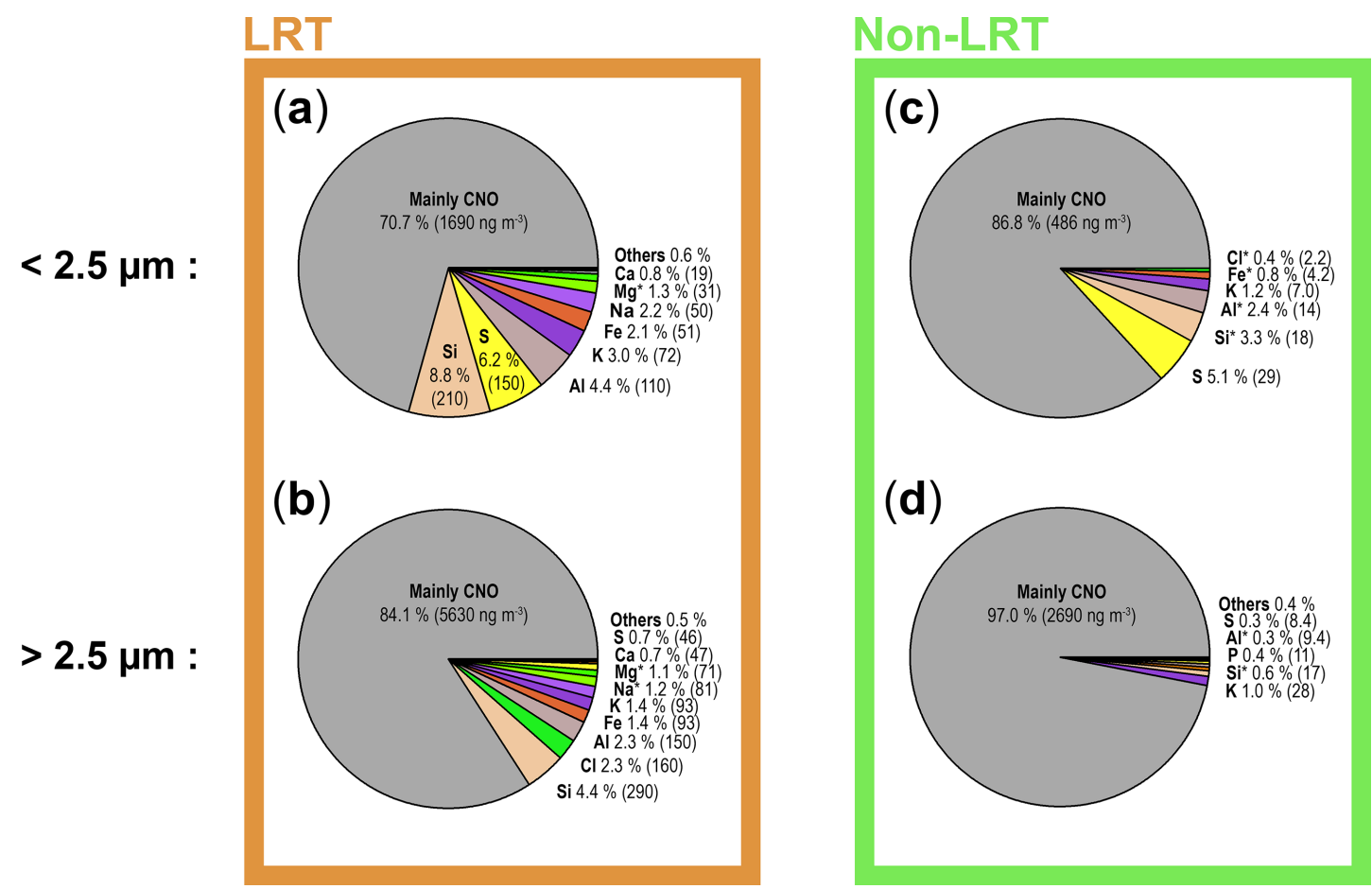

Figure 14. Mean relative mass fractions (in percent) and elemental mass concentrations (in $\mathrm{ng} \mathrm{m}^{-3}$, in parenthesis) of aerosol particles in the size fractions $>2.5$ and $<2.5 \mu \mathrm{m}$ for LRT episodes vs. periods without LRT influence (called non-LRT here). The sampling periods of the 5 LRT filters and the 4 non-LRT filters are specified in Sect. 2.4 and plotted in Fig. S10. The average elemental fractions are quantified relative to the average deposited mass on the LRT vs. non-LRT filters, respectively. The EDXRF analysis allows to quantify the masses of elements with atomic numbers larger 10 (i.e., starting with Na). Accordingly, the lighter elements in the periods 1 and 2 of the periodic table of the elements account for the remaining mass. The elements $\mathrm{C}, \mathrm{N}$, and $\mathrm{O}$ represent the predominant contributors here. The results visualized here are provided in detail in the corresponding Table S3. If element are marked with *, some data point were excluded from the analysis since they were below the detection limit according to Arana et al. (2014) (see also Sect. 2.4).

\section{Conclusion}

In this manuscript, the long-term variability and properties of coarse mode aerosols in the Amazon rain forest are investigated based on an extensive data set starting in 2014 at the Amazon Tall Tower Observatory (ATTO) site.

The coarse mode aerosols originate from different sources, such as direct emissions of primary biological aerosol particles, marine aerosols, long-range transport (LRT) of Saharan dust plumes, and a coarse mode fraction of biomass burning aerosols (Martin et al., 2010b; Huffman et al., 2012). Therefore, different aspects, such as the seasonal variability of the background coarse mode properties compared to frequent LRT intrusions are highlighted.

The complex meso-scale nature of annually re-occurring LRT events in the Amazon Basin is investigated based on a detailed air mass history cluster analysis and further remote sensing and in situ data. Tracking a typical dust layer on its way from the African to the American continent reveals the most important prerequisites for the efficient advection of LRT aerosols: (1) arrival and availability of LRT aerosol plumes at the South American coast, (2) atmospheric circulation in the NE basin and its efficiency in the transport of dust from the coast towards the ATTO site, and (3) the extent of wet deposition of the aerosol load en route. Consequently, air mass trajectories with high average air mass velocity, northernmost tracks, and lowest integrated precipitation rates overlap best with off-shore areas of increased dust loading and tend to be the most efficient dust transporters to the ATTO site region.

In contrast to the sub-micron aerosol fraction, the atmospheric life cycle of the aerosol coarse mode is not primarily driven by a pollution-related seasonality. The emission and transport of natural aerosols released and dispersed on different spatiotemporal scales lead to a rather defined and surprisingly stable coarse mode mass concentration of $4-7 \mu \mathrm{g} \mathrm{m}^{-3}$. The seasonal coarse mode number and mass concentration levels $\left(N_{1-10}\right.$ and $\left.M_{1-10}\right)$ show a modest increase from the wet season $\left(N_{1-10}=0.42 \pm 0.34 \mathrm{~cm}^{-3}, \quad M_{1-10}=4.04 \pm 2.72 \mu \mathrm{g} \mathrm{m}^{-3}\right)$ over the transition periods $\left(N_{1-10}=0.81 \pm 0.75 \mathrm{~cm}^{-3}\right.$, $M_{1-10}=5.24 \pm 3.46 \mu \mathrm{g} \mathrm{m}^{-3}$ ) to the dry season $\left(N_{1-10}=1.15 \pm 0.81 \mathrm{~cm}^{-3}, \quad M_{1-10}=6.47 \pm 2.69 \mu \mathrm{g} \mathrm{m}^{-3}\right)$. During the wet season, frequent intrusions of LRT aerosols 
Table 4. Estimated annual deposition of LRT-related elements in the ATTO region. The results are based on the modeled total dust aerosol deposition of $5-10 \mathrm{~kg} \mathrm{ha}^{-1} \mathrm{a}^{-1}$ as discussed in Sect. 3.3 in combination with the EDXRF results in Fig. 14. Note that these numbers represent only the part of the dust deposition gradient in Fig. 7 that includes the ATTO site (yellow area). For comparison, elemental deposition flux reported by Swap et al. (1992) are reported as well.

\begin{tabular}{lrr}
\hline \multirow{2}{*}{ Element } & \multicolumn{2}{c}{ Estimated flux deposition $\left[\mathrm{g} \mathrm{ha}^{-1} \mathrm{a}^{-1}\right]$} \\
\cline { 2 - 3 } & This study & Swap et al. $(1992)$ \\
\hline $\mathrm{Na}$ & $110-230$ & $800-3400^{\mathrm{a}} / 730-2900^{\mathrm{b}}$ \\
$\mathrm{Mg}$ & $89-180$ & - \\
$\mathrm{Al}$ & $200-410$ & - \\
$\mathrm{Si}$ & $410-810$ & - \\
$\mathrm{P}$ & $9-17$ & $11-46^{\mathrm{a}} / 3-39^{\mathrm{b}}$ \\
$\mathrm{S}$ & $140-270$ & $140-2340^{\mathrm{a}} / 400-1040^{\mathrm{b}}$ \\
$\mathrm{Cl}$ & $130-260$ & $2500-4900^{\mathrm{a}} / 1400-5100^{\mathrm{b}}$ \\
$\mathrm{K}$ & $110-230$ & $230-870^{\mathrm{a}} / 410-2300^{\mathrm{b}}$ \\
$\mathrm{Ca}$ & $54-110$ & - \\
$\mathrm{Ti}$ & $17-33$ & - \\
$\mathrm{Mn}$ & $6-12$ & - \\
$\mathrm{Fe}$ & $120-240$ & - \\
\hline
\end{tabular}

${ }^{\mathrm{a}}$ Dust intrusion estimate. ${ }^{\mathrm{b}}$ Precipitation estimate.

significantly alter the particle number size distribution and chemical composition. Accordingly, the highest $N_{1-10}$ and $M_{1-10}$ levels clearly occurred during African LRT influence, leading to average $N_{1-10}=2.03 \pm 1.87 \mathrm{~cm}^{-3}$ and $M_{1-10}=11.28 \pm 9.05 \mu \mathrm{g} \mathrm{m}^{-3}$. During major LRT events, the coarse mode mass concentration typically increases by about one order of magnitude, occasionally reaching peak concentrations of $M_{1-10}=100 \mu \mathrm{g} \mathrm{m}^{-3}$.

Under wet season conditions (without LRT), the entire coarse mode can be characterized as broad monomodal distribution with large mean geometric diameter $(4.2 \mu \mathrm{m}$ in the volume size distributions). In contrast, during the dry season, the coarse mode appears to have a multimodal shape with a strong, rather narrow peak located at about $2.0 \mu \mathrm{m}$ (volume size distribution) and pronounced shoulder towards larger particles. The coarse mode shape during Saharan dust influence shows a monomodal distribution with its maximum at $2.4 \mu \mathrm{m}$ (volume size distribution).

A closer look at the diurnal cycling of particle mass concentrations during wet season conditions (without LRT) reveals a maximum in coarse mode abundance during the night (i.e., around 01:00-02:00 LT) and a minimum during the afternoon hours, which is consistent with previous observations by Huffman et al. (2012) and Whitehead et al. (2016). As suggested by Huffman et al., these trends are driven by a combination of variable dispersal of biological aerosols, connected to environmental and meteorological variables, as well as the oscillating height of the atmospheric boundary layer that concentrates and dilutes local emissions. In con- trast, the diurnal pattern during LRT episodes shows highest coarse mode mass concentrations around 12:00 LT, collocated with the maximum in incoming solar radiation and increasing vertical mixing. This observation suggests that the intrusion of LRT aerosols into the near-surface boundary layer occurs via convective mixing with (lofted) aerosol layers at higher altitudes. After sunset, as soon as less efficient vertical mixing cuts further supply, an instantaneous decrease in $M_{1-10}$ levels suggests efficient deposition of the LRT aerosol load to surfaces in the canopy space.

The arrival of African LRT plumes clearly coincides with increased equivalent black carbon mass concentrations $\left(M_{\mathrm{BCe}}\right)$ and light scattering coefficients $\left(\sigma_{\mathrm{sp}}\right)$, underlining that the LRT aerosols typically represent mixtures of Saharan dust, biomass burning smoke, and sea spray (Talbot et al., 1990; Quinn et al., 1996; O'Dowd et al., 2008; Wang et al., 2016; Aller et al., 2017; Huang and Jaeglé, 2017). The degree of "smokiness" of the arriving LRT plumes decreases towards the end of the wet season (April) which is consistent with the decreasing biomass burning activity in Africa, and simultaneously marks the cleanest periods at the ATTO site.

The complex emission, transport, and transformation processes involved in the LRT of African dust into the Amazon Basin is well represented in a recent modeling study by Wang et al. (2016). Measured and modeled results of dust mass concentrations are in good agreement and encourage quantifying regional deposition fluxes of individual chemical components. Based on these results, we estimated a dust deposition flux of $5-10 \mathrm{~kg} \mathrm{ha}^{-1} \mathrm{a}^{-1}$ in the ATTO region, which is in good agreement with previous studies (Swap et al., 1992; Yu et al., 2015). Furthermore, a chemical analysis of aerosol filters with and without LRT influence confirmed an increase of crustal and sea salt elements during the LRT events. With this compositional information, we estimated elemental deposition fluxes in the ATTO region, which is particularly relevant for those elements that are considered as dust-related nutrients for the rain forest ecosystem.

Overall, this study provides a comprehensive overview of the physical and chemical properties of coarse mode aerosols in the Amazon Basin, highlighting background PBAP and LRT conditions. The results serve as a basis for further indepth studies on the complex coarse mode aerosol composition and cycling as well as its significance for atmospheric, biogeochemical, and ecological processes.

Data availability. The data of the key results presented here have been made available for use in follow-up studies. The daily averaged multi-year OPS time series are available as a file called OPS_TimeSeries.dat in NASA Ames format under https://doi.org/10.17617/3.1m (Moran-Zuloaga et al., 2018). The seasonally averaged aerosol size distributions, as shown in Fig. 6, are available in data tables in the Supplement of this study. For data requests beyond these data sets, please refer to the corresponding authors. 


\section{Appendix A: List of acronyms}

\begin{tabular}{|c|c|}
\hline Acronym & Description \\
\hline AIRS & Atmospheric infrared sounder \\
\hline AOD & Aerosol optical depth \\
\hline $\mathrm{AOD}_{\mathrm{ROI}}$ off & Aerosol optical depth within the region $\mathrm{ROI}_{\mathrm{off}}$ \\
\hline ATTO & Amazon Tall Tower Observatory \\
\hline $\mathrm{BC}_{\mathrm{e}}$ & Equivalent black carbon \\
\hline BT & Backward trajectory \\
\hline CALIPSO & Cloud-Aerosol Lidar and Infrared Pathfinder Satellite Observation \\
\hline CALIOP & Cloud-Aerosol Lidar with Orthogonal Polarization \\
\hline CCD & Charge coupled device \\
\hline $\mathrm{CCN}$ & Cloud condensation nuclei \\
\hline $\mathrm{CN}$ & Condensation nuclei \\
\hline $\mathrm{CPC}$ & Condensation particle counter \\
\hline $\mathrm{CA}$ & Cluster analysis \\
\hline $\mathrm{CO}$ & Carbon monoxide \\
\hline $\mathrm{E}$ & East \\
\hline EDXRF & Energy dispersive $\mathrm{x}$-ray fluorescence \\
\hline ENE & East-northeast \\
\hline ENSO & El Niño-Southern Oscillation \\
\hline ESE & East-southeast \\
\hline FWHM & Full width at half maximum \\
\hline GEOS-Chem & Goddard Earth Observing System coupled with chemistry \\
\hline GIOVANNI & Geospatial Interactive Online Visualization and Analyze Infrastructure \\
\hline GoAmazon2014/5 & Green Ocean Amazon 2014/5 \\
\hline HYSPLIT & Hybrid Single Particle Lagrangian Trajectory Model \\
\hline IN & Ice nuclei \\
\hline IOP & Intensive observation period \\
\hline ITCZ & Intertropical convergence zone \\
\hline IQR & Interquartile range (i.e., difference between 75 th and 25 th percentiles) \\
\hline $\log (x)$ & $\log _{10}(x)$, i.e., the logarithm of $x$ to base 10 \\
\hline LRT & Long-range transport \\
\hline LT & Local time \\
\hline MAAP & Multi-Angle Absorption Photometer \\
\hline MAC & Mass absorption coefficient \\
\hline MODIS & Moderate Resolution Imaging Spectroradiometer \\
\hline NASA & National Aeronautics and Space Administration \\
\hline NCEP & National Center for Environmental Prediction \\
\hline $\mathrm{NE}$ & Northeast \\
\hline NOAA & National Oceanic and Atmospheric Administration \\
\hline OPS & Optical Particle Sizer \\
\hline PBAP & Primary biological aerosol particle \\
\hline PSL & Polystyrene latex \\
\hline RH & Relative humidity \\
\hline $\mathrm{ROI}_{\text {off }}$ & Offshore region of interest \\
\hline ROI $_{\text {ATTO }}$ & ATTO region of interest \\
\hline SAL & Saharan Air Layer \\
\hline
\end{tabular}


SE Southeast

SOM Secondary organic matter

SMPS Scanning Mobility Particle Sizer

SOA Secondary organic aerosol

TRMM Tropical Rainforest Measuring Mission

TSP Total suspended particles

UHSAS Ultra-High Sensitive Aerosol Spectrometer

UTC Coordinated Universal Time

UV-APS Ultra-Violet Aerodynamic Particle Sizer

VOC Volatile organic compounds

WIBS Wideband Integrated Bioaerosol Sensor

\section{Appendix B: List of symbols}

\begin{tabular}{|c|c|}
\hline Symbol & Quantity and unit \\
\hline$D$ & Aerosol particle diameter, $\mu \mathrm{m}$ \\
\hline$D_{\mathrm{o}}$ & Optical particle diameter, $\mu \mathrm{m}$ \\
\hline$D_{\mathrm{a}}$ & Aerodynamic particle diameter, $\mu \mathrm{m}$ \\
\hline$D_{\mathrm{p}}$ & Physical or geometric particle diameter, $\mu \mathrm{m}$ \\
\hline$f_{\mathrm{BT}, \text { clusters }}$ & Frequency of occurrence of back trajectory clusters \\
\hline & Wavelength \\
\hline$M$ & Aerosol mass concentration, $\mu \mathrm{g} \mathrm{m}^{-3}$ \\
\hline$M_{0.3-1}$ & Aerosol mass concentration from 0.3 to $10 \mu \mathrm{m}, \mu \mathrm{g} \mathrm{m}^{-3}$ \\
\hline$M_{2.5-10}$ & Aerosol mass concentration from 2.5 to $10 \mu \mathrm{m}, \mu \mathrm{g} \mathrm{m}^{-3}$ \\
\hline$M_{0.3-10}$ & Aerosol mass concentration from 0.3 to $10 \mu \mathrm{m}, \mu \mathrm{g} \mathrm{m}^{-3}$ \\
\hline$M_{1-10}$ & Aerosol mass concentration from 1 to $10 \mu \mathrm{m}$ (coarse mode), $\mu \mathrm{g} \mathrm{m}^{-3}$ \\
\hline$M_{\mathrm{BCe}}$ & Mass concentration of black carbon equivalent, $\mu \mathrm{g} \mathrm{m}^{-3}$ \\
\hline$N$ & Number concentration, $\mathrm{cm}^{-3}$ \\
\hline$c_{\mathrm{CO}}$ & Carbon monoxide mole fraction, ppb \\
\hline$N_{\text {Ait }}$ & Number concentration of Aitken mode, $\mathrm{cm}^{-3}$ \\
\hline$N_{\text {acc }}$ & Number concentration of accumulation mode, $\mathrm{cm}^{-3}$ \\
\hline$N_{\mathrm{c}}$ & Number concentration of coarse mode, $\mathrm{cm}^{-3}$ \\
\hline$N_{0.3-1}$ & Number concentration from 0.3 to $1 \mu \mathrm{m}, \mathrm{cm}^{-3}$ \\
\hline$N_{0.3-10}$ & Number concentration from 0.3 to $10 \mu \mathrm{m}, \mathrm{cm}^{-3}$ \\
\hline$N_{1-10}$ & Number concentration from 1 to $10 \mu \mathrm{m}, \mathrm{cm}^{-3}$ \\
\hline$N_{\text {total }}$ & Total number concentration $(>5 \mathrm{~nm}), \mathrm{cm}^{-3}$ \\
\hline $\mathrm{d} N / \mathrm{d} \log D$ & Number size distribution, $\mathrm{cm}^{-3}$ \\
\hline $\mathrm{d} S / \mathrm{d} \log D$ & Surface size distribution, $\mu \mathrm{m}^{2} \mathrm{~cm}^{-3}$ \\
\hline $\mathrm{d} V / \mathrm{d} \log D$ & Volume size distribution, $\mu \mathrm{m}^{3} \mathrm{~cm}^{-3}$ \\
\hline $\mathrm{d} M / \mathrm{d} \log D$ & Mass size distribution, $\mu \mathrm{g} \mathrm{m}^{-3}$ \\
\hline$P_{\mathrm{BT}}$ & Precipitation from HYSPLIT back trajectory model, $\mathrm{mm}$ \\
\hline$P_{\text {TRMM }}$ & Precipitation rate from Tropical Rainfall Measurement Mission, $\mathrm{mm} \mathrm{h}^{-1}$ \\
\hline$\rho_{0.85}$ & Aerosol density at $0.8 \mathrm{~g} \mathrm{~m}^{-3}, \mathrm{~g} \mathrm{~cm}^{-3}$ \\
\hline$\rho_{1.0}$ & Aerosol density at $1.0 \mathrm{~g} \mathrm{~m}^{-3}, \mathrm{~g} \mathrm{~cm}^{-3}$ \\
\hline$\rho_{1.2}$ & Aerosol density at $1.2 \mathrm{~g} \mathrm{~m}^{-3}, \mathrm{~g} \mathrm{~cm}^{-3}$ \\
\hline$\rho_{2.0}$ & Aerosol density at $2.0 \mathrm{~g} \mathrm{~m}^{-3}, \mathrm{~g} \mathrm{~cm}^{-3}$ \\
\hline$\sigma_{\mathrm{sp}}$ & Aerosol light scattering coefficient, $\mathrm{Mm}^{-1}$ \\
\hline
\end{tabular}




\section{The Supplement related to this article is available online at https://doi.org/10.5194/acp-18-10055-2018- supplement.}

Competing interests. The authors declare that they have no conflict of interest.

Special issue statement. This article is part of the special issue "Amazon Tall Tower Observatory (ATTO) Special Issue". It is not associated with a conference.

Acknowledgements. This work has been supported by the Max Planck Society (MPG). For the operation of the ATTO site, we acknowledge the support by the German Federal Ministry of Education and Research (BMBF contract 01LB1001A) and the Brazilian Ministério da Ciência, Tecnologia e Inovação (MCTI/FINEP contract 01.11.01248.00) as well as the Amazon State University (UEA), FAPEAM, LBA/INPA and SDS/CEUC/RDS-Uatumã. This paper contains results of research conducted under the Technical/Scientific Cooperation Agreement between the National Institute for Amazonian Research, the State University of Amazonas, and the Max-Planck-Gesellschaft e.V.; the opinions expressed are entirely the responsibility of the authors and not of the participating institutions. We highly acknowledge the support by the Instituto Nacional de Pesquisas da Amazônia (INPA). We would like to especially thank all the people involved in the technical, logistical, and scientific support of the ATTO project, in particular Jürgen Kesselmeier, Carlos Alberto Quesada, Susan Trumbore, Reiner Ditz, Matthias Sörgel, Thomas Disper, Thomas Klimach, Björn Nillius, Andrew Crozier, Uwe Schulz, Steffen Schmidt, Alessandro Araùjo, Antonio Ocimar Manzi, Niro Higuchi, Alcides Camargo Ribeiro, Hermes Braga Xavier, Elton Mendes da Silva, Nagib Alberto de Castro Souza, Adir Vasconcelos Brandão, Amauri Rodriguês Perreira, Antonio Huxley Melo Nascimento, Thiago de Lima Xavier, Josué Ferreira de Souza, Roberta Pereira de Souza, Bruno Takeshi, and Wallace Rabelo Costa. Further, we thank the GoAmazon2014/5 team for the fruitful collaboration and discussions. Moreover, we thank Tobias Könemann, Maria Praß, Jan-David Förster, Andrea Arangio, Emilio Rodríguez Caballero, Ovid O. Krüger, and Oliver Lauer for their support and stimulating discussions. The authors gratefully acknowledge the NOAA Air Resources Laboratory (ARL) for the provision of the HYSPLIT transport and dispersion model and/or READY website (http://www.ready.noaa.gov, last access: 12 June 2018) used in this publication.

The article processing charges for this open-access publication were covered by the Max Planck Society.

Edited by: Markku Kulmala

Reviewed by: two anonymous referees

\section{References}

Abdelkader, M., Metzger, S., Steil, B., Klingmüller, K., Tost, H., Pozzer, A., Stenchikov, G., Barrie, L., and Lelieveld, J.: Sensitivity of transatlantic dust transport to chemical aging and related atmospheric processes, Atmos. Chem. Phys., 17, 37993821, https://doi.org/10.5194/acp-17-3799-2017, 2017.

Abouchami, W., Näthe, K., Kumar, A., Galer, S. J. G., Jochum, K. P., Williams, E., Horbe, A. M. C., Rosa, J. W. C., Balsam, W., Adams, D., Mezger, K., and Andreae, M. O.: Geochemical and isotopic characterization of the Bodélé Depression dust source and implications for transatlantic dust transport to the Amazon Basin, Earth Planet. Sc. Lett., 380, 112-123, https://doi.org/10.1016/j.epsl.2013.08.028, 2013.

Acker, J. G. and Leptoukh, G.: Online analysis enhances use of NASA Earth science data, EOS T. Am. Geophys. Un., 88, 1417, https://doi.org/10.1029/2007EO020003, 2007.

Allan, J., Petäjä, T., Karl, T., Silva Dias, M. A., Garrett, T., and Schmidt, W. (Eds.): Observations and Modeling of the Green Ocean Amazon (GoAmazon2014/5) (ACP/AMT/GI/GMD inter-journal SI), Atmos. Chem. Phys., https://www.atmos-chem-phys.net/special_issue392.html, 2015.

Aller, J., Radway, J., Kilthau, W., Bothe, D., Wilson, T., Vaillancourt, R., Quinn, P., Coffman, D., Murray, B., and Knopf, D.: Size resolved characterization of the polysaccharidic and proteinaceous components of sea spray aerosol, Atmos. Environ., 154, 331-347 https://doi.org/10.1016/j.atmosenv.2017.01.053, 2017.

Andreae, M. O.: Soot Carbon and Excess Fine Potassium: LongRange Transport of Combustion-Derived Aerosols, Science, 220, 1148, https://doi.org/10.1126/science.220.4602.1148, 1983.

Andreae, M. O.: Aerosols Before Pollution, Science, 315, 50-51, https://doi.org/10.1126/science.1136529, 2007.

Andreae, M. O., Browell, E. V., Garstang, M., Gregory, G. L., Harriss, R. C., Hill, G. F., Jacob, D. J., Pereira, M. C., Sachse, G. W., Setzer, A. W., Dias, P. L. S., Talbot, R. W., Torres, A. L., and Wofsy, S. C.: Biomass-burning emissions and associated haze layers over Amazonia, J. Geophys. Res.-Atmos., 93, 1509-1527, https://doi.org/10.1029/JD093iD02p01509, 1988.

Andreae, M. O., Rosenfeld, D., Artaxo, P., Costa, A. A., Frank, G. P., Longo, K. M., and Silva-Dias, M. A. F.: Smoking Rain Clouds over the Amazon, Science, 303, 1337, https://doi.org/10.1126/science.1092779, 2004.

Andreae, M. O., Artaxo, P., Beck, V., Bela, M., Freitas, S., Gerbig, C., Longo, K., Munger, J. W., Wiedemann, K. T., and Wofsy, S. C.: Carbon monoxide and related trace gases and aerosols over the Amazon Basin during the wet and dry seasons, Atmos. Chem. Phys., 12, 6041-6065, https://doi.org/10.5194/acp12-6041-2012, 2012.

Andreae, M. O., Acevedo, O. C., Araùjo, A., Artaxo, P., Barbosa, C. G. G., Barbosa, H. M. J., Brito, J., Carbone, S., Chi, X., Cintra, B. B. L., da Silva, N. F., Dias, N. L., Dias-Júnior, C. Q., Ditas, F., Ditz, R., Godoi, A. F. L., Godoi, R. H. M., Heimann, M., Hoffmann, T., Kesselmeier, J., Könemann, T., Krüger, M. L., Lavric, J. V., Manzi, A. O., Lopes, A. P., Martins, D. L., Mikhailov, E. F., Moran-Zuloaga, D., Nelson, B. W., Nölscher, A. C., Santos Nogueira, D., Piedade, M. T. F., Pöhlker, C., Pöschl, U., Quesada, C. A., Rizzo, L. V., Ro, C.-U., Ruckteschler, N., Sá, L. D. A., de Oliveira Sá, M., Sales, C. B., dos Santos, R. M. N., Saturno, J., Schöngart, J., Sörgel, M., de Souza, C. M., de Souza, 
R. A. F., Su, H., Targhetta, N., Tóta, J., Trebs, I., Trumbore, S., van Eijck, A., Walter, D., Wang, Z., Weber, B., Williams, J., Winderlich, J., Wittmann, F., Wolff, S., and Yáñez-Serrano, A. M.: The Amazon Tall Tower Observatory (ATTO): overview of pilot measurements on ecosystem ecology, meteorology, trace gases, and aerosols, Atmos. Chem. Phys., 15, 10723-10776, https://doi.org/10.5194/acp-15-10723-2015, 2015.

Andreae, M. O., Afchine, A., Albrecht, R., Holanda, B. A., Artaxo, P., Barbosa, H. M. J., Borrmann, S., Cecchini, M. A., Costa, A., Dollner, M., Fütterer, D., Järvinen, E., Jurkat, T., Klimach, T., Konemann, T., Knote, C., Krämer, M., Krisna, T., Machado, L. A. T., Mertes, S., Minikin, A., Pöhlker, C., Pöhlker, M. L., Pöschl, U., Rosenfeld, D., Sauer, D., Schlager, H., Schnaiter, M., Schneider, J., Schulz, C., Spanu, A., Sperling, V. B., Voigt, C., Walser, A., Wang, J., Weinzierl, B., Wendisch, M., and Ziereis, H.: Aerosol characteristics and particle production in the upper troposphere over the Amazon Basin, Atmos. Chem. Phys., 18, 921-961, https://doi.org/10.5194/acp-18-921-2018, 2018.

Ansmann, A., Baars, H., Tesche, M., Muller, D., Althausen, D., Engelmann, R., Pauliquevis, T., and Artaxo, P.: Dust and smoke transport from Africa to South America: Lidar profiling over Cape Verde and the Amazon rainforest, Geophys. Res. Lett., 36, L11802, https://doi.org/10.1029/2009g1037923, 2009.

Arana, A., Loureiro, A. L., Barbosa, H. M. J., Van Grieken, R., and Artaxo, P.: Optimized energy dispersive X-ray fluorescence analysis of atmospheric aerosols collected at pristine and perturbed Amazon Basin sites, X-Ray Spectrom., 43, 228-237, https://doi.org/10.1002/xrs.2544, 2014.

Artaxo, P., Gerab, F., and Rabello, M. L. C.: Elemental composition of aerosol-particles from 2 atmospheric monitoring stations in the Amazon basin, Nucl. Instrum. Meth. B, 75, 277-281, https://doi.org/10.1016/0168-583x(93)95658-r, 1993.

Artaxo, P., Martins, J. V., Yamasoe, M. A., Procópio, A. S., Pauliquevis, T. M., Andreae, M. O., Guyon, P., Gatti, L. V., and Leal, A. M. C.: Physical and chemical properties of aerosols in the wet and dry seasons in Rondônia, Amazonia, J. Geophys. Res.-Atmos., 107, 8081, https://doi.org/10.1029/2001JD000666, 2002.

Artaxo, P., Barbosa, H. M. J., Rizzo, L. V., Brito, J. F., Sena, E. T., Cirino, G. G., and Arana, A.: Aerosols in Amazonia: Natural biogenic particles and large scale biomass burning impacts, AIP Conf. Proc., 1527, 487-490, https://doi.org/10.1063/1.4803311, 2013a.

Artaxo, P., Rizzo, L. V., Brito, J. F., Barbosa, H. M. J., Arana, A., Sena, E. T., Cirino, G. G., Bastos, W., Martin, S. T., and Andreae, M. O.: Atmospheric aerosols in Amazonia and land use change: from natural biogenic to biomass burning conditions, Faraday Discuss., 165, 203-235, https://doi.org/10.1039/c3fd00052d, 2013b.

Baars, H., Ansmann, A., Althausen, D., Engelmann, R., Artaxo, P., Pauliquevis, T., and Souza, R.: Further evidence for significant smoke transport from Africa to Amazonia, Geophys. Res. Lett., 38, L20802, https://doi.org/10.1029/2011g1049200, 2011.

Barbosa, P. M., Stroppiana, D., Gregoire, J. M., and Pereira, J. M. C.: An assessment of vegetation fire in Africa (1981-1991): Burned areas, burned biomass, and atmospheric emissions, Global Biogeochem. Cy., 13, 933-950, https://doi.org/10.1029/1999gb900042, 1999.
Ben-Ami, Y., Koren, I., Rudich, Y., Artaxo, P., Martin, S. T., and Andreae, M. O.: Transport of North African dust from the Bodélé depression to the Amazon Basin: a case study, Atmos. Chem. Phys., 10, 7533-7544, https://doi.org/10.5194/acp10-7533-2010, 2010.

Bristow, C. S., Hudson-Edwards, K. A., and Chappell, A.: Fertilizing the Amazon and equatorial Atlantic with West African dust, Geophys. Res. Lett., 37, L14807, https://doi.org/10.1029/2010gl043486, 2010.

Brito, J., Rizzo, L. V., Morgan, W. T., Coe, H., Johnson, B., Haywood, J., Longo, K., Freitas, S., Andreae, M. O., and Artaxo, P.: Ground-based aerosol characterization during the South American Biomass Burning Analysis (SAMBBA) field experiment, Atmos. Chem. Phys., 14, 12069-12083, https://doi.org/10.5194/acp-14-12069-2014, 2014.

Byeon, S.-S., Cho, M.-Y., Lee, J.-C., and Kim, Y.-J.: Numerical Study on the Particle Trajectory Tracking in a Micro-UV BioFluorescence Sensor, J. Nanosci. Nanotechno., 15, 2221-2225, https://doi.org/10.1166/jnn.2015.10248, 2015.

Davidson, E. A., de Araujo, A. C., Artaxo, P., Balch, J. K., Brown, I. F., C. Bustamante, M. M., Coe, M. T., DeFries, R. S., Keller, M., Longo, M., Munger, J. W., Schroeder, W., Soares-Filho, B. S., Souza, C. M., and Wofsy, S. C.: The Amazon basin in transition, Nature, 481, 321-328, 2012.

Di Biagio, C., Formenti, P., Balkanski, Y., Caponi, L., Cazaunau, M., Pangui, E., Journet, E., Nowak, S., Caquineau, S., Andreae, M. O., Kandler, K., Saeed, T., Piketh, S., Seibert, D., Williams, E., and Doussin, J.-F.: Global scale variability of the mineral dust long-wave refractive index: a new dataset of in situ measurements for climate modeling and remote sensing, Atmos. Chem. Phys., 17, 1901-1929, https://doi.org/10.5194/acp17-1901-2017, 2017.

Edwards, D. P., Emmons, L. K., Gille, J. C., Chu, A., Attié, J. L., Giglio, L., Wood, S. W., Haywood, J., Deeter, M. N., Massie, S. T., Ziskin, D. C., and Drummond, J. R.: Satellite-observed pollution from Southern Hemisphere biomass burning, J. Geophys. Res.-Atmos., 111, D14312, https://doi.org/10.1029/2005JD006655, 2006.

Formenti, P., Andreae, M. O., Lange, L., Roberts, G., Cafmeyer, J., Rajta, I., Maenhaut, W., Holben, B. N., Artaxo, P., and Lelieveld, J.: Saharan dust in Brazil and Suriname during the Large-Scale Biosphere-Atmosphere Experiment in Amazonia (LBA) - Cooperative LBA Regional Experiment (CLAIRE) in March 1998, J. Geophys. Res.-Atmos., 106, 14919-14934, https://doi.org/10.1029/2000jd900827, 2001.

Fröhlich-Nowoisky, J., Kampf, C. J., Weber, B., Huffman, J. A., Pöhlker, C., Andreae, M. O., Lang-Yona, N., Burrows, S. M., Gunthe, S. S., Elbert, W., Su, H., Hoor, P., Thines, E., Hoffmann, T., Després, V. R., and Pöschl, U.: Bioaerosols in the Earth System: Climate, Health, and Ecosystem Interactions, Atmos. Res., 182, 346-376, https://doi.org/10.1016/j.atmosres.2016.07.018, 2016.

Fuchs, J. and Cermak, J.: Where Aerosols Become Clouds - Potential for Global Analysis Based on CALIPSO Data, Remote Sensing, 7, 4178, https://doi.org/10.3390/rs70404178, 2015.

Gläser, G., Wernli, H., Kerkweg, A., and Teubler, F.: The transatlantic dust transport from North Africa to the Americas - Its characteristics and source regions, J. Geophys. Res.-Atmos., 120, 11231-11252, https://doi.org/10.1002/2015JD023792, 2015. 
Graham, B., Guyon, P., Maenhaut, W., Taylor, P. E., Ebert, M., Matthias-Maser, S., Mayol-Bracero, O. L., Godoi, R. H. M., Artaxo, P., Meixner, F. X., Moura, M. A. L., Rocha, C. H. E. D. A., Grieken, R. V., Glovsky, M. M., Flagan, R. C., and Andreae, M. O.: Composition and diurnal variability of the natural Amazonian aerosol, J. Geophys. Res.-Atmos., 108, 4765, https://doi.org/10.1029/2003JD004049, 2003.

Guyon, P., Graham, B., Beck, J., Boucher, O., Gerasopoulos, E., Mayol-Bracero, O. L., Roberts, G. C., Artaxo, P., and Andreae, M. O.: Physical properties and concentration of aerosol particles over the Amazon tropical forest during background and biomass burning conditions, Atmos. Chem. Phys., 3, 951-967, https://doi.org/10.5194/acp-3-951-2003, 2003.

Gwaze, P., Annegarn, H. J., Huth, J., and Helas, G.: Comparison of particle sizes determined with impactor, AFM and SEM, Atmos. Res., 86, 93-104, https://doi.org/10.1016/j.atmosres.2007.02.009, 2007.

Harriss, R. C., Garstang, M., Wofsy, S. C., Beck, S. M., Bendura, R. J., Coelho, J. R. B., Drewry, J. W., Hoell, J. M., Matson, P. A., McNeal, R. J., Molion, L. C. B., Navarro, R. L., Rabine, V., and Snell, R. L.: The Amazon Boundary Layer Experiment: Wet season 1987, J. Geophys. Res.-Atmos., 95, 16721-16736, https://doi.org/10.1029/JD095iD10p16721, 1990.

Heese, B., Flentje, H., Althausen, D., Ansmann, A., and Frey, S.: Ceilometer lidar comparison: backscatter coefficient retrieval and signal-to-noise ratio determination, Atmos. Meas. Tech., 3, 1763-1770, https://doi.org/10.5194/amt-3-1763-2010, 2010.

Huang, J., Zhang, C., and Prospero, J. M.: AerosolInduced Large-Scale Variability in Precipitation over the Tropical Atlantic, J. Climate, 22, 4970-4988, https://doi.org/10.1175/2009JCLI2531.1, 2009.

Huang, J., Zhang, C., and Prospero, J. M.: African dust outbreaks: A satellite perspective of temporal and spatial variability over the tropical Atlantic Ocean, J. Geophys. Res.-Atmos., 115, D05202, https://doi.org/10.1029/2009JD012516, 2010.

Huang, J. and Jaeglé, L.: Wintertime enhancements of sea salt aerosol in polar regions consistent with a sea ice source from blowing snow, Atmos. Chem. Phys., 17, 3699-3712, https://doi.org/10.5194/acp-17-3699-2017, 2017.

Huffman, J. A., Sinha, B., Garland, R. M., Snee-Pollmann, A., Gunthe, S. S., Artaxo, P., Martin, S. T., Andreae, M. O., and Pöschl, U.: Size distributions and temporal variations of biological aerosol particles in the Amazon rainforest characterized by microscopy and real-time UV-APS fluorescence techniques during AMAZE-08, Atmos. Chem. Phys., 12, 11997-12019, https://doi.org/10.5194/acp-12-11997-2012, 2012.

Koren, I., Yoram, J. K., Richard, W., Martin, C. T., Yinon, R., Martins., J. V., and Daniel, R.: The Bodélé depression: a single spot in the Sahara that provides most of the mineral dust to the Amazon forest, Environ. Res. Lett., 1, 014005, https://doi.org/10.1088/1748-9326/1/1/014005, 2006.

Laskin, A., Moffet, R. C., Gilles, M. K., Fast, J. D., Zaveri, R. A., Wang, B., Nigge, P., and Shutthanandan, J.: Tropospheric chemistry of internally mixed sea salt and organic particles: Surprising reactivity of $\mathrm{NaCl}$ with weak organic acids, J. Geophys. Res.Atmos., 117, D15302, https://doi.org/10.1029/2012JD017743, 2012.

Lawson, D. R. and Winchester, J. W.: Sulfur, potassium, and phosphorus associations in aerosols from South American trop- ical rain forests, J. Geophys. Res.-Oceans, 84, 3723-3727, https://doi.org/10.1029/JC084iC07p03723, 1979.

Lenton, T. M., Held, H., Kriegler, E., Hall, J. W., Lucht, W., Rahmstorf, S., and Schellnhuber, H. J.: Tipping elements in the Earth's climate system, P. Natl. Acad. Sci. USA, 105, 17861793, https://doi.org/10.1073/pnas.0705414105, 2008.

Liu, Z., Omar, A., Vaughan, M., Hair, J., Kittaka, C., Hu, Y., Powell, K., Trepte, C., Winker, D., Hostetler, C., Ferrare, R., and Pierce, R.: CALIPSO lidar observations of the optical properties of Saharan dust: A case study of long-range transport, J. Geophys. Res.-Atmos., 113, D07207, https://doi.org/10.1029/2007JD008878, 2008.

Machado, L. A. T., Dias, M. A. F. S., Morales, C., Fisch, G., Vila, D., Albrecht, R., Goodman, S. J., Calheiros, A. J. P., Biscaro, T., Kummerow, C., Cohen, J., Fitzjarrald, D., Nascimento, E. L., Sakamoto, M. S., Cunningham, C., Chaboureau, J.-P., Petersen, W. A., Adams, D. K., Baldini, L., Angelis, C. F., Sapucci, L. F., Salio, P., Barbosa, H. M. J., Landulfo, E., Souza, R. A. F., Blakeslee, R. J., Bailey, J., Freitas, S., Lima, W. F. A., and Tokay, A.: The Chuva Project: How Does Convection Vary across Brazil?, B. Am. Meteorol. Soc., 95, 1365-1380, https://doi.org/10.1175/BAMS-D-13-00084.1, 2014.

Martin, S. T., Andreae, M. O., Althausen, D., Artaxo, P., Baars, H., Borrmann, S., Chen, Q., Farmer, D. K., Guenther, A., Gunthe, S. S., Jimenez, J. L., Karl, T., Longo, K., Manzi, A., Müller, T., Pauliquevis, T., Petters, M. D., Prenni, A. J., Pöschl, U., Rizzo, L. V., Schneider, J., Smith, J. N., Swietlicki, E., Tota, J., Wang, J., Wiedensohler, A., and Zorn, S. R.: An overview of the Amazonian Aerosol Characterization Experiment 2008 (AMAZE-08), Atmos. Chem. Phys., 10, 1141511438, https://doi.org/10.5194/acp-10-11415-2010, 2010a.

Martin, S. T., Andreae, M. O., Artaxo, P., Baumgardner, D., Chen, Q., Goldstein, A. H., Guenther, A., Heald, C. L., Mayol-Bracero, O. L., McMurry, P. H., Pauliquevis, T., Poschl, U., Prather, K. A., Roberts, G. C., Saleska, S. R., Dias, M. A. S., Spracklen, D. V., Swietlicki, E., and Trebs, I.: Sources and properties of the Amazonian aerosol particles, Rev. Geophys., 48, RG2002, https://doi.org/10.1029/2008rg000280, 2010b.

Martin, S. T., Artaxo, P., Machado, L. A. T., Manzi, A. O., Souza, R. A. F., Schumacher, C., Wang, J., Andreae, M. O., Barbosa, H. M. J., Fan, J., Fisch, G., Goldstein, A. H., Guenther, A., Jimenez, J. L., Pöschl, U., Silva Dias, M. A., Smith, J. N., and Wendisch, M.: Introduction: Observations and Modeling of the Green Ocean Amazon (GoAmazon2014/5), Atmos. Chem. Phys., 16, 47854797, https://doi.org/10.5194/acp-16-4785-2016, 2016.

Martin, S. T., Artaxo, P., Machado, L., Manzi, A. O., Souza, R. A. F., Schumacher, C., Wang, J., Biscaro, T., Brito, J., Calheiros, A., Jardine, K., Medeiros, A., Portela, B., Sá, S. S. d., Adachi, K., Aiken, A. C., Albrecht, R., Alexander, L., Andreae, M. O., Barbosa, H. M. J., Buseck, P., Chand, D., Comstock, J. M., Day, D. A., Dubey, M., Fan, J., Fast, J., Fisch, G., Fortner, E., Giangrande, S., Gilles, M., Goldstein, A. H., Guenther, A., Hubbe, J., Jensen, M., Jimenez, J. L., Keutsch, F. N., Kim, S., Kuang, C., Laskin, A., McKinney, K., Mei, F., Miller, M., Nascimento, R., Pauliquevis, T., Pekour, M., Peres, J., Petäjä, T., Pöhlker, C., Pöschl, U., Rizzo, L., Schmid, B., Shilling, J. E., Dias, M. A. S., Smith, J. N., Tomlinson, J. M., Tóta, J., and Wendisch, M.: The Green Ocean Amazon Experiment (GoAmazon2014/5) Observes Pollution Affecting Gases, Aerosols, Clouds, and Rain- 
fall over the Rain Forest, B. Am. Meteorol. Soc., 98, 981-997, https://doi.org/10.1175/bams-d-15-00221.1, 2017.

Moran-Zuloaga, D., Ditas, F., Walter, D., Saturno, J., Brito, J., Carbone, S., Chi, X., Hrabe de Angelis, I., Baars, H., Godoi, R. H. M., Heese, B., Holanda, B. A., Lavrič, J. V., Martin, S. T., Ming, J., Pöhlker, M., Ruckteschler, N., Su, H., Wang, Y., Wang, Q., Wang, Z., Weber, B., Wolff, S., Artaxo, P., Pöschl, U., Andreae, M. O., and Pöhlker, C.: Available data for ATTO coarse mode study, https://doi.org/10.17617/3.1m, 2018.

O’Dowd, C. D., Langmann, B., Varghese, S., Scannell, C., Ceburnis, D., and Facchini, M. C.: A combined organic-inorganic sea-spray source function, Geophys. Res. Lett., 35, L01801, https://doi.org/10.1029/2007GL030331, 2008.

Okin, G. S., Mahowald, N., Chadwick, O. A., and Artaxo, P.: Impact of desert dust on the biogeochemistry of phosphorus in terrestrial ecosystems, Global Biogeochem. Cy., 18, GB2005, https://doi.org/10.1029/2003GB002145, 2004.

Pöhlker, C., Walter, D., Paulsen, H., Könemann, T., RodríguezCaballero, E., Moran-Zuloaga, D., Brito, J., Carbone, S., Degrendele, C., Després, V., Ditas, F., Holanda, B., Kaiser, J. W., Lammel, G., Lavric, J. V., Ming, J., Pickersgill, D., Pöhkler, M., Praß, M., Ruckteschler, N., Saturno, J., Sörgel, M., Wang, Q., Weber, B., Wolff, S., Artaxo, P., Pöschl, U., and Andreae, M. O.: Land cover and its transformation in the backward trajectory footprint of the Amazon Tall Tower Observatory, Atmos. Chem. Phys. Discuss., in preparation, 2018.

Pöhlker, M. L., Pöhlker, C., Ditas, F., Klimach, T., Hrabe de Angelis, I., Araújo, A., Brito, J., Carbone, S., Cheng, Y., Chi, X., Ditz, R., Gunthe, S. S., Kesselmeier, J., Könemann, T., Lavric, J. V., Martin, S. T., Mikhailov, E., Moran-Zuloaga, D., Rose, D., Saturno, J., Su, H., Thalman, R., Walter, D., Wang, J., Wolff, S., Barbosa, H. M. J., Artaxo, P., Andreae, M. O., and Pöschl, U.: Longterm observations of cloud condensation nuclei in the Amazon rain forest - Part 1: Aerosol size distribution, hygroscopicity, and new model parametrizations for CCN prediction, Atmos. Chem. Phys., 16, 15709-15740, https://doi.org/10.5194/acp-16-157092016, 2016.

Pöhlker, M. L., Ditas, F., Saturno, J., Klimach, T., Hrabe de Angelis, I., Araùjo, A., Brito, J., Carbone, S., Cheng, Y., Chi, X., Ditz, R., Gunthe, S. S., Kandler, K., Kesselmeier, J., Könemann, T., Lavric, J. V., Martin, S. T., Mikhailov, E., Moran-Zuloaga, D., Rizzo, L. V., Rose, D., Su, H., Thalman, R., Walter, D., Wang, J., Wolff, S., Barbosa, H. M. J., Artaxo, P., Andreae, M. O., Pöschl, U., and Pöhlker, C.: Long-term observations of cloud condensation nuclei in the Amazon rain forest - Part 2: Variability and characteristic differences under near-pristine, biomass burning, and long-range transport conditions, Atmos. Chem. Phys. Discuss., https://doi.org/10.5194/acp-2017-847, in review, 2017.

Pöschl, U., Martin, S. T., Sinha, B., Chen, Q., Gunthe, S. S., Huffman, J. A., Borrmann, S., Farmer, D. K., Garland, R. M., Helas, G., Jimenez, J. L., King, S. M., Manzi, A., Mikhailov, E., Pauliquevis, T., Petters, M. D., Prenni, A. J., Roldin, P., Rose, D., Schneider, J., Su, H., Zorn, S. R., Artaxo, P., and Andreae, M. O.: Rainforest Aerosols as Biogenic Nuclei of Clouds and Precipitation in the Amazon, Science, 329, 15131516, https://doi.org/10.1126/science.1191056, 2010.

Prenni, A. J., Petters, M. D., Kreidenweis, S. M., Heald, C. L., Martin, S. T., Artaxo, P., Garland, R. M., Wollny, A. G., and Poschl, U.: Relative roles of biogenic emissions and Saharan dust as ice nuclei in the Amazon basin, Nat. Geosci., 2, 401-404, https://doi.org/10.1038/ngeo517, 2009.

Prospero, J. M., Glaccum, R. A., and Nees, R. T.: Atmospheric transport of soil dust from African to South America, Nature, 289, 570-572, https://doi.org/10.1038/289570a0, 1981.

Prospero, J. M., Collard, F. X., Molinie, J., and Jeannot, A.: Characterizing the annual cycle of African dust transport to the Caribbean Basin and South America and its impact on the environment and air quality, Global Biogeochem. Cy., 28, 757-773, https://doi.org/10.1002/2013gb004802, 2014.

Quinn, P. K., Kapustin, V. N., Bates, T. S., and Covert, D. S.: Chemical and optical properties of marine boundary layer aerosol particles of the mid-Pacific in relation to sources and meteorological transport, J. Geophys. Res.-Atmos., 101, 6931-6951, https://doi.org/10.1029/95JD03444, 1996.

R Development Core Team: R: A language and environment for statistical computing, in, R Foundation for Statistical Computing, Vienna, Austria, 2010.

Reid, J. S., Jonsson, H. H., Maring, H. B., Smirnov, A., Savoie, D. L., Cliff, S. S., Reid, E. A., Livingston, J. M., Meier, M. M., Dubovik, O., and Tsay, S.-C.: Comparison of size and morphological measurements of coarse mode dust particles from Africa, J. Geophys. Res.-Atmos., 108, 8593, https://doi.org/10.1029/2002JD002485, 2003a.

Reid, J. S., Kinney, J. E., Westphal, D. L., Holben, B. N., Welton, E. J., Tsay, S.-C., Eleuterio, D. P., Campbell, J. R., Christopher, S. A., Colarco, P. R., Jonsson, H. H., Livingston, J. M., Maring, H. B., Meier, M. L., Pilewskie, P., Prospero, J. M., Reid, E. A., Remer, L. A., Russell, P. B., Savoie, D. L., Smirnov, A., and Tanré, D.: Analysis of measurements of Saharan dust by airborne and ground-based remote sensing methods during the Puerto Rico Dust Experiment (PRIDE), J. Geophys. Res.-Atmos., 108, 8586, https://doi.org/10.1029/2002JD002493, 2003b.

Rizzolo, J. A., Barbosa, C. G. G., Borillo, G. C., Godoi, A. F. L., Souza, R. A. F., Andreoli, R. V., Manzi, A. O., Sá, M. O., Alves, E. G., Pöhlker, C., Angelis, I. H., Ditas, F., Saturno, J., MoranZuloaga, D., Rizzo, L. V., Rosário, N. E., Pauliquevis, T., Santos, R. M. N., Yamamoto, C. I., Andreae, M. O., Artaxo, P., Taylor, P. E., and Godoi, R. H. M.: Soluble iron nutrients in Saharan dust over the central Amazon rainforest, Atmos. Chem. Phys., 17, 2673-2687, https://doi.org/10.5194/acp-17-2673-2017, 2017.

Saturno, J., Holanda, B. A., Pöhlker, C., Ditas, F., Wang, Q., Moran-Zuloaga, D., Brito, J., Carbone, S., Cheng, Y., Chi, X., Ditas, J., Hoffmann, T., Hrabe de Angelis, I., Könemann, T., Lavric, J. V., Ma, N., Ming, J., Paulsen, H., Pöhlker, M. L., Rizzo, L. V., Schlag, P., Su, H., Walter, D., Wolff, S., Zhang, Y., Artaxo, P., Pöschl, U., and Andreae, M. O.: Black and brown carbon over central Amazonia: Long-term aerosol measurements at the ATTO site, Atmos. Chem. Phys. Discuss. https://doi.org/10.5194/acp-2017-1097, in review, 2017a.

Saturno, J., Ditas, F., Penning de Vries, M., Holanda, B. A., Pöhlker, M. L., Carbone, S., Walter, D., Bobrowski, N., Brito, J., Chi, X., Gutmann, A., Hrabe de Angelis, I., Machado, L. A. T., MoranZuloaga, D., Rüdiger, J., Schneider, J., Schulz, C., Wang, Q., Wendisch, M., Artaxo, P., Wagner, T., Pöschl, U., Andreae, M. O., and Pöhlker, C.: African volcanic emissions influencing atmospheric aerosol particles over the Amazon rain forest, Atmos. Chem. Phys. Discuss., https://doi.org/10.5194/acp-2017-1152, in review, 2017b. 
Schepanski, K., Tegen, I., and Macke, A.: Saharan dust transport and deposition towards the tropical northern Atlantic, Atmos. Chem. Phys., 9, 1173-1189, https://doi.org/10.5194/acp-9-11732009, 2009.

Schumacher, C. J., Pöhlker, C., Aalto, P., Hiltunen, V., Petäjä, T., Kulmala, M., Pöschl, U., and Huffman, J. A.: Seasonal cycles of fluorescent biological aerosol particles in boreal and semi-arid forests of Finland and Colorado, Atmos. Chem. Phys., 13, 11987-12001, https://doi.org/10.5194/acp-13-11987-2013, 2013.

Swap, R., Garstang, M., Greco, S., Talbot, R., and Kallberg, P.: Saharan dust in the Amazon Basin, Tellus B, 44, https://doi.org/10.3402/tellusb.v44i2.15434, 1992.

Talbot, R. W., Andreae, M. O., Andreae, T. W., and Harriss, R. C.: Regional aerosol chemistry of the Amazon Basin during the dry season, J. Geophys. Res.-Atmos., 93, 1499-1508, https://doi.org/10.1029/JD093iD02p01499, 1988.

Talbot, R. W., Andreae, M. O., Berresheim, H., Artaxo, P., Garstang, M., Harriss, R. C., Beecher, K. M., and Li, S. M.: Aerosol chemistry during the wet season in central Amazonia- the influence of long-range transport, J. Geophys. Res.-Atmos., 95, 1695516969, https://doi.org/10.1029/JD095iD10p16955, 1990.

Tuch, T. M., Haudek, A., Müller, T., Nowak, A., Wex, H., and Wiedensohler, A.: Design and performance of an automatic regenerating adsorption aerosol dryer for continuous operation at monitoring sites, Atmos. Meas. Tech., 2, 417-422, https://doi.org/10.5194/amt-2-417-2009, 2009.

Tukey, J. W.: Exploratory Data Analysis, Addison-Wesley Publishing Company, Menlo Park, Cal., London, Amsterdam, Don Mills, Ontario, Sydney, 1977.

von der Weiden, S.-L., Drewnick, F., and Borrmann, S.: Particle Loss Calculator - a new software tool for the assessment of the performance of aerosol inlet systems, Atmos. Meas. Tech., 2, 479-494, https://doi.org/10.5194/amt-2-479-2009, 2009.

Wang, Q., Saturno, J., Chi, X., Walter, D., Lavric, J. V., Moran-Zuloaga, D., Ditas, F., Pöhlker, C., Brito, J., Carbone, S., Artaxo, P., and Andreae, M. O.: Modeling investigation of light-absorbing aerosols in the Amazon Basin during the wet season, Atmos. Chem. Phys., 16, 14775-14794, https://doi.org/10.5194/acp-16-14775-2016, 2016.

Wang, Y. Q.: MeteoInfo: GIS software for meteorological data visualization and analysis, Meteorol. Appl., 21, 360-368, https://doi.org/10.1002/met.1345, 2014.
Wendisch, M., Pöschl, U., Andreae, M. O., Machado, L. A. T., Albrecht, R., Schlager, H., Rosenfeld, D., Martin, S. T., Abdelmonem, A., Afchine, A., Araùjo, A., Artaxo, P., Aufmhoff, H., Barbosa, H. M. J., Borrmann, S., Braga, R., Buchholz, B., Cecchini, M. A., Costa, A., Curtius, J., Dollner, M., Dorf, M., Dreiling, V., Ebert, V., Ehrlich, A., Ewald, F., Fisch, G., Fix, A., Frank, F., Fütterer, D., Heckl, C., Heidelberg, F., Hüneke, T., Jäkel, E., Järvinen, E., Jurkat, T., Kanter, S., Kästner, U., Kenntner, M., Kesselmeier, J., Klimach, T., Knecht, M., Kohl, R., Kölling, T., Krämer, M., Krüger, M., Krisna, T. C., Lavric, J. V., Longo, K., Mahnke, C., Manzi, A. O., Mayer, B., Mertes, S., Minikin, A., Molleker, S., Münch, S., Nillius, B., Pfeilsticker, K., Pöhlker, C., Roiger, A., Rose, D., Rosenow, D., Sauer, D., Schnaiter, M., Schneider, J., Schulz, C., Souza, R. A. F. d., Spanu, A., Stock, P., Vila, D., Voigt, C., Walser, A., Walter, D., Weigel, R., Weinzierl, B., Werner, F., Yamasoe, M. A., Ziereis, H., Zinner, T., and Zöger, M.: The ACRIDICON-CHUVA campaign: Studying tropical deep convective clouds and precipitation over Amazonia using the new German research aircraft HALO, B. Am. Meteorol. Soc., 97, 1885-1908, https://doi.org/10.1175/BAMS-D-14$00255.1,2016$.

Whitehead, J. D., Darbyshire, E., Brito, J., Barbosa, H. M. J., Crawford, I., Stern, R., Gallagher, M. W., Kaye, P. H., Allan, J. D., Coe, H., Artaxo, P., and McFiggans, G.: Biogenic cloud nuclei in the central Amazon during the transition from wet to dry season, Atmos. Chem. Phys., 16, 9727-9743, https://doi.org/10.5194/acp-16-9727-2016, 2016.

Womack, A. M., Artaxo, P. E., Ishida, F. Y., Mueller, R. C., Saleska, S. R., Wiedemann, K. T., Bohannan, B. J. M., and Green, J. L.: Characterization of active and total fungal communities in the atmosphere over the Amazon rainforest, Biogeosciences, 12, 6337-6349, https://doi.org/10.5194/bg-12-6337-2015, 2015.

Yu, H. B., Chin, M., Yuan, T. L., Bian, H. S., Remer, L. A., Prospero, J. M., Omar, A., Winker, D., Yang, Y. K., Zhang, Y., Zhang, Z. B., and Zhao, C.: The fertilizing role of African dust in the Amazon rainforest: A first multiyear assessment based on data from Cloud-Aerosol Lidar and Infrared Pathfinder Satellite Observations, Geophys. Res. Lett., 42, 1984-1991, https://doi.org/10.1002/2015g1063040, 2015.

Zhou, J. C., Swietlicki, E., Hansson, H. C., and Artaxo, P.: Submicrometer aerosol particle size distribution and hygroscopic growth measured in the Amazon rain forest during the wet season, J. Geophys. Res.-Atmos., 107, 8055, https://doi.org/10.1029/2000jd000203, 2002. 